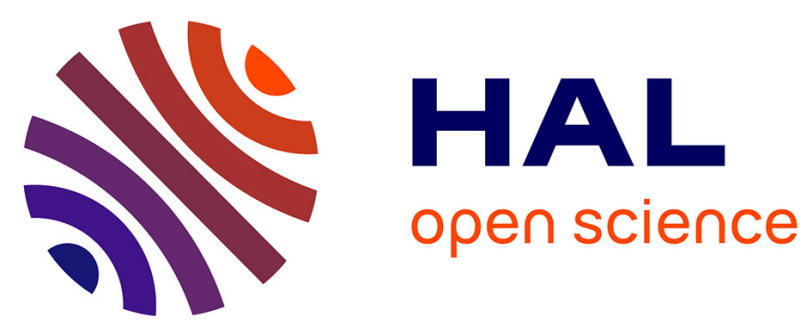

\title{
L'OUBLI DES ORIGINES. AMNÉSIE ET INFORMATION GÉNÉALOGIQUES EN HISTOIRE ET EN ETHNOLOGIE
}

Laurent Barry, Michael Gasperoni

\section{- To cite this version:}

Laurent Barry, Michael Gasperoni. L'OUBLI DES ORIGINES. AMNÉSIE ET INFORMATION GÉNÉALOGIQUES EN HISTOIRE ET EN ETHNOLOGIE. Annales de démographie historique, 2008, Les réseaux de parenté: refonder l'analyse, 2 (116), pp.AD. hal-01077653

\section{HAL Id: hal-01077653 \\ https://hal.science/hal-01077653}

Submitted on 19 Nov 2014

HAL is a multi-disciplinary open access archive for the deposit and dissemination of scientific research documents, whether they are published or not. The documents may come from teaching and research institutions in France or abroad, or from public or private research centers.
L'archive ouverte pluridisciplinaire HAL, est destinée au dépôt et à la diffusion de documents scientifiques de niveau recherche, publiés ou non, émanant des établissements d'enseignement et de recherche français ou étrangers, des laboratoires publics ou privés. 


\title{
L'OUBLI DES ORIGINES. AMNÉSIE ET INFORMATION GÉNÉALOGIQUES EN HISTOIRE ET EN ETHNOLOGIE
}

\author{
par Laurent BARRY et Michaël GASPERONI
}

L'étude des systèmes de parenté et d'alliance en histoire comme en ethnologie repose notamment, ce depuis une vingtaine d'années, sur l'analyse informatique de corpus généalogiques empiriques. Or, si ces corpus peuvent donner un sentiment de limpidité et de transparence en première analyse, il s'agit en réalité d'un assemblage d'objets complexes, d'une construction sociotechnique ambiguë que l'ethnologue ou l'historien doit toujours commencer par interroger.

En ethnologie, elle marie à la fois des informations directement issues de la mémoire généalogique d'individus réels et des artefacts mémoriels élaborés à partir de bribes d'informations artificiellement détachés de ces mêmes mémoires. Elle met donc sur le même plan des informations biographiques individuelles obtenues auprès des acteurs euxmêmes et des traces biographiques que d'autres individus ont laissées dans leurs mémoires, mêlant artificiellement informateurs réels et virtuels.

En histoire, les mémoires s'enchevêtrent aussi : celle des acteurs, qu'ils soient les protagonistes eux-mêmes ou ceux par qui - c'est-à-dire une minorité de lettrés nous est parvenue l'information; celle que, à partir de là, le chercheur a réussi à mobiliser et à faire émerger d'une documentation souvent lacunaire, parfois immense, parsemée d'embûches et de fausses pistes, assommée qu'elle est par le silence ou le brouhaha de la foule qu'il recense. Ceci est surtout vrai pour les classes «laborieuses», innombrables et longtemps invisibles; ça l'est encore davantage pour les femmes. La facilité éprouvée pour reconstruire les lignes agnatiques porte irrémédiablement le chercheur dans cette voie, et la plupart des généalogies imprimées sont largement masculines et rarement complètes, et lorsqu'elles se rapportent à des groupes aristocratiques, difficilement généralisables.

Grand paradoxe, pourtant, pour qui travaille sur des sociétés cognatiques, où les interdits sont parfaitement symétriques; paradoxe qui obscurcit les cercles d'échanges et de circulations, qui porte à ignorer des pans entiers des réseaux matrimoniaux, à n'en voir que la partie visible, à se détourner d'une structure dont on n'observe souvent que des pans fonctionnels, propres à certaines démonstrations, notamment en ce qui concerne les pratiques de dévolution du patrimoine, pour ne prendre que cet exemple. C'est pourquoi une attention particulière doit être portée, en amont, à une reconstitution cognatique des généalogies, qui ne peut s'opérer qu'en multipliant et en croisant systématiquement les différentes sources disponibles, afin de produire un réseau homogène.

Reste que même avec de considérables efforts, une reconstitution généalogique 
"parfaite» et absolue demeurera toujours un objectif inatteignable, surtout lorsque l'on travaille sur des réseaux matrimoniaux étendus. Cela ne signifie pas pour autant que l'on ne peut étudier, en histoire ou en ethnologie, la parenté de manière sérielle et réticulaire, mais qu'une réflexion méthodologique sur l'élaboration des corpus généalogiques, autant que sur leur analyse, est un passage obligé afin de ne pas décrédibiliser ce type d'approche.

Cette complexité de l'objet généalogique n'a pas seulement une incidence sur notre appréhension de celui-ci dans ses horizons philosophiques les plus lointains, mais aussi, concrètement, dans le procès immédiat de la recherche et dans les résultats et mesures quantitatives établis à partir de ces corpus. Pour illustrer certaines des difficultés méthodologiques et théoriques que pose l'analyse de tels agrégats généalogiques, nous nous proposons, dans cet article, d'envisager celles-ci à partir de l'examen de deux corpus empiriques issues de nos propres travaux: l'un historique, celui de la République de Saint-Marin en Italie, l'autre ethnographique, celui des Peuls de l'Adamaoua au Cameroun. De là, nous proposerons également une méthode pour contourner la méconnaissance généalogique certaine, et inévitable, que comportent les réseaux reconstitués.

\section{LES CORPUS :}

\section{ENTRE HISTOIRE ET ETHNOGRAPHIE}

\section{Un corpus historique: Saint-Marin}

Le corpus généalogique historique concerne la République de Saint-Marin. Enclavée entre les Marches et la Romagne, en Italie, elle a su maintenir son indépendance, et compte aujourd'hui encore parmi les micro-États européens (60 km², 29000 habitants). Le réseau matrimonial est le fruit d'une enquête menée sept ans durant à partir d'un large panel de sources. Il comprend 24049 individus (13697 hommes et 10352 femmes) et 6682 mariages, déployés sur 33 générations. La majorité des individus sont répartis entre le début du XVI et les deux premiers tiers du XIXe siècle.

L'étude a fait l'objet d'une publication (Gasperoni, 2009), qui traite du rapport entre pratiques sociales au sens large, et pratiques matrimoniales. La constitution des groupes sociaux, la mobilité sociale, ou encore les phénomènes migratoires ont été appréhendés au regard de la parenté. Il a été montré, à l'aide du logiciel Puck, que les interdits de mariage, cognatiques, ont été largement respectés, et ce sur l'ensemble de la période. On ne note pas, malgré une endogamie géographique importante, une augmentation considérable des unions prohibées, qui restent à un niveau particulièrement bas, tant dans la consanguinité que dans l'affinité, aux $\mathrm{XVIII}^{\mathrm{e}}$ et XIX $\mathrm{X}^{\mathrm{e}}$ siècles.

Nous avons insisté dans ce premier travail sur le caractère " ouvert " de la société saint-marinaise avant le XVII ${ }^{e}$ siècle, laquelle connut jusqu'à cette date une importante fluidité des rapports ville/campagne, des rapports sociaux et matrimoniaux, avant que ne s'amorce, à partir du premier tiers du Seicento, un repli des couches supérieures (aristocratie mais aussi bourgeoisie) sur elles-mêmes. Nous avons montré comment la constitution d'un nouveau groupe social, se représentant lui-même comme un nouvel ordre, une véritable "noblesse», s'était accompagnée, en amont, de mariages internes (Fioretti, 1994, 143) 
et entre proches parents, en deçà des interdits matrimoniaux. Ces comportements endogames, cette volonté de l'" entre soi ", apparaissent comme un acte fondateur d'une identité commune et indissociable, et une façon, pour les principales, de se détacher du socle des activités mécaniques auxquels ils se consacraient à l'origine. À ces pratiques endogames succède une attitude radicalement nouvelle, et complètement exogame: à partir de la fin du XVII siècle, en effet, les alliances matrimoniales des familles aristocratiques se concrétisent principalement avec des familles influentes des cités pontificales voisines ou plus éloignées.

Si à Saint-Marin au XVII ${ }^{\mathrm{e}}$ siècle, les mariages consanguins, en deçà des interdits, concernent essentiellement une aristocratie qui s'imperméabilise, au siècle suivant la tendance s'inverse, et on observe au sein de la paysannerie une nette augmentation des unions prohibées. On assiste moins, au XVII siècle, à une "explosion» des unions consanguines qu'à une augmentation, certes remarquable, mais non excessive, et à une décristallisation, par le haut, des potentialités d'alliances. Des mariages consanguins au "très proche" apparaissent mais ne sont pas la norme: les unions au $4^{\mathrm{e}}$ degré (canon) restent majoritaires et on descend très rarement en deçà du $3^{\mathrm{e}}$. Si l'endogamie géographique pèse sur la paysannerie, qui devient alors le principal groupe demandeur de dispenses, il faut noter que certaines familles paysannes, la plupart du temps les plus aisées, multiplient les demandes de dispenses.

Les mariages très proches restent marginaux: ils sont aussi les moins appréciés par l'Église, qui a toujours considéré la parenté comme nécessairement exogame.
Néanmoins, l'obligation d'exogamie est effective tant que le souvenir perdure, et le mariage entre parents, dès lors que les prohibitions s'éteignent, devient envisageable voire recommandé: on retrouve cette idée chez Pierre Damien et, avant lui, chez Isidore de Séville et saint Augustin $^{1}$. Sitôt que cessent les interdits, on épouse selon le principe de prédilection pour la zone située entre le «très proche et le pas trop loin» (Zonabend, 1981, 311318). Ce n'est sans doute pas un hasard si la majorité des demandes de dispenses concerne l'empêchement au $4^{\mathrm{e}}$ degré, moment transitoire d'une parenté qui se sait encore, mais qui est au bord de l'oubli ou de l'effritement. La distance est certes trop proche pour ne pas susciter la réprobation de l'Église qui, en octroyant la dispense, réaffirme par la même occasion son autorité sur le mariage; elle est néanmoins assez éloignée pour que l'octroi soit accordé sans trop de difficultés.

C'est exactement en ces termes que Don Giovanni Antonio Belluzzi, ecclésiastique issu d'une des familles les plus en vue de la République, justifie «le désir qu'il a toujours eu [...] de renouveler la parenté», une fois que la dispense de consanguinité sera obtenue, pour la «conservation et le maintien de la bonne intelligence et parenté passée depuis très longtemps entre sa maison et celle de ses ancêtres, et la maison de Melchiorre Maggi de Belluzzi $»^{2}$. Giacomo, le neveu de Giovanni Antonio, épouse ainsi, en 1640, Lucrezia Maggi Belluzzi, dont il est le parent aux $3^{\mathrm{e}}$ et $4^{\mathrm{e}}$ degrés, mais aussi aux $5^{\mathrm{e}}$ et $6^{\mathrm{e}}$ degrés, et au-delà, de manière bilatérale, pour les deux conjoints (figure 1).

Un mariage consanguin n'est pas toujours synonyme d'endogamie géographique: quelques dispenses de consanguinité ont été accordées pour 
Fig. 1 Les familles Belluzzi et Maggi

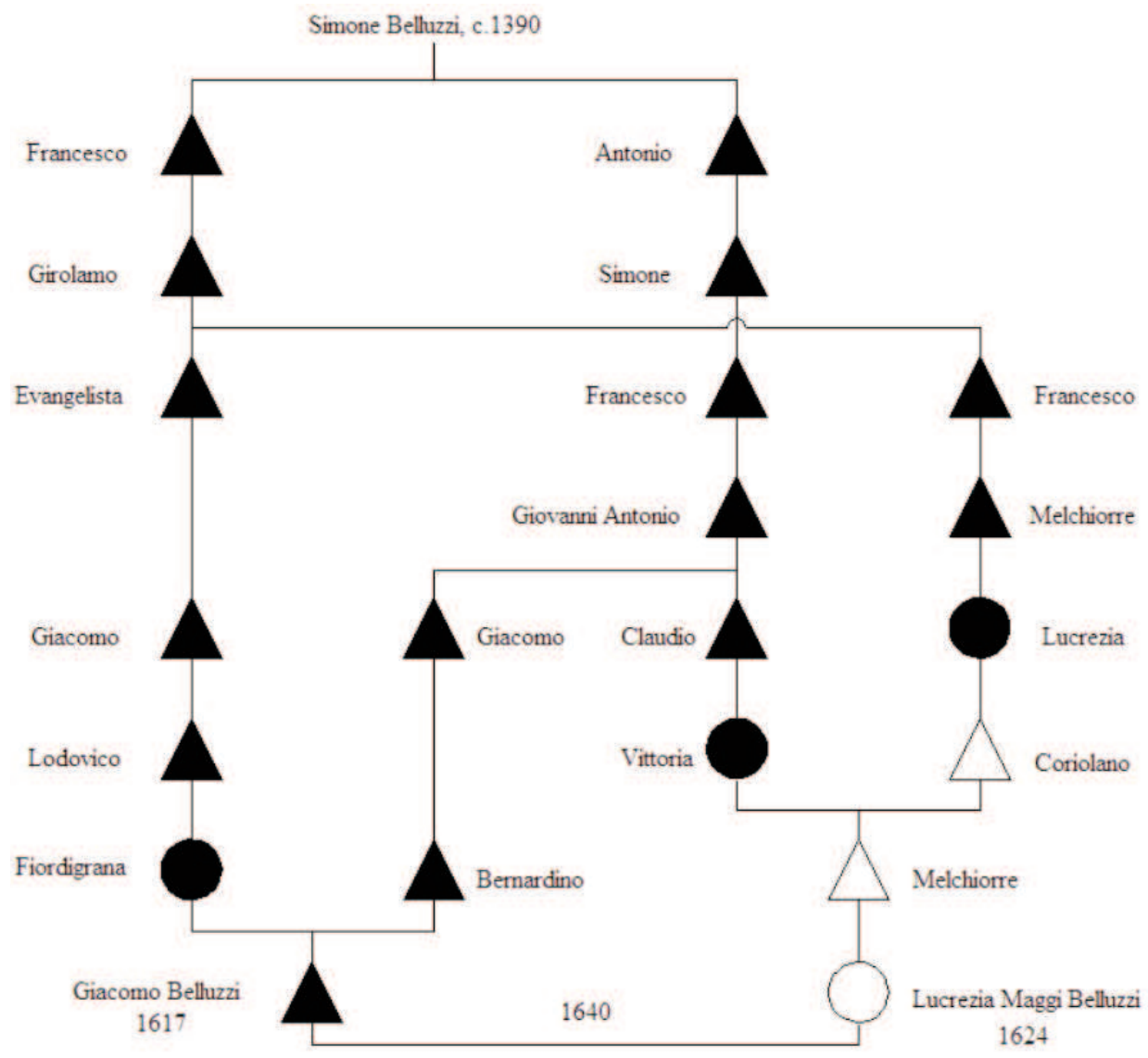

des mariages géographiquement exogames, ce qui montre aussi l'efficacité du contrôle d'une Église qui n'ignore pas qu'un mariage avec un conjoint extérieur à la paroisse peut être un mariage proche et interdit. Dans les représentations, il est aussi très probable qu'un parent proche qui réside loin soit moins interdit - ou perçu comme tel - qu'un parent un peu moins proche mais qui réside près de soi, comme si d'une certaine manière, l'éloignement géographique relativisait la proximité généalogique $^{3}$. De fait, l'une des deux unions au second degré (FBD) qui a été recensée concerne un couple - par ailleurs issu de l'aristocratie - dont l'époux est né et a grandi à une dizaine de kilomètres.

Si la mobilisation intensive des sources a permis de produire un corpus généalogique conséquent, et d'analyser les pratiques matrimoniales que nous venons brièvement d'exposer, la reconstitution des familles et de la population s'est heurtée à des difficultés d'ordre pratique et méthodologique. La plus importante a été celle de la reconstitution cognatique des généalogies, mise à mal par l'absence, l'état de conservation ou l'inflexion des sources. Car si les 
patrilignées sont facilement repérables, par la typologie même du mode de résidence, patri-virilocale, les femmes et les matrilignes ont en outre davantage pâti du déséquilibre flagrant d'informations que contiennent les sources. Immédiatement intuitive et palpable, cette asymétrie peut être mesurée grâce au logiciel Puck, soit de manière globale, soit plus précisément, et selon des critères répondant à diverses exigences.

\section{Les femmes absentes des sources}

Dans un monde où les hommes - et particulièrement les hommes de religion - détiennent la parole et la maîtrise de l'écrit, véhiculent leurs propres conceptions et représentations, ou celles de leur temps, les femmes ont longtemps figuré parmi les laissés-pour-compte. La rencontre avec l'anthropologie a attiré le regard des historiens sur «l'autre moitié» de l'humanité, longtemps ignorée, suscitant, à partir des années 1970 , une abondante littérature. Ce déplacement du regard s'est notamment orienté vers l'étude de la place et du rôle des femmes, de leur "condition", la réélaboration des catégories liées au genre, et l'examen d'autres documents (Duby et Perrot, 2002). À l'instar de certains groupes sociaux et autres "oubliés", $a$ priori moins visibles, les femmes sont souvent absentes de la documentation et des généalogies, lesquelles persistent, le plus souvent, à être majoritairement masculines.

Cette propension à donner de plus amples informations sur les hommes plutôt que sur les femmes est en effet prégnante dans les sources, notamment démographiques, dont se servent les historiens pour reconstituer les familles: lorsqu'elles n'en sont tout simplement pas absentes, les femmes n'y sont souvent connues qu'en tant que mère ou épouse - plus rarement "fille de», ou fille d'un homme plutôt que d'une femme - et, par conséquent, de nombreux liens de parenté et d'alliance demeurent inconnus. Quelquefois, même en présence d'une dispense de consanguinité accordée à des conjoints, il n'a pas été possible de retrouver leur ascendant commun, parce que de la mère, de la grand-mère ou de l'arrièregrand-mère de l'un d'eux, on ne connaissait tout au plus que le prénom. Ce n'est donc pas la mémoire des acteurs qui est ici en cause, mais celle que le chercheur réussit à capter, à reconstituer, par l'intermédiaire des sources.

Si l'inégale distribution des hommes et des femmes dans notre corpus se constate d'emblée ( $57 \%$ vs $43 \%)$, elle est à mettre en relation avec la disponibilité des sources, même si les recensements de population dont nous disposons montrent que d'une manière générale, à Saint-Marin, les hommes furent régulièrement plus nombreux que les femmes: en 1772, par exemple, ils représentaient $52,25 \%$ de la population de six des huit paroisses de la République, contre $47,75 \%$ de femmes; la situation est identique au milieu du siècle suivant, la proportion d'hommes s'élevant à $52,7 \%$ contre $47,3 \%$ de femmes, selon une étude portant sur quatre paroisses (Verducci, 1995, 81, 96, 119).

La répartition chronologique des individus, dans le cas présent, reflète amplement la disponibilité et le type de sources employées pour recenser la population: tandis que pour la période précédant le XVII siècle, le recours aux archives non démographiques, notamment notariales (testaments, contrats de mariages, etc.) n'a pu fournir que des informations partielles, davantage qualitatives et sensiblement plus andro- 
centrées, le développement et la généralisation des archives paroissiales (XVII ${ }^{\mathrm{e}}$ XVIII ${ }^{e}$ siècles) et des recensements de population (1865-1899) ont permis de constituer un échantillon étendu et plus représentatif de la population de référence étudiée, laquelle a pu être appréhendée dans son ensemble, ce qui explique l'écart croissant entre le nombre d'hommes et de femmes à mesure que l'on remonte le temps (tableau 1 et figure 2).

Tab. 1 Corpus San Marino, répartition par siècle des individus selon leur sexe

\begin{tabular}{lll}
\hline & $\mathrm{H}$ & $\mathrm{F}$ \\
\hline $\mathrm{XIII}^{\mathrm{e}}-\mathrm{XVI}^{\mathrm{e}}$ siècles & $77 \%$ & $23 \%$ \\
\hline $\mathrm{XVI}^{\mathrm{e}}$ siècle & $66 \%$ & $34 \%$ \\
\hline $\mathrm{XVII}^{\mathrm{e}}$ siècle & $57 \%$ & $43 \%$ \\
\hline $\mathrm{XVIII}^{\mathrm{e}}$ siècle & $55 \%$ & $45 \%$ \\
\hline $\mathrm{XIX}^{\mathrm{e}}$ siècle & $51 \%$ & $49 \%$ \\
\hline
\end{tabular}

Fig. 2 Corpus San Marino, répartition chronologique des individus

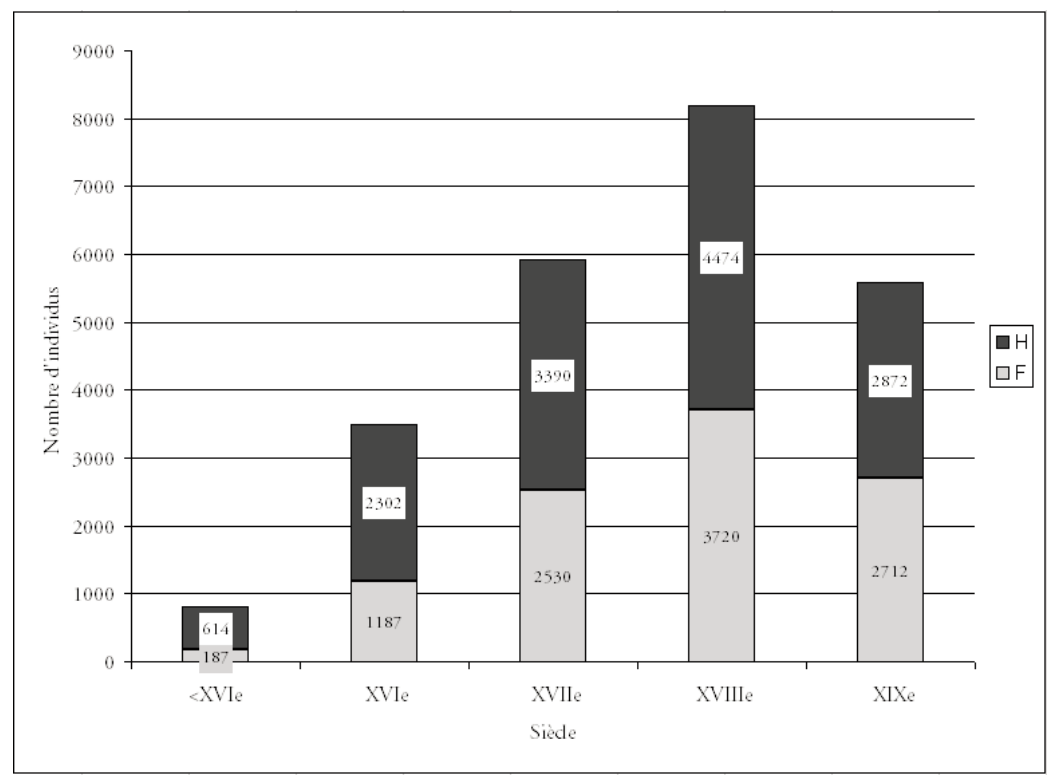

La documentation d'archives pose un certain nombre de problèmes sur lesquels nous nous attarderons quelque peu ici. Leur conservation, tout d'abord, est très inégale: si les registres des baptêmes de la principale paroisse (Pieve) couvrent une longue période, sans discontinuité à partir de 1562, les registres des sépultures sont pauvres en informations, et ceux de mariages, qui nous intéressent le plus puisqu'ils représentent notre première source sur les femmes, n'englobent qu'un peu moins d'un siècle (1588-1670). Nous disposons néanmoins des bans de publications, dont la série est complète à partir de 1705; ils ont en outre l'avantage, au contraire des registres de mariages, de recenser tous les conjoints, soit ceux qui se 
sont mariés en dehors de la paroisse, et ceux qui proviennent de l'extérieur. Complets, les livres où étaient enregistrés les baptêmes sont néanmoins très peu bavards en ce qui concernent les épouses. De 1562 à 1580, seuls les prénoms de l'enfant, de son père et éventuellement de son grand-père paternel sont en effet mentionnés. De 1580 à 1740 , si le prénom de la mère est désormais systématiquement reporté, il n'en va pas de même pour son patronyme, qui ne commence à être spécifié qu'au milieu du XVIII siècle.

Recommandés par le concile de Trente, les "états des âmes" (stati delle anime), sorte de recensement de population à la conservation et à la qualité très variables, constituent une source essentielle pour l'étude des comportements démographiques, et permettent aussi une approche sociologique ou anthropologique des structures familiales, en plus d'avoir l'avantage de "photographier» littéralement la population à un moment donnét. Concernant notre terrain, une trentaine de ces recensements ont été conservés, et reflètent parfaitement le caractère androcentrique des informations contenues dans les registres paroissiaux. Si le premier état des âmes, daté de 1672, est très complet et nous renseigne sur l'identité des épouses, pour lesquelles le patronyme et le nom du père sont systématiquement annotés, il n'en va pas de même pour les dénombrements suivants, qui ne fournissent que leurs prénoms. Notons en outre des périodes caractérisées par l'absence totale de ces sources (1672-1745, 1785-1820), lesquelles ont probablement été égarées. Absence qui détériore les généalogies et renforce le déséquilibre des informations, créant une dissymétrie dont la population féminine pâtit le plus.
Au XIX siècle, le souci des autorités d'une meilleure connaissance de la population a pour conséquence la mise en place de recensements plus précis et affinés de l'ensemble des individus présents sur le territoire. Plus soignés, ces documents comportent néanmoins quelques lacunes. Dans le premier recensement, daté de 1865 , seule la paternité des individus est spécifiée, tandis que dans les suivants (1874 et 1899), bien qu'ils soient régulièrement mentionnés, le prénom et le nom de la mère viennent souvent à manquer. Tous ces éléments concourent à une connaissance patrilinéaire plus marquée des ascendances. Le recours à des sources de substitution s'avère nécessaire, pour recouper, compléter, affiner la documentation démographique. Parmi elles, les archives notariales se révèlent les plus utiles, mais aussi les plus longues à exploiter. Le caractère andro-centrique des informations croît à mesure que l'on remonte dans le temps. En effet, avant le $\mathrm{XVIII}^{\mathrm{e}}$ siècle, il n'est pas rare que les patronymes soient absents. Régulièrement les individus ne sont désignés et distingués que par le prénom d'un ancêtre, soit celui du père, soit celui du grand-père ou d'un aïeul, toujours paternel. De fait, la plupart des noms de familles locaux, ou patronymes, comme leur nom l'indique, sont fondés sur le prénom d'un ancêtre agnatique.

De manière générale, les femmes sont moins visibles dans les sources, et ce n'est que lorsqu'elles se substituent à l'homme, souvent dans le cadre d'une union hypogamique, en porte-parole et vecteur de la transmission d'un patrimoine symbolique (le patronyme, le pouvoir) ou matériel (les biens), qu'une place leur est pleinement accordée, non pas en tant que femmes, mais comme 
représentantes d'un autre groupe agnatique - en l'occurrence le leur - qui entend, par son intermédiaire, affirmer son "besoin d'éternité" (Visceglia, 1988), fût-ce par une femme plutôt que par un homme.

\section{Résidence et connaissance des ancêtres}

À l'époque moderne, si la résidence des conjoints est généralement de type patrivirilocal - ce qui induit d'emblée un repérage plus aisé des lignées et des généalogies agnatiques -, la cérémonie du mariage s'effectue la plupart du temps dans la paroisse de l'épouse, ajoutant ainsi une difficulté supplémentaire pour connaître l'identité d'une femme si celle-ci provient de l'extérieur, puisque l'acte de mariage est généralement conservé dans sa paroisse d'origine. Létude des registres paroissiaux de SaintMarin a confirmé cette tendance : la proportion des conjointes originaires de la paroisse est sensiblement plus élevée que celle des conjoints $(85 \%$ contre $57,6 \%$ ), de même le pourcentage de conjoints non originaires de la paroisse est quatre fois supérieur à celui des conjointes provenant de l'extérieur (tableau 2). Si l'endogamie géographique est fréquente (plus des deux tiers des unions), il n'est cependant pas rare qu'un homme prenne une épouse dans une autre paroisse que la sienne et, de fait, un certain nombre d'unions nous a échappé.

Tab. 2 Saint-Marin (Pieve), proportion des conjoints et conjointes selon leur origine géographique et leur sexe (1588-1670)

\begin{tabular}{lcccc}
\hline & De la paroisse (Pieve) & $\begin{array}{c}\text { Autres paroisses } \\
\text { de la République }\end{array}$ & $\begin{array}{c}\text { Non originaires } \\
\text { de Saint-Marin }\end{array}$ & $\begin{array}{c}\text { Origine } \\
\text { indéterminée }\end{array}$ \\
\hline Total & $71,30 \%$ & $9,10 \%$ & $17,60 \%$ & $2,00 \%$ \\
\hline Femmes & $85,00 \%$ & $4,00 \%$ & $8,20 \%$ & $2,80 \%$ \\
\hline Hommes & $57,60 \%$ & $14,20 \%$ & $27,00 \%$ & $1,20 \%$ \\
\hline
\end{tabular}

Il a été observé, pour Saint-Marin, que la population et les familles se sont constamment renouvelées, notamment grâce à une constante immigration. Celle-ci se caractérise moins par l'apport de groupes familiaux déjà constitués que par la venue de migrants qui, après s'être mariés sur place, soit fondent de nouvelles lignées, soit pérennisent les lignages "agnazione»- de leurs épouses, en adoptant leurs patronymes et en assurant leurs continuités patrimoniales et résidentielles. Ces pratiques migratoires, qui perdurent jusqu'au début du XIX ${ }^{\mathrm{e}}$ siècle, s'apparentent aux "migrations de rupture», telles que les a définies PaulAndré Rosental (1990, 1403-1431), et s'appuient largement sur l'alliance et l'uxorilocalité. La captation, dans l'espace d'arrivée, de biens hérités de la famille de l'épouse contribue fortement à sédentariser le migrant, et le pousse à s'enraciner durablement et à orienter localement ses aspirations. Même si des liens - notamment matrimoniaux peuvent subsister avec l'espace d'origine vers lequel des retours sont possibles, l'analyse des généalogies montre qu'une fois établis, les migrants s'insèrent et $s$ 'investissent davantage dans l'espace d'arrivée, où les mariages, aux générations successives, sont endogènes voire endogames; un tiers des dispenses de consanguinité recensées concerne des 
individus dont les pères sont issus de l'immigration, comme si, d'une certaine manière, le bouclage dans la consanguinité, à la génération suivante, était une façon de s'intégrer pleinement au lieu et à la population d'accueil, en y renforçant ses liens de parenté et d'identité.

On pourrait penser que ces deux phénomènes (mariage dans la paroisse de l'épouse et immigration des hommes) engendrent une «inflexion» utérine dans la connaissance des ancêtres, ou tout du moins un certain rééquilibrage, puisque la généalogie de l'épouse est davantage connue que celle du mari, dont nous ne connaissons pas l'ascendance (parfois le prénom du père, pratiquement jamais celui de la mère). Néanmoins, dans le cas où l'époux vient simplement "prendre" une femme dans la paroisse, sans pour autant s'y établir, les descendants du couple ne figurent pas dans le réseau, ce qui ne contribue à aucun rééquilibrage en faveur de la représentation des liens utérins; dans l'autre cas, celui du migrant, c'est la connaissance du groupe agnatique de l'épouse qui est renforcée.

\section{Des corpus ethnographiques:}

\section{les Peuls de l'Adamaoua (Nord Cameroun)}

Les descriptions ethnographiques rapportées ici sont issues d'une série d'enquêtes menées entre 1991 et 2002 sur les hauts plateaux de l'Adamaoua au Nord-Cameroun. Ces enquêtes sur l'Hosseere, sur "la montagne», concernaient un grand nombre de communautés peules, mais nous n'en retiendrons ici que deux exemples pour illustrer la discussion autour des questions généalogiques qui seront évoquées dans cet article.

$\mathrm{Au}$ soulèvement en 1804 du Séhou Oussoumanou Dan Fodio («Oussouma- nou, fils de Fodio" ") seere demeurait encore largement terra incognita des pasteurs peuls. Alors qu'il soumettait une à une les communautés hausas, les pasteurs implantés plus au sud, au Fombina, allaient eux aussi se soulever contre les populations "païennes", ce qui conduira bientôt à l'invasion puis à la domination peule sur «la Montagne». Ici pourtant le Jihad prendra deux formes bien distinctes.

Dans la plaine de la Bénoué il prit, à l'instar du déroulement du Jihad en pays Hausa, toutes les apparences extérieures d'un mouvement d'inspiration religieuse. Il sera conduit par Adama, un Moodibbo (un "lettré») officiellement reconnu par Dan Fodio comme son mandataire pour l'ensemble de ces régions qui prendront par la suite le nom d'Adamaoua.

Aux marches méridionales du nouvel Émirat, sur l'Hosseere, il sera par contre plus ouvertement le fait de riches arDo'en (chefs politiques et/ou militaires) en quête de nouveaux pâturages et désireux de se soustraire dans la mesure du possible à l'autorité d'Adama. Nominalement vassaux du nouvel émirat du Fombina, ces chefs peuls, qui prendront plus tard le titre de laamiiBe ${ }^{6}$, ne maintiendront le plus souvent qu'un lien politique assez lâche avec les provinces du Nord et l'histoire du plateau sera dans une large mesure modelée par leurs velléités d'indépendance vis-à-vis d'un pouvoir central symbolisé par Yola, la future capitale du Fombina.

Si le déroulement de cette conquête foulbée suscita bien des interrogations de la part des historiens et anthropologues, l'arrivée plus tardive dans l'Adamaoua d'autres groupes peuls restés plus attachés aux valeurs pastorales, ceux des Mbororos, fut plus discrète et demeure 
aujourd'hui encore bien moins documentée.

La venue de ces groupes s'est, en effet, effectuée en marge des grands épisodes militaires et politique qui embrasèrent la région au XIXe siècle, même si elle a pu profiter de la présence des Foulbés pour s'assurer une protection contre les trop fréquentes exactions des chefs locaux. Fruit d'une série d'infiltrations progressives et généralement pacifiques, elle n’a donné lieu ni à de grands déplacements de population, ni à la constitution de nouveaux royaumes.

C'est cette double dimension de l'histoire de l'implantation des Peuls dans cette région, une histoire où se croisent pasteurs et guerriers, que nous retiendrons pour illustrer ici quelques aspects de leur système de parenté. Nous évoquerons en effet trois exemples emblématiques de cette opposition locale propre à l'Adamaoua entre "Foulbés» d'une part, conquérants belliqueux et fondateurs d'empire, et "Mbororos", pasteurs timides plus conservateurs: ceux de la cité-État foulbée de Banyo, du seul lamidat mbororo existant au Cameroun, celui des Jafun du village de Lompta, et enfin de diverses communautés pastorales mbororos (WoDaaBe, Aku et Jafun) rassemblées autour de petites chefferies secondaires qui se maintinrent historiquement à distance des centres politiques de premier plan.

\section{Deux communautés pour un système}

Le corpus matrimonial peul global que nous avons recueilli lors de nos enquêtes comprend au total 5005 individus (vivants ou décédés) et 3390 mariages.

$\mathrm{Si}$ ces deux communautés culturelles globales - «foulbé» versus «mbororo» (nous parlerons désormais par commodité de «fractions» pour les désigner) -, relèvent bien entendu au même titre de la mosaïque culturelle peule (foulbé n'est que la forme francisée du terme fulBe, "les Peuls», dont le singulier pullo, «un peul», a donné l'ethnonyme français), il n'en demeure pas moins que leurs histoires particulières ainsi que leur plus ou moins grand investissement dans les pratiques pastorales, la plus ou moins grande proximité qu'ils entretiennent avec les centres de pouvoir politique, etc., ont conduit à l'établissement de sensibles différences dans leurs conceptions généalogiques ainsi que dans leurs comportements matrimoniaux. Et tout d'abord au fait que si les différents lignages composant ces deux "fractions " peules échangent parfois entre eux des partenaires, ce n'est plus le cas de ces deux fractions prises globalement, lesquels ne s'inter-marient pratiquement pas, ou si peu.

Nous le vérifions ainsi à la lecture de ce premier tableau synthétique (tableau 3 ), qui montre non seulement que Foulbés et Mbororos ne s'allient pas entre eux (seules 5 femmes foulbées et 7 femmes mbororos ont épousé des hommes de l'autre groupe, soit $1 \%$ et $0,9 \%$ de leurs 486 et 819 unions respectives), mais qu'ils préferent même épouser des haaBe, des "non peuls", plutôt que des peuls membres de l'autre fraction. Ce sera surtout vrai d'ailleurs des hommes foulbés, pour lesquels les unions hors de l'ethnie représentent $20,6 \%$ des unions ( 135 des 655 mariages d'hommes foulbés) alors qu'à peine $1,4 \%$ des hommes mbororos font de même (12 des 872 mariages). Là aussi, l'on remarque bien un tropisme culturel nettement divergent entre ces deux fractions peules, conduisant les uns 
- les Foulbés - à s'ouvrir quelque peu à l'extérieur, là où les autres - les Mbororos - privilégieront encore et toujours l'entre soi.

Cette idée même d'ouverture à l'extérieur est pourtant à relativiser, de même dans le cas foulbé. Ainsi, comme en témoigne ce second tableau synthétique (tableau 4) il apparaît que l'endogamie de fraction ne tombe jamais en dessous de $53 \%$ (pour les mariages secondaires des hommes foulbés) et est en moyenne de $80,55 \%$ et de $98,27 \%$ respectivement pour l'ensemble

Enfin, l'endogamie est un marqueur très important au niveau du groupe sociologique d'Ego lui-même, celui à partir duquel l'on évoque à l'ordinaire la notion "d'endogamie» elle-même: le lignage ${ }^{7}$.

L'on remarquera ainsi que, si l'endogamie lignagère ne concerne qu'environ un tiers des mariages chez les Foulbés (dont beaucoup parmi les jeunes citadins ignorent même le nom de leur lignage), elle atteint en revanche des taux records chez les Mbororos: d'un peu plus de $50 \%$ des unions chez les Jafun jusqu'à près de $100 \%$ chez les $\mathrm{WoDaaBe}^{8}$.

Comme toutefois nous avons pu le montrer ailleurs (Barry, 1998; 2008), ce rapport endogamie/exogamie, qu'on l'envisage au niveau de "l'ethnie», de la "fraction " ou du lignage, n'a pas de réelle incidence sur la structure interne du système matrimonial peul. Si l'on considère en effet les pratiques et préférences de mariages, les deux communautés, foulbé et mbororo, suivent en réalité un seul et même modèle global dont nous nous sommes essayé à montrer (Barry, 2000; 2008) qu'il était propre non au seul monde peul, mais bien à l'ensemble des systèmes d'alliance qui privilégient un agencement que l'on désigne à l'ordinaire sous l'expression de «mariage arabe».

Ce modèle s'exprime d'abord et avant tout dans les proportions relatives des différents types de mariages consanguins. Si nous examinons à présent le rapport entre ces derniers (donc uniquement les unions pour lesquelles nous pouvons retracer précisément l'apparentement généalogique entre les conjoints) et l'ensemble des alliances, nous constatons - du moins en première analyse que ces mariages consanguins représentent en moyenne (pour l'ensemble des groupes peuls) $35,29 \%$ du total des unions (tableau 6).

Dans ce dernier ensemble, la "préférence" pour l'union entre cousins parallèles patrilatéraux réels ou classificatoires, pour le «mariage arabe», est alors fortement marquée dans l'ensemble des communautés peules. En fait, ce type d'alliance sous sa seule forme non classificatoire - entre parents au $4^{\text {e }}$ degré civil - représente déjà 30,24\% de l'ensemble des mariages consanguins, $58,28 \%$ des unions consanguines étant par ailleurs réalisées entre cousins au $4^{\mathrm{C}}$ degré $(264$ mariages d'hommes dont 137 avec FBD, 61 avec MBD, 45 avec FZD et 21 avec MZD; voir tableau 7).

Le fait que les mariages consanguins connus représentent ici environ un tiers des alliances $(35,29 \%$ des unions du corpus global) semblerait pouvoir conforter l'analyse de certains auteurs (voir par exemple Cuisenier, 1962; Bourdieu, 1980; Conte, 1979 \& 1983; Caratini, 1989; Ferchiou, 1992) selon laquelle la part importante d'alliances contractées dans le lignage ou dans la fraction qui ne semble pas immédiatement passible d'une analyse en terme de "mariage de parents" 
devrait nous amener à relativiser le degré de fermeture - i.e. d'endogamie de ces systèmes fondés sur le mariage arabe. L'endogamie elle même se verrait alors reléguée à un artifice de l'alliance entendu en tant que système d'échange (Lévi-Strauss, 1949) ou à une simple idéologie permettant de masquer les enjeux et stratégies idiosyncrasiques individuels, ceux que Pierre Bourdieu discernait dans les pratiques kabyles.

Or, cette discussion va nous amener précisément à interroger la signification de tels pourcentages, ceux exprimant la proportion mariages consanguins/non consanguins, dans ce corpus précis et plus largement dans ceux produits par ethnologues et historiens. Ces pourcentages en effet, en dépit de la croyance si répandue en l'objectivité du nombre et de la sanctification du chiffre, n'ont bien souvent - ce sera le cas ici - pas de signification intrinsèque réelle.

Cette critique de la magie du chiffre nous allons la mener à présent lors d'une discussion autour des usages et mésusages de deux des outils qui nous permettront d'estimer la signification réelle de tels pourcentages. Nous verrons que la pertinence de ces derniers repose pour l'essentiel sur la qualité de l'information généalogique disponible, elle même dépendante de la mémoire et de l'oubli, des réminiscences qu'ont de leurs origines les acteurs ou les sources qui nous en parlent.

Ces deux outils - que sont les notions de «poids/biais agnatique» et de "connaissance généalogique " - s'ils s'attachent à proposer une description des mêmes phénomènes, correspondent pourtant à deux épistémès bien différentes. Les deux approches méthodologiques étant implémentées dans le logiciel Puck, nous allons pouvoir en vérifier l'efficace et l'intérêt pour le traitement des corpus historiques et ethnographiques, mais aussi montrer que la nature même et l'origine des sources d'information constitutives de ces corpus les situent parfois dans des univers taxinomiques relativement imperméables les uns aux autres, sans que cette fracture ne suive, une fois n'est pas coutume, les traditionnelles lignes de faille disciplinaires.

Tab. 3 Endogamie ethnique peule (3390 conjoints issus de 1695 unions)

\begin{tabular}{|c|c|c|c|c|c|c|}
\hline \multicolumn{7}{|c|}{ Époux } \\
\hline Épouses & & $\begin{array}{l}\text { D'origine } \\
\text { inconnue }\end{array}$ & $\begin{array}{l}\text { D'origine non } \\
\text { peule }\end{array}$ & Foulbé & Mbororo & Total \\
\hline & $\begin{array}{l}\text { D'origine } \\
\text { inconnue }\end{array}$ & 12 & 11 & 130 & 61 & 214 \\
\hline & $\begin{array}{l}\text { D'origine } \\
\text { non peule }\end{array}$ & 4 & 0 & 135 & 12 & 176 \\
\hline & Foulbé & 60 & 38 & 383 & 5 & 486 \\
\hline & Mbororo & 14 & 4 & 7 & 794 & 819 \\
\hline & Total & 90 & 78 & 655 & 872 & 1695 \\
\hline
\end{tabular}


L'OUBLI DES ORIGINES. AMNÉSIE ET INFORMATION GÉNÉALOGIQUES

Tab. 4 Endogamie de fraction (tableau récapitulatif)

\begin{tabular}{|c|c|c|c|c|}
\hline $\begin{array}{l}\text { Endogamie } \\
\text { de fraction }\end{array}$ & $\begin{array}{c}\text { Fraction } \\
\text { d'Ego }\end{array}$ & Sexe & $\begin{array}{l}\text { Mariages dans la fraction / Total des } \\
\text { mariages où l'ethnie ou } \\
\text { la fraction d'Alter est connue }\end{array}$ & $\begin{array}{l}\% \\
\text { d'endogamie } \\
\text { de fraction }\end{array}$ \\
\hline \multirow{4}{*}{$1^{\text {ers }}$ mariages } & \multirow{2}{*}{ Foulbé } & F & $358 / 396$ & $90,40 \%$ \\
\hline & & $\mathrm{H}$ & $287 / 344$ & $83,43 \%$ \\
\hline & \multirow{2}{*}{ Mbororo } & $\mathrm{F}$ & $739 / 746$ & $99,06 \%$ \\
\hline & & $\mathrm{H}$ & $612 / 619$ & $98,87 \%$ \\
\hline \multirow{4}{*}{$\begin{array}{c}\text { Mariages } \\
\text { secondaires }\end{array}$} & \multirow{2}{*}{ Foulbé } & F & $25 / 30$ & $83,33 \%$ \\
\hline & & $\mathrm{H}$ & $96 / 181$ & $53,04 \%$ \\
\hline & \multirow{2}{*}{ Mbororo } & F & $55 / 59$ & $93,22 \%$ \\
\hline & & $\mathrm{H}$ & $182 / 192$ & $94,79 \%$ \\
\hline \multirow{7}{*}{$\begin{array}{c}\text { Tous } \\
\text { mariages }\end{array}$} & \multirow{3}{*}{ Foulbé } & F & $383 / 426$ & $89,91 \%$ \\
\hline & & $\mathrm{H}$ & $383 / 525$ & $72,95 \%$ \\
\hline & & Tous & $766 / 951$ & $80,55 \%$ \\
\hline & \multirow{3}{*}{ Mbororo } & $\mathrm{F}$ & $794 / 805$ & $98,63 \%$ \\
\hline & & $\mathrm{H}$ & $794 / 811$ & $97,90 \%$ \\
\hline & & Tous & $1588 / 1616$ & $98,27 \%$ \\
\hline & Tous & & $2354 / 2567$ & $98,71 \%$ \\
\hline
\end{tabular}

Tab. 5 Endogamie lignagère (tableau synoptique)

\begin{tabular}{|c|c|c|c|c|c|c|c|c|c|c|}
\hline \multirow[b]{3}{*}{ Sexe } & \multicolumn{4}{|c|}{$1^{\mathrm{ers}}$ mariages } & \multicolumn{4}{|c|}{ Mariages secondaires } & \multirow{2}{*}{\multicolumn{2}{|c|}{$\begin{array}{c}\begin{array}{c}\text { Tous } \\
\text { Mariages }\end{array} \\
\%\end{array}$}} \\
\hline & \multicolumn{2}{|c|}{ Même lignage / Autre } & \multicolumn{2}{|c|}{$\%$} & \multicolumn{2}{|c|}{ Même lignage / Autre } & \multicolumn{2}{|c|}{$\%$} & & \\
\hline & $\mathrm{F}$ & $\mathrm{H}$ & $\mathrm{F}$ & $\mathrm{H}$ & $\mathrm{F}$ & $\mathrm{H}$ & $\mathrm{F}$ & $\mathrm{H}$ & $\mathrm{F}$ & $\mathrm{H}$ \\
\hline Foulbés & $187 / 363$ & $153 / 322$ & 34 & 32,2 & $11 / 9$ & $45 / 40$ & 55 & 52,9 & 34,7 & 35,4 \\
\hline Mbororo & $452 / 188$ & $395 / 138$ & 70,6 & 74,1 & $29 / 24$ & $86 / 79$ & 54,7 & 52,1 & 69,4 & 68,9 \\
\hline Aku & $131 / 29$ & $117 / 27$ & 81,9 & 81,3 & $5 / 2$ & $19 / 5$ & 71,4 & 79,2 & 81,4 & 81 \\
\hline Jafun & $168 / 154$ & $141 / 107$ & 52,2 & 56,9 & $17 / 22$ & $44 / 72$ & 43,6 & 37,9 & 51,3 & 50,8 \\
\hline WoDaaBe & $153 / 5$ & $137 / 4$ & 96,8 & 97,2 & $7 / 0$ & $23 / 2$ & 100 & 92 & 97 & 96,4 \\
\hline
\end{tabular}


Tab. 6 Rapport des mariages consanguins sur l'ensemble des mariages

\begin{tabular}{|c|c|c|c|c|c|}
\hline & & $\begin{array}{c}\text { Mariages } \\
\text { consanguins }\end{array}$ & $\begin{array}{l}\text { Redoublements } \\
\text { d'alliances }\end{array}$ & $\begin{array}{l}\text { Dont mariages } \\
\text { consanguins } \cap \\
\text { redoublements }\end{array}$ & $\begin{array}{c}\text { Mariages consanguins } \cup \\
\text { redoublements } \\
\text { d'alliances }\end{array}$ \\
\hline & & $\begin{array}{c}35,29 \% \\
\text { des alliances }\end{array}$ & $\begin{array}{c}21,66 \% \\
\text { des alliances }\end{array}$ & $\begin{array}{c}9,54 \% \\
\text { des alliances }\end{array}$ & $\begin{array}{c}47,41 \% \\
\text { des alliances }\end{array}$ \\
\hline \multirow{3}{*}{$\mathrm{H}$} & $\begin{array}{c}1^{\text {er }} \text { mariages } \\
(\mathrm{n}=963)\end{array}$ & 348 & 185 & 89 & 444 \\
\hline & $\begin{array}{l}\text { Mariages } \\
\text { secondaires } \\
(\mathrm{n}=373)\end{array}$ & 105 & 161 & 96 & 170 \\
\hline & $\begin{array}{l}\text { Somme H } \\
(\mathrm{n}=1336)\end{array}$ & 453 & 346 & 185 & 614 \\
\hline \multirow{3}{*}{$\mathrm{F}$} & $\begin{array}{c}1^{\mathrm{er}} \text { mariages } \\
(\mathrm{n}=1142)\end{array}$ & 422 & 160 & 35 & 547 \\
\hline & $\begin{array}{l}\text { Mariages } \\
\text { secondaires } \\
(\mathrm{n}=89)\end{array}$ & 31 & 50 & 25 & 56 \\
\hline & $\begin{array}{l}\text { Somme F } \\
(\mathrm{n}=1231)\end{array}$ & 453 & 210 & 60 & 603 \\
\hline $\begin{array}{c}\text { Total } \\
(\mathrm{n}=2567)\end{array}$ & & 906 & 556 & 245 & 1217 \\
\hline
\end{tabular}

N.B. : Calculs effectués pour 5005 individus et 3390 mariages, dont 2567 mariages de Peuls où le groupe ethnique du conjoint est connu (1 231 mariages de femmes peules et 1336 d'hommes peuls)

Tab. 7 Répartition des unions entre cousins au $4^{e}$ degré

\begin{tabular}{|c|c|c|c|c|c|c|}
\hline $\begin{array}{l}\text { Mariages } \\
\text { des cousins } \\
\text { au } 4^{\mathrm{e}} \text { degré }\end{array}$ & & $\mathrm{FBCh}$ & $\mathrm{MBCh}$ & $\mathrm{FZCh}$ & $\mathrm{MZCh}$ & $\begin{array}{c}\text { \% des mariages } \\
\text { entre cousins } \\
\text { germains / } \\
\text { Tous mariages } \\
\text { consanguins }\end{array}$ \\
\hline & & $\begin{array}{c}(30,24 \% \\
\text { des mariages } \\
\text { consanguins) }\end{array}$ & $\begin{array}{c}(11,70 \% \\
\text { des mariages } \\
\text { consanguins })\end{array}$ & $\begin{array}{c}(11,70 \% \\
\text { des mariages } \\
\text { consanguins })\end{array}$ & $\begin{array}{c}(4,64 \% \\
\text { des mariages } \\
\text { consanguins })\end{array}$ & \\
\hline \multirow[b]{3}{*}{$\mathrm{H}$} & $1^{\mathrm{ers}}$ mariages & 112 & 52 & 38 & 15 & $62,36 \%$ \\
\hline & $\begin{array}{c}\text { Mariages } \\
\text { secondaires }\end{array}$ & 25 & 9 & 7 & 6 & $44,76 \%$ \\
\hline & Total H & $\begin{array}{c}137 \\
(51,89 \% \text { des } \\
\text { mariages avec } \\
\text { une cousine } \\
\text { au } 4^{\text {ème }} \text { degré) }\end{array}$ & $\begin{array}{c}61 \\
(23,11 \% \text { des } \\
\text { mariages avec } \\
\text { une cousine } \\
\text { au } 4^{\text {ème }} \text { degré) }\end{array}$ & $\begin{array}{c}45 \\
(17,05 \% \text { des } \\
\text { mariages avec } \\
\text { une cousine } \\
\text { au 4 }{ }^{\text {ìme }} \text { degré) }\end{array}$ & $\begin{array}{c}21 \\
\text { ( } 7,95 \% \text { des } \\
\text { mariages avec } \\
\text { une cousine } \\
\text { au } 4^{\text {ème degré) }}\end{array}$ & $\begin{array}{c}=264, \\
\text { soit } 58,28 \% \\
\text { des } 453 \text { mariages } \\
\text { consanguins } \\
\text { d'hommes }\end{array}$ \\
\hline \multirow[b]{3}{*}{$\mathrm{F}$} & $1^{\mathrm{ers}}$ mariages & 131 & 40 & 61 & 20 & $59,72 \%$ \\
\hline & $\begin{array}{c}\text { Mariages } \\
\text { secondaires }\end{array}$ & 6 & 5 & 0 & 1 & $38,71 \%$ \\
\hline & Total F & $\begin{array}{c}137 \\
(51,89 \% \text { des } \\
\text { mariages avec } \\
\text { un cousin } \\
\text { au } 4^{\text {ème }} \text { degré) }\end{array}$ & $\begin{array}{c}45 \\
(17,05 \% \text { des } \\
\text { mariages avec } \\
\text { un cousin } \\
\text { au } 4^{\text {ème degré }}\end{array}$ & $\begin{array}{c}61 \\
(23,11 \% \text { des } \\
\text { mariages avec } \\
\text { un cousin } \\
\text { au } 4^{\text {ème }} \text { degré) }\end{array}$ & $\begin{array}{c}21 \\
(7,95 \% \text { des } \\
\text { mariages avec } \\
\text { un cousin } \\
\text { au } 4^{\text {ème }} \text { degré) }\end{array}$ & $\begin{array}{l}\quad=264 \text {, soit } \\
58,28 \% \text { des } 453 \\
\text { mariages consan- } \\
\text { guins de femmes }\end{array}$ \\
\hline
\end{tabular}


Tab. 7 Répartition des unions entre cousins au 4e degré (suite)

\begin{tabular}{|c|c|c|c|c|c|}
\hline $\begin{array}{l}\text { Mariages } \\
\text { des cousins } \\
\text { au } 4^{\mathrm{e}} \text { degré }\end{array}$ & $\mathrm{FBCh}$ & $\mathrm{MBCh}$ & FZCh & $\mathrm{MZCh}$ & $\begin{array}{c}\text { \% des mariages } \\
\text { entre cousins } \\
\text { germains / } \\
\text { Tous mariages } \\
\text { consanguins }\end{array}$ \\
\hline Total & 274 & 106 & 106 & 42 & $\begin{array}{c}=528, \text { soit } \\
58,28 \% \text { des } \\
906 \text { mariages } \\
\text { consanguins } \\
\text { d'hommes et de } \\
\text { femmes peuls }\end{array}$ \\
\hline $\begin{array}{c}\text { En \% des } \\
\text { mariages entre } \\
\text { cousins } \\
\text { du } 4^{\text {ème }} \text { degré }\end{array}$ & $51,89 \%$ & 20,06 & 20,06 & 7,95 & $\begin{array}{c}\text { Soit } 58,28 \% \\
\text { des mariages } \\
\text { consanguins }\end{array}$ \\
\hline
\end{tabular}

\section{DE LA CONNAISSANCE DES ANCÊTRES}

Il est une évidence avec laquelle historiens, démographes et ethnologues doivent composer: les corpus généalogiques sont la plupart du temps largement incomplets ; ils ne demeureront, en effet, qu'un miroir fuyant, un canevas inachevé qui, bien qu'ayant été constitué avec méthode et rigueur, propose une exhaustivité relative. Nous avons vu que des sources historiques de l'époque moderne émergeait une première et nette constatation : nous sommes sensiblement mieux renseignés sur les hommes plutôt que sur les femmes, ce qui signifie que les corpus généalogiques reconstitués à partir de ces sources comporteront inévitablement une inflexion, qui se concrétisera par ce que l'on peut appeler un "biais agnatique». Par biais agnatique, nous entendons la sur-représentation et la plus grande fluidité, dans un corpus généalogique, des relations agnatiques, tant dans leur verticalité que dans leur horizontalité, tant dans l'ascendance, donc, que dans la collatéralité. Autrement dit le fait que ces relations soient dans ce corpus plus nombreuses et plus étendues, mais aussi plus «fluides», c'est-à-dire plus intensément connectées.

Il est possible, avec l'aide du logiciel Puck, de repérer précisément cette prévalence des liens agnatiques qui caractérise fréquemment les réseaux matrimoniaux. En effet, le logiciel produit un certain nombre d'opérations permettant d'obtenir un rapide aperçu de la morphologie d'un corpus, notamment concernant la "mémoire " généalogique. Il permet de calculer le nombre d'ascendants connus à des degrés donnés, de qualifier les chaînes d'ascendance et de repérer précisément la déperdition de l'information généalogique dans les réseaux matrimoniaux reconstitués.

Or, la décision de mettre ainsi en valeur dans les options de calculs proposées d'emblée par le logiciel ces indices spécifiques plutôt que d'autres, nous semble témoigner assez clairement d'un parti pris théorique sous-jacent à la conceptualisation de Puck. Celui selon lequel l'amnésie généalogique aurait une incidence forte sur la connaissance que nous possédons des pratiques 
matrimoniales, voire modifierait sensiblement la proportion et l'ordonnancement des unions consanguines?.

Ne partageant pas ce point de vue, nous nous attacherons pour notre part à mettre en exergue la déperdition de l'information généalogique que subissent les réseaux matrimoniaux, qu'ils soient historiques ou ethnographiques. Mais nous efforcerons de montrer, ce faisant, qu'il n'y a aucune évidence à ce que la méconnaissance de certaines relations de parenté ait pour conséquence un bouleversement profond des recensements matrimoniaux, ce en proposant une méthode de recensement alternative pour contourner la méconnaissance certaine qui émerge des corpus généalogiques «bruts»

\section{Mémoires réelles, mémoires virtuelles}

Il nous faut en effet préciser, comme nous l'indiquions en introduction, que la lecture des informations fournies à la suite de l'application d'outils informatiques à des corpus généalogiques peut conduire à une totale mésestimation des résultats si l'on en vient à confondre les notions de "mémoire des acteurs" et «d'information disponible pour le chercheur».

Nous allons ainsi montrer, dans les pages qui suivent, que les corpus peuls et San Marino - comme la majorité des corpus en fait - connaissent une très nette déperdition de l'information disponible concernant certains types de liens (en l'occurrence les liens utérins) là où la connaissance d'autres (les liens agnatiques) reste assez élevée.

Cette déperdition d'information sur certains parents a pu conduire certains ethnologues à rapprocher cette méconnaissance généalogique de certaines règles de mariage. Ainsi, dans le cadre de sociétés pratiquant des formes de «mariage arabe», comme c'est le cas des Peuls par exemple, ce serait l'ignorance dans laquelle seraient les acteurs de ces liens utérins qui expliquerait qu'ils n'épousent que rarement des parents par les femmes et, a contrario, ce serait leur bonne connaissance des liens agnatiques qui rendrait compte du fait qu'ils privilégient le mariage entre parents par les hommes.

Or, cette hypothèse découle d'une réification des artefacts sociotechniques issus de l'analyse informatique, réification qui conduit à confondre ceux-ci avec les usages symboliques et praxéologiques réels des acteurs. Ainsi, dans le cas qui nous occupe à présent, elle s'est établie sur une confusion, celle que nous faisons entre l'information disponible pour le chercheur au terme de l'analyse informatique d'un corpus et la mémoire généalogique réelle que les individus étudiés dans le corpus ont de leurs réseaux de parenté.

Pour comprendre le hiatus entre ces deux notions - hiatus présent, il est important de le souligner, dans la totalité des résultats que nous présenterons par la suite - un exemple simple devrait suffire. Un corpus est en effet à la fois constitué d'individus que nous qualifierons de "réels " - dans le cas d'un corpus ethnographique, il s'agira des informateurs -, et d'individus que nous appellerons «virtuels» dans la mesure où ils n'y apparaissent pas en tant qu'informateurs, mais uniquement comme " avatars biographiques " faisant partie de la mémoire généalogique des premiers. Chaque informateur interrogé étant généralement capable de se rappeler plusieurs de ses parents et alliés, il est alors facile de comprendre que la somme 
Fig. 3 Mémoire réelle, mémoire virtuelle

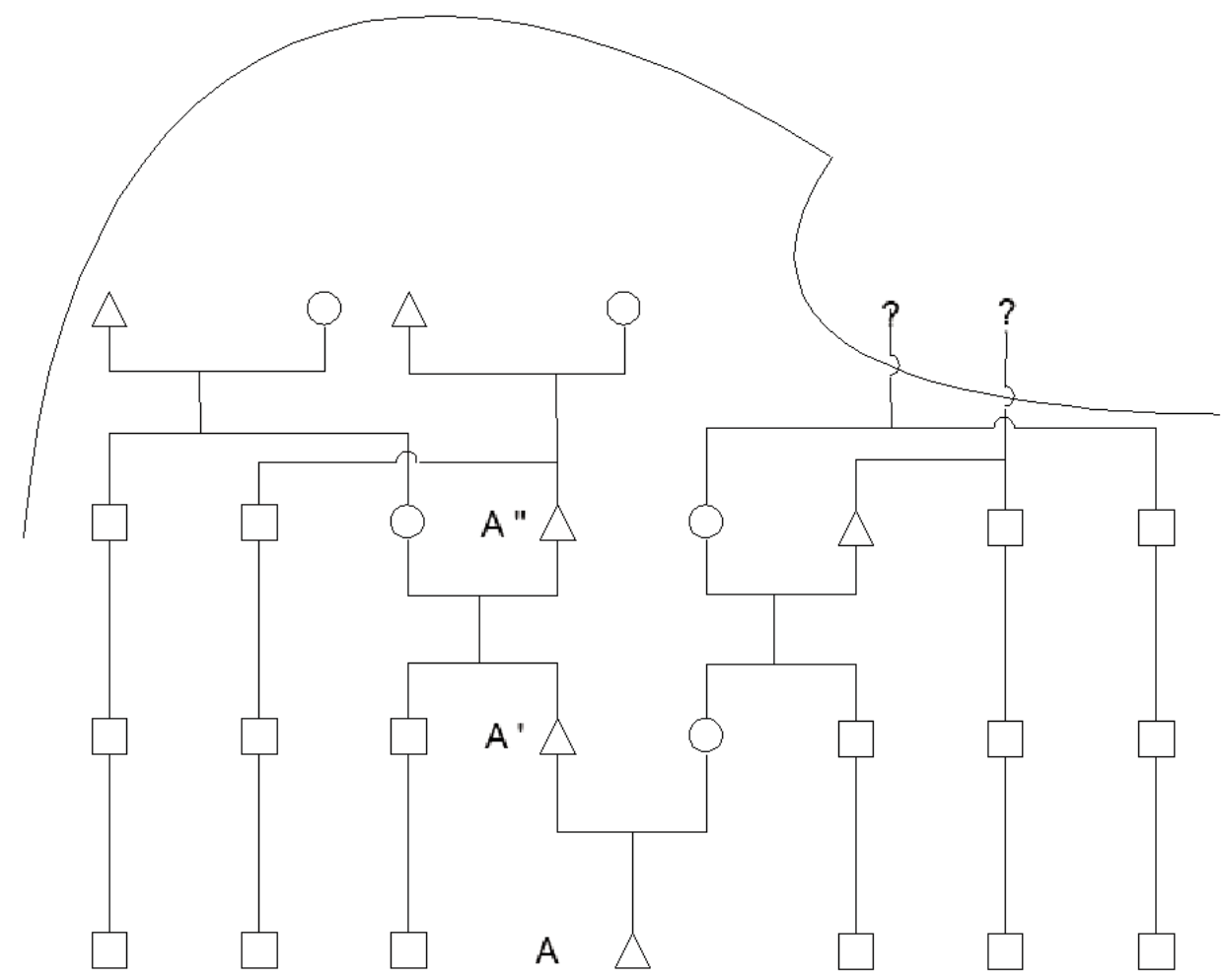

des individus "virtuels» dépasse de les résultats obtenus et donne in fine la beaucoup la somme des individus que nous avons qualifiés de "réels".

Or, et c'est là d'où naît la confusion qui est à l'origine de l'hypothèse que nous venons d'évoquer, tous les calculs portant sur des corpus généalogiques et qui s'essayent à définir la mémoire et la connaissance que les acteurs ont de leur parenté portent à la fois sur la mémoire des individus «réels» et "virtuels» et donc, compte tenu de la sur-représentation automatique ${ }^{10}$ de ces individus "virtuels», en réalité majoritairement sur celle de ces derniers. Le fait d'utiliser alors ces «avatars mémoriels" plutôt que la mémoire d'individus réels comme source principale d'information conduit alors à gauchir considérablement tous trompeuse impression d'une amnésie généalogique généralisée des acteurs. Un schéma illustrera plus clairement l'origine de la méprise (voir supra figure 3 ).

Dans ce schéma, A est un informateur réel. Il se souvient de ses deux parents, dont $A^{\prime}$ son père qui dans ce corpus est déjà un individu "virtuel» (il n'est pas un informateur, mais juste un individu présent à la mémoire d'un informateur). Il se souvient aussi des germains de ses deux parents et de leurs enfants, ses cousins (nous ne représentons pas tous ces collatéraux pour ne pas encombrer le schéma). A se souvient également de ses quatre grands-parents (dont A" qui est lui aussi un individu "virtuel»), de leurs germains, des enfants et petits-enfants de 
ces derniers (ses oncles et tantes classificatoires et ses cousins et cousines classificatoires, que nous ne représentons pas à nouveau). Par contre, imaginons qu'en $\mathrm{G}$ +3 , A ne se souvient déjà plus vraiment de ses arrière-grands-parents maternels alors qu'il se souvient encore d'une partie au moins de ses arrière-grands-parents agnatiques (disons que $\mathrm{A}$ appartient à un groupe patrilinéaire et qu'il conserve plus lointainement la mémoire des ancêtres agnatiques qu'utérins). C'est cette réminiscence plus complète du côté agnatique que du côté utérin que nous avons symbolisé ici par un arc de cercle «biseauté» du côté des parents utérins en $\mathrm{G}+3$.

Imaginons à présent que la mémoire généalogique de $\mathrm{A}$ corresponde mutatis mutandis à la mémoire généalogique qu'ont, à l'ordinaire, les gens de la société à laquelle il appartient. Dans ce cas, nous pouvons affirmer que la mémoire généalogique individuelle dans cette société porte (en moyenne) au moins sur les deux premières générations ascendantes et sur leurs descendances : un individu y connaît donc tous ses cousins et cousines au $4^{\mathrm{e}}$ et au $6^{e}$ degré civil. Les phénomènes d'amnésie généalogique ne commenceront ici qu'à $\mathrm{G}+3$ et toucheront d'abord les parents utérins.

Est-ce alors à cette même conclusion que vont se ranger les résultats de l'analyse informatique d'un corpus généalogique? En fait, non, puisque, faute de pouvoir différencier entre individus «réels» et «virtuels» (autrement dit entre ceux qui sont à la source de l'information et ceux qui sont contenus dans l'information), les logiciels feront porter leurs calculs sur la totalité des «individus» présents dans le corpus. Ils caractériseront ainsi la connaissance généalogique moyenne comme la moyenne de la connaissance que $A, A^{\prime}, A^{\prime \prime}$, etc., et tous les individus de leurs générations ont de leurs ascendants et collatéraux. Comme on le voit sur le schéma, la connaissance généalogique calculée informatiquement correspondra à la moyenne de celle des individus de la génération de A (qui porte sur deux générations et incomplètement sur une troisième), des individus de la génération de A' (qui ne porte plus que sur une génération et incomplètement sur une deuxième), des individus de la génération A" (qui ne porte plus que sur une génération et uniquement sur la branche agnatique de celle-ci) et enfin des individus en $\mathrm{G}+3$ qui n'auront quant à eux connaissance d'aucun de leurs parents.

Bref, alors que la mémoire généalogique réelle des individus de cet exemple portait ici sur deux générations et demie, elle sera ramenée par le truchement du traitement informatique à un niveau moyen bien plus faible, et surtout sociologiquement totalement absurde: certains individus du corpus étant censés ne connaître aucun de leurs parents, d'autres seulement l'un des deux et d'autres encore étant supposés ne pas connaître la moitié de leurs grandsparents.

Ainsi, quand nous dirons, en commentant les tableaux infra, que dans un quart à un tiers des cas, nous ne connaissons aucun des grands-parents d'un individu donné, ou quand il apparaitra, par exemple, que les Peuls semblent mieux connaître leurs cousins agnatiques qu'utérins, il s'agira toujours de moyennes établies sur ces «individus virtuels", reflet de l'information disponible, et non de la mémoire généalogique d'individus réels qui, chez les Peuls comme chez les San-Marinais, connaissent dans l'immense majorité des cas très bien tous leurs parents proches: parents, grands-parents, 
cousins et cousines, voire même cousins issus de germains et autres... " parents à la mode de Bretagne».

Il est difficile d'échapper à ce biais (et c'est la raison pour laquelle nous n'avons pas cherché à nous y soustraire, mais juste à le mettre en évidence) dans la mesure où pour ce faire il conviendrait de ne faire porter les calculs informatiques que sur les seuls individus qui sont des informateurs eux-mêmes, ce qui, dans le cas des corpus ethnographiques réduirait considérablement leur représentativité statistique et dans celui des corpus historiques poserait le problème de l'identification même des "informateurs".

Ce qu'il convient alors de conserver à l'esprit, c'est que tous les calculs suivants, comme tous ceux en fait présentés dans d'autres travaux portant sur l'idée de "mémoire généalogique», sont toujours en définitive de simples mesures caractérisant l'information disponible pour le chercheur, jamais la mémoire familiale des acteurs.

\section{Connaissance généalogique et primauté des agnats}

Si la distribution des individus selon leur sexe peut être un premier indicateur du déséquilibre des informations généalogiques au sein d'un corpus, précisons qu'il est aussi à relativiser, dans la mesure où nous avons constaté, au cours de notre enquête, que de nombreuses femmes étaient présentes deux fois, voire plus, dans le réseau, en tant qu'épouses dont on ne connaît pas l'ascendance, et en tant que filles non mariées : ainsi, à mesure que le sondage a progressé dans les archives, nombre de ces doublons ont été éliminés, faisant à la fois baisser le biais agnatique présent dans le corpus, mais aussi le nombre de femmes. Il faut également avoir à l'esprit que la distribution des individus selon leur sexe doit être mise en relation avec leur distribution générationnelle: on pourrait avoir beaucoup plus de femmes dans un corpus généalogique tout en ayant une connaissance plus importante des lignées agnatiques, si par exemple la population féminine était très conséquente dans les dernières générations, disons à $G 0$ ou $G+1$, et très peu représentée dans les générations supérieures.

Considérer un réseau dans son ensemble, comme le propose le logiciel Puck, permet de percevoir une structure et l'interdépendance et les interconnexions des différents points d'un réseau. Mais, dans le même temps, et c'est précisément ici que se situe à la fois l'atout et le défaut de l'approche sociocentrée que privilégie ce logiciel, cette perspective, en ce qu'elle ne distingue pas a priori, comme nous venons de le voir, entre différents types de "mémoires» - réelles ou virtuelles - place sur le même plan des "individus" et des "avatars mémoriels». Cette question vaut particulièrement, bien entendu, pour la connaissance généalogique, laquelle sera fort différente selon que l'on se trouve «en bas» ou "en haut» de la hiérarchie générationnelle d'un réseau généalogique, autrement dit lorsqu'il s'agira de la mémoire réelle d'un informateur ou d'un "extrait» de cette mémoire que cette approche sociocentrée prêtera à l'individu virtuel posé comme l'ancêtre du précédent. Cet amalgame aura alors finalement et globalement pour résultat de minorer largement, comme nous l'avons montré plus haut, l'étendue du champ de la mémoire réelle des acteurs ainsi que d'augmenter artificiellement l'impact du "biais agnatique ».

Néanmoins, une telle opération peut s'avérer utile au moins dans une 
première étape, comme nous allons le voir à présent, afin de rappeler que la complétude généalogique est loin d'être toujours atteinte, ce même pour les générations les plus basses.

En effet, la vue d'ensemble d'un corpus - dont il faut absolument garder à l'esprit qu'elle reflète non pas la connaissance généalogique réelle des acteurs mais l'information disponible au terme du traitement informatique pour le chercheur -, montre d'emblée une rapide déperdition d'informations concernant les ancêtres, et ce dès la génération des grands-parents. Cette diminution croît d'ailleurs sensiblement avec la profondeur généalogique. Si l'on connaît les deux parents pour près de deux tiers ou plus de l'ensemble des individus dans les quatre corpus étudiés, la proportion de ceux pour lesquels nous disposons d'une complète information généalogique chute de moitié ou plus à la génération suivante, n'atteignant pas les $10 \%$ à $\mathrm{G}+3$ et étant nulle ou quasiment nulle à $\mathrm{G}+4$, où la connaissance généalogique ne concerne là qu'un quart ou un huitième des ancêtres. Au-delà, le nombre d'ancêtres théoriquement attendu n'est jamais atteint, et les individus pour lesquels l'information généalogique ascendante est maximale ne représentent qu'une part infime du corpus. Ce qui signifie que les chaînes unisexuées menant à des ancêtres apicaux agnatiques sont nombreuses, ce à quoi l'on s'attendait, mais aussi que la connaissance généalogique des cohortes situées dans les générations les plus basses, c'est-à-dire celles pour lesquelles on s'attendrait à ce que l'information généalogique soit presque parfaite, en tout cas meilleure, comporte également des lacunes, même si la connaissance d'un ancêtre ou plus, que ce soit à $\mathrm{G}+1$ ou $\mathrm{G}+4$, se vérifie pour tous les corpus (voir les tableaux 8 et 9).
Ceci, il convient d'insister sur ce point, nous montre bien une fois encore que ces chiffres reflètent l'information disponible accessible au chercheur et en aucun cas la mémoire réelle des acteurs. En effet, est-il vraiment crédible de supposer que près d'un tiers des Peuls ou des San Marinais ignorent l'identité de leurs propres parents? Est-il également un tant soit peu raisonnable de supposer que seul un cinquième à un tiers de ces mêmes acteurs connaissent l'identité de leurs propres grands-parents?

Les tableaux montrent immédiatement le faible nombre d'individus pour lesquels nous disposons d'une connaissance généalogique complète dès la troisième génération, si l'on considère le réseau dans son ensemble; ils révèlent un décrochage abrupt à partir de la quatrième génération, et lorsque l'on ne connaît qu'une partie des ascendants, il s'agit toujours, et à une écrasante majorité, des lignes agnatiques : la déperdition de l'information généalogique s'opère dans un sens bien précis, celui des lignes utérines.

Lorsque l'on ne connaît, qu'un seul des deux parents par exemple - le « on » désignant ici le chercheur et non l'acteur bien entendu -, il s'agit du père dans près de $99 \%$ des cas pour le corpus San Marino, $96 \%$ pour les corpus Banyo et Jafun et $83 \%$ pour les Mbororos. Dans le cas où seul un des quatre grands-parents est connu, il s'agit toujours des grands-pères, d'abord paternel, à une écrasante majorité, puis maternel, et rarement ou quasiment jamais des grands-mères, le corpus Mbororos faisant figure d'exception, puisque la grand-mère paternelle est alors largement plus représentée que le grandpère maternel. Situation semblable à $\mathrm{G}+3$, où les ancêtres masculins dominent la connaissance généalogique, tandis que les ancêtres féminins sont inexistants ou presque (tableaux 10, 11, 12). 
L'OUBLI DES ORIGINES. AMNÉSIE ET INFORMATION GÉNÉALOGIQUES

Tab. 8 Connaissance généalogique de la totalité des corpus, G+1-4

\begin{tabular}{|c|c|c|c|c|c|}
\hline Profondeur généalogique & Nombre d'ascendants connus & Banyo & Jafun & Mbororos & San Marino \\
\hline \multirow[t]{4}{*}{$\mathrm{G}+1$} & 1 à 2 & 73,63 & 80,42 & 79,2 & 82,19 \\
\hline & 0 sur 2 & 26,37 & 19,58 & 20,8 & 17,81 \\
\hline & 1 sur 2 & 13,56 & 16,1 & 9,89 & 14,6 \\
\hline & 2 sur 2 & 60,07 & 64,32 & 69,31 & 67,59 \\
\hline \multirow[t]{6}{*}{$\mathrm{G}+2$} & 1 à 4 & 63,59 & 73,24 & 67,88 & 69,76 \\
\hline & 0 sur 4 & 36,41 & 26,76 & 32,12 & 30,24 \\
\hline & $1 \operatorname{sur} 4$ & 5,9 & 10,03 & 6,38 & 8,31 \\
\hline & $2 \operatorname{sur} 4$ & 27,25 & 19,58 & 18,06 & 16,07 \\
\hline & $3 \operatorname{sur} 4$ & 10,98 & 18,95 & 9,95 & 12,38 \\
\hline & $4 \operatorname{sur} 4$ & 19,46 & 24,67 & 33,49 & 33 \\
\hline \multirow[t]{10}{*}{$\mathrm{G}+3$} & 1 à 8 & 61,29 & 68,57 & 54,35 & 61,53 \\
\hline & 0 sur 8 & 38,71 & 31,43 & 45,65 & 38,47 \\
\hline & $1 \operatorname{sur} 8$ & 7,59 & 6,62 & 5,18 & 5,71 \\
\hline & $2 \operatorname{sur} 8$ & 30,03 & 15,96 & 10,13 & 8,95 \\
\hline & 3 sur 8 & 6,92 & 10,52 & 4,83 & 7,48 \\
\hline & $4 \operatorname{sur} 8$ & 9,76 & 9,2 & 10,91 & 13,2 \\
\hline & $5 \operatorname{sur} 8$ & 4,27 & 7,53 & 5,13 & 5,2 \\
\hline & 6 sur 8 & 2,24 & 9,41 & 10,13 & 7,65 \\
\hline & 7 sur 8 & 0,47 & 3,55 & 2,44 & 5,41 \\
\hline & 8 sur 8 & 0 & 5,78 & 5,6 & 7,93 \\
\hline \multirow[t]{18}{*}{$\mathrm{G}+4$} & 1 à 16 & 60,07 & 62,58 & 33,91 & 55,89 \\
\hline & 0 sur 16 & 39,93 & 37,42 & 66,09 & 44,11 \\
\hline & 1 sur 16 & 15,53 & 7,8 & 3,64 & 4,05 \\
\hline & 2 sur 16 & 19,73 & 16,45 & 6,26 & 6,08 \\
\hline & 3 sur 16 & 5,69 & 5,51 & 4,11 & 4,99 \\
\hline & 4 sur 16 & 12 & 8,57 & 7,75 & 7,01 \\
\hline & 5 sur 16 & 4 & 3 & 2,86 & 3,58 \\
\hline & 6 sur 16 & 1,97 & 5,92 & 3,04 & 5,12 \\
\hline & 7 sur 16 & 0,95 & 1,46 & 0,42 & 4,58 \\
\hline & 8 sur 16 & 0,07 & 5,09 & 0,24 & 6,1 \\
\hline & 9 sur 16 & 0,14 & 1,88 & 0,42 & 2,29 \\
\hline & 10 sur 16 & 0 & 5,57 & 2,09 & 3,1 \\
\hline & 11 sur 16 & 0 & 0,35 & 1,13 & 2,53 \\
\hline & 12 sur 16 & 0 & 0,49 & 1,31 & 2,63 \\
\hline & 13 sur 16 & 0 & 0,35 & 0,24 & 1,31 \\
\hline & 14 sur 16 & 0 & 0,14 & 0,36 & 1,22 \\
\hline & 15 sur 16 & 0 & 0 & 0,06 & 0,87 \\
\hline & 16 sur 16 & 0 & 0 & 0 & 0,44 \\
\hline
\end{tabular}

Répartition en \% des individus de chaque corpus selon la proportion de leurs ancêtres connus à chaque génération ascendante théorique. 
Tab. 9 Complétude généalogique attendue et réelle dans les 4 corpus

\begin{tabular}{llcccc}
\hline & Attendus & Banyo & Jafun & Mbororos & San Marino \\
\hline $\mathrm{G}+1$ & $\mathbf{2}$ & $2(60,07)$ & $2(64,32)$ & $2(69,31)$ & $2(67,59)$ \\
\hline $\mathrm{G}+2$ & $\mathbf{4}$ & $4(19,46)$ & $4(24,67)$ & $4(33,49)$ & $4(33,00)$ \\
\hline $\mathrm{G}+3$ & $\mathbf{8}$ & $7(0,47)$ & $8(5,78)$ & $8(5,60)$ & $8(7,93)$ \\
\hline $\mathrm{G}+4$ & $\mathbf{1 6}$ & $9(0,14)$ & $14(0,14)$ & $15(0,06)$ & $16(0,44)$ \\
\hline $\mathrm{G}+5$ & 32 & $10(0,54)$ & $18(0,14)$ & $14(0,12)$ & $31(0,021)$ \\
\hline $\mathrm{G}+6$ & $\mathbf{6 4}$ & $8(0,27)$ & $18(0,14)$ & $6(0,12)$ & $51(0,025)$ \\
\hline $\mathrm{G}+7$ & $\mathbf{1 2 8}$ & $6(0,68)$ & $16(0,14)$ & $4(0,12)$ & $85(0,004)$ \\
\hline $\mathrm{G}+8$ & $\mathbf{2 5 6}$ & $4(0,75)$ & $9(0,14)$ & $0(0)$ & $141(0,004)$ \\
\hline $\mathrm{G}+9$ & 512 & $4(0,07)$ & $2(0,07)$ & $0(0)$ & $181(0,004)$ \\
\hline $\mathrm{G}+10$ & $\mathbf{1 0 2 4}$ & $4(0,07)$ & $0(0)$ & $0(0)$ & $223(0,008)$ \\
\hline
\end{tabular}

NB: Les chiffres indiqués dans les colonnes de corpus correspondent d'une part au nombre maximum d'ascendants réellement connus pour un ou des individus de chaque corpus à un niveau de profondeur généalogique donnée, et d'autre part à la proportion d'individus au sein de l'effectif du corpus pour lesquels ce niveau maximum réel de connaissance est atteint.

Tab. 10 Individus dont on ne connaît qu'un seul parent ${ }^{11}$

\begin{tabular}{lcccc}
\hline & Banyo & Jafun & Mbororos & San Marino \\
\hline$(\mathrm{H})$ & $96 \%$ & $95,70 \%$ & $83,10 \%$ & $98,80 \%$ \\
\hline$(\mathrm{F})$ & $4 \%$ & $4,30 \%$ & $16,90 \%$ & $1,20 \%$ \\
\hline $\begin{array}{l}\text { Nombre de cas / } \\
\text { ensemble du corpus }\end{array}$ & $200 / 1475$ & $231 / 1435$ & $166 / 1678$ & $3510 / 4049$ \\
\hline
\end{tabular}

Tab. 11 Individus dont on ne connaît qu'un seul grand-parent

\begin{tabular}{lcccc}
\hline & Banyo & Jafun & Mbororos & San Marino \\
\hline Grand-père paternel X H(H) & $85 \%$ & $91,70 \%$ & $73,80 \%$ & $90 \%$ \\
\hline Grand-père maternel X F $(\mathrm{H})$ & $10,40 \%$ & $6,20 \%$ & $3,80 \%$ & $9,20 \%$ \\
\hline Grand-mère paternelle X H(F) & $3,45 \%$ & $1,40 \%$ & $16,82 \%$ & $0,55 \%$ \\
\hline Grand-mère maternelle X F(F) & $1,15 \%$ & $0,70 \%$ & $5,60 \%$ & $0,25 \%$ \\
\hline Nombre de cas/ensemble du corpus & $87 / 1475$ & $144 / 1435$ & $107 / 1678$ & $1999 / 24049$ \\
\hline
\end{tabular}

Tab.12 Individus dont on ne connầt qu'un seul arrière-grand-parent

\begin{tabular}{lcccc}
\hline & Banyo & Jafun & Mbororos & San Marino \\
\hline $\mathrm{XHH}(\mathrm{H})$ & $90,17 \%$ & $92,60 \%$ & $86,20 \%$ & $73 \%$ \\
\hline $\mathrm{XFH}(\mathrm{H})$ & $6,25 \%$ & $2,10 \%$ & $9,20 \%$ & $23,20 \%$ \\
\hline $\mathrm{XHF}(\mathrm{H})$ & $2,67 \%$ & $1,05 \%$ & $3,45 \%$ & $1,80 \%$ \\
\hline $\mathrm{XFF}(\mathrm{H})$ & $0 \%$ & $1,05 \%$ & $0 \%$ & $2 \%$ \\
\hline $\mathrm{XHH}(\mathrm{F})$ & $0,89 \%$ & $3,20 \%$ & $0 \%$ & $0 \%$ \\
\hline $\mathrm{XFH}(\mathrm{F})$ & $0 \%$ & $0 \%$ & $0 \%$ & $0 \%$ \\
\hline $\mathrm{XHF}(\mathrm{F})$ & $0 \%$ & $0 \%$ & $1,15 \%$ & $0 \%$ \\
\hline $\mathrm{XFF}(\mathrm{F})$ & $0 \%$ & $0 \%$ & $0 \%$ & $0 \%$ \\
\hline Nombre de caslensemble du corpus & $112 / 1475$ & $95 / 1435$ & $87 / 1678$ & $1372 / 24049$ \\
\hline
\end{tabular}


Le logiciel Puck permet d'obtenir graphiquement une vue d'ensemble des chaînes d'ascendance connues à $\mathrm{G}+3$ (figures $4 a, b$, c et d). Les quatre corpus sont marqués par la nette domination des relations purement agnatiques $(\mathrm{XHHH}(\mathrm{H}))$, et la faiblesse de celles strictement utérines $(\mathrm{XFFF}(\mathrm{F}))$. On relève toutefois quelques différences, dont certaines sont particulièrement intéressantes.

Pour le corpus San Marino émergent clairement quatre catégories. La première, purement agnatique $(\mathrm{XHH}(\mathrm{H}))$, domine largement. Elle est suivie des trois chaînes ne comportant qu'une seule relation utérine (XFH(H), XHH(F), XHF(H)). Vient ensuite le troisième groupe $(\mathrm{XFF}(\mathrm{H})$, $\mathrm{XFH}(\mathrm{F}), \mathrm{XHF}(\mathrm{F}))$, caractérisé par la même homogénéité et la présence de deux relations utérines. La dernière catégorie, enfin, purement utérine $(\mathrm{XFF}(\mathrm{F}))$, arrive en dernière position. Nous sommes sensiblement mieux renseignés sur les ancêtres agnatiques des parents d'Ego ; lorsque l'on connaît davantage une arrière-grand-mère plutôt qu'un arrière-grand-père, il s'agit d'un ancêtre agnatique $(\mathrm{XHH}(\mathrm{F}))$. Notons que nous sommes mieux informés sur l'arrière-grandpère utérin plutôt que sur l'arrièregrand-mère paternelle $(\mathrm{XHF}(\mathrm{F}))$.

Les trois premières catégories d'ancêtres connus à $\mathrm{G}+3$ sont communes aux corpus Peuls, dans lesquels les deux ancêtres strictement agnatiques d'Ego (arrière-grand-père et arrière-grandmère agnatiques) sont les plus représentés, suivis de l'ancêtre agnatique de la mère d'Ego. Les relations à dominante utérine $(\mathrm{XHF}(\mathrm{F}), \operatorname{XFF}(\mathrm{H})$ et $\mathrm{XFF}(\mathrm{F}))$ sont reléguées en dernière position, à l'exception du corpus Mbororos dans lequel la grand-mère utérine du père d'Ego devance le grand-père maternel du père d'Ego. Il est intéressant de noter que pour le corpus Banyo, l'arrièregrand-mère utérine $(\mathrm{XFF}(\mathrm{F})$ est mieux connue que la grand-mère utérine du père d'Ego $(\mathrm{XHF}(\mathrm{F}))$.

Fig. 4a Qualification des chaînes d'ascendance en G+3, corpus San Marino

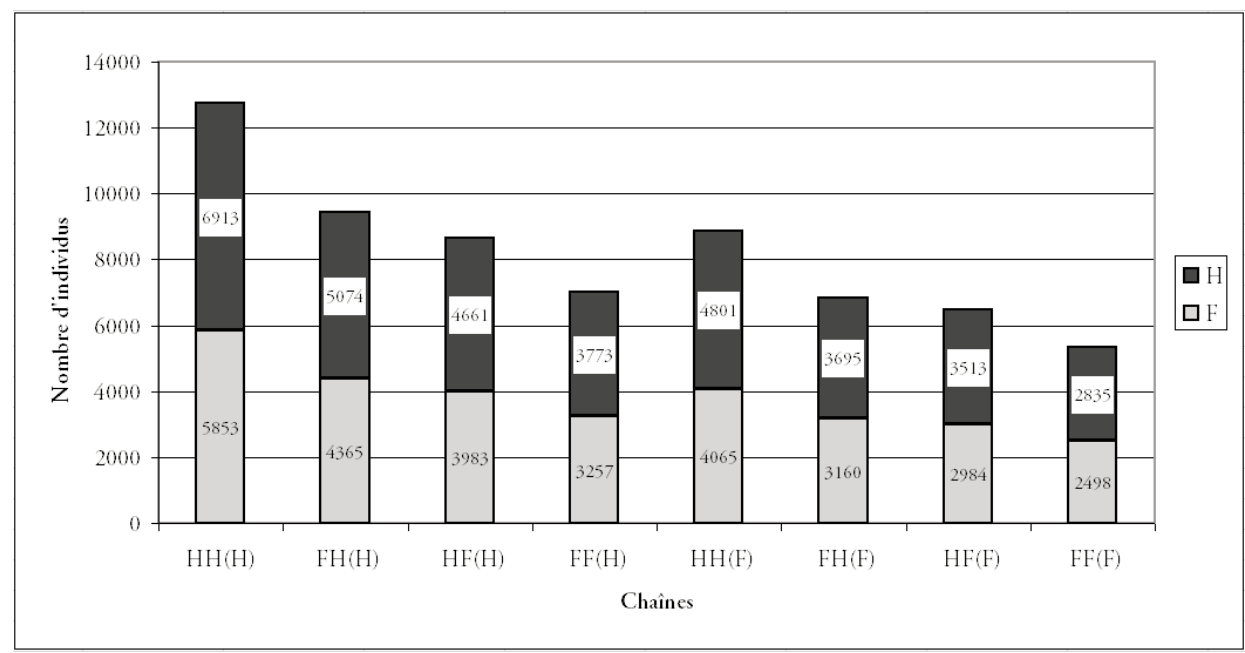


Fig. 4b Qualification des chaînes d'ascendance en $G+3$, corpus Banyo

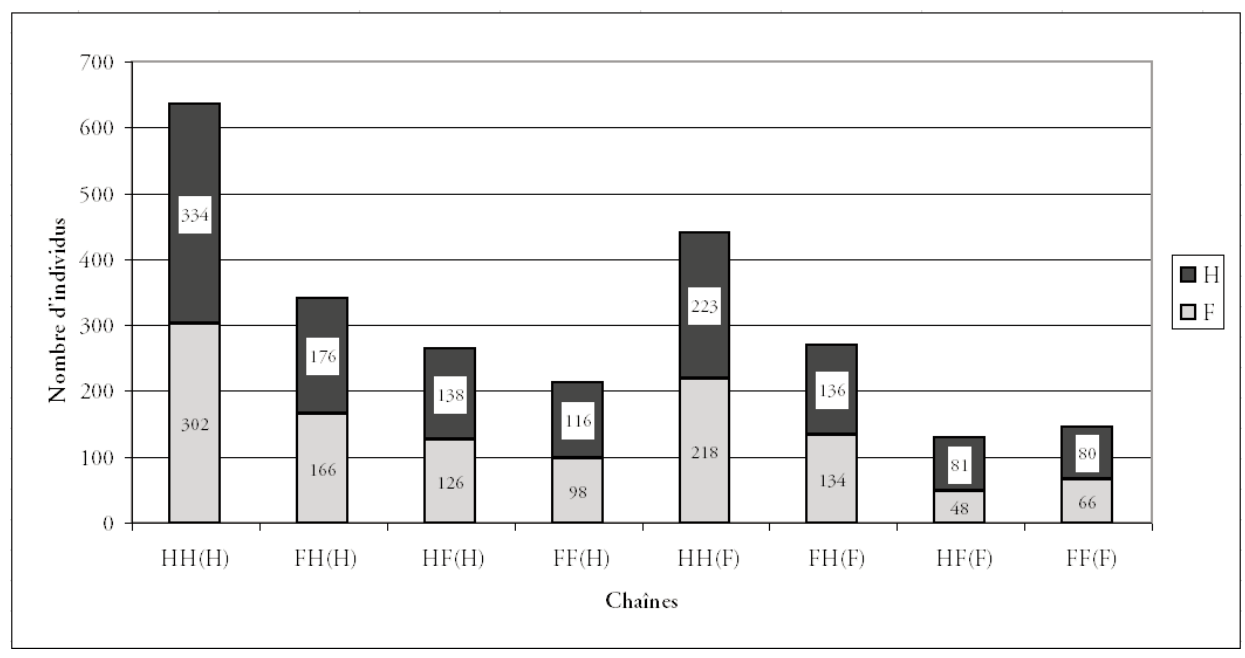

Fig. 4c Qualification des chaînes d'ascendance en $G+3$, corpus Mbororos

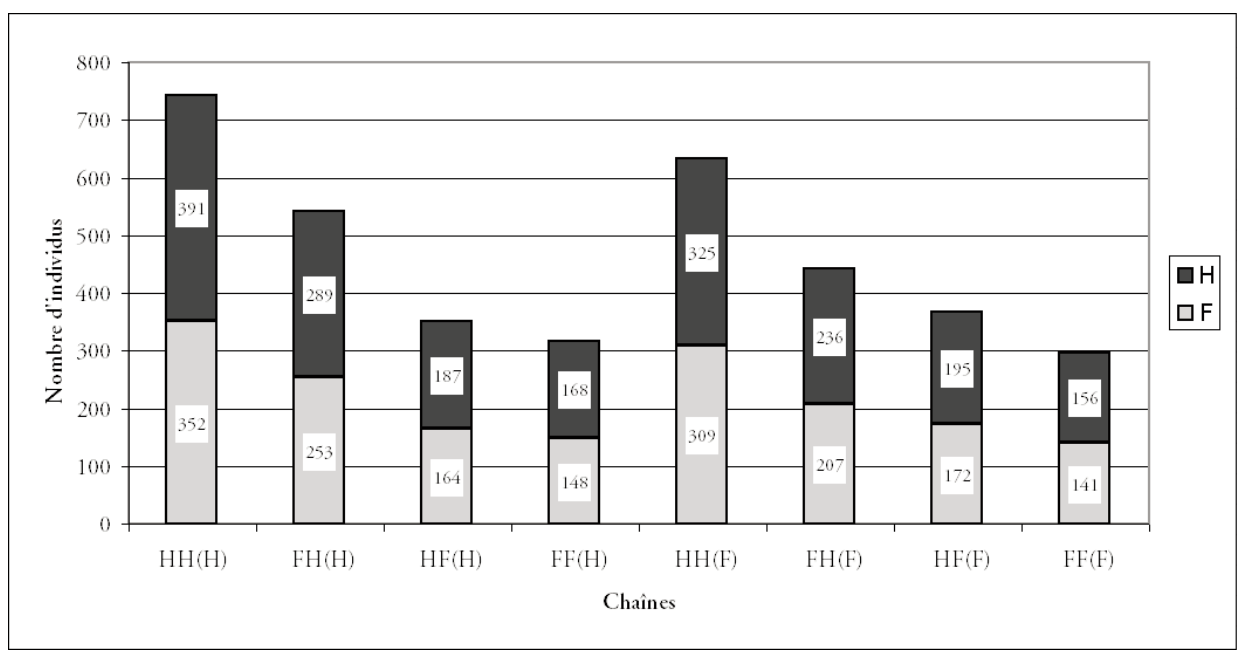


Fig. 4d Qualification des chaînes d'ascendance en $G+3$, corpus Jafun

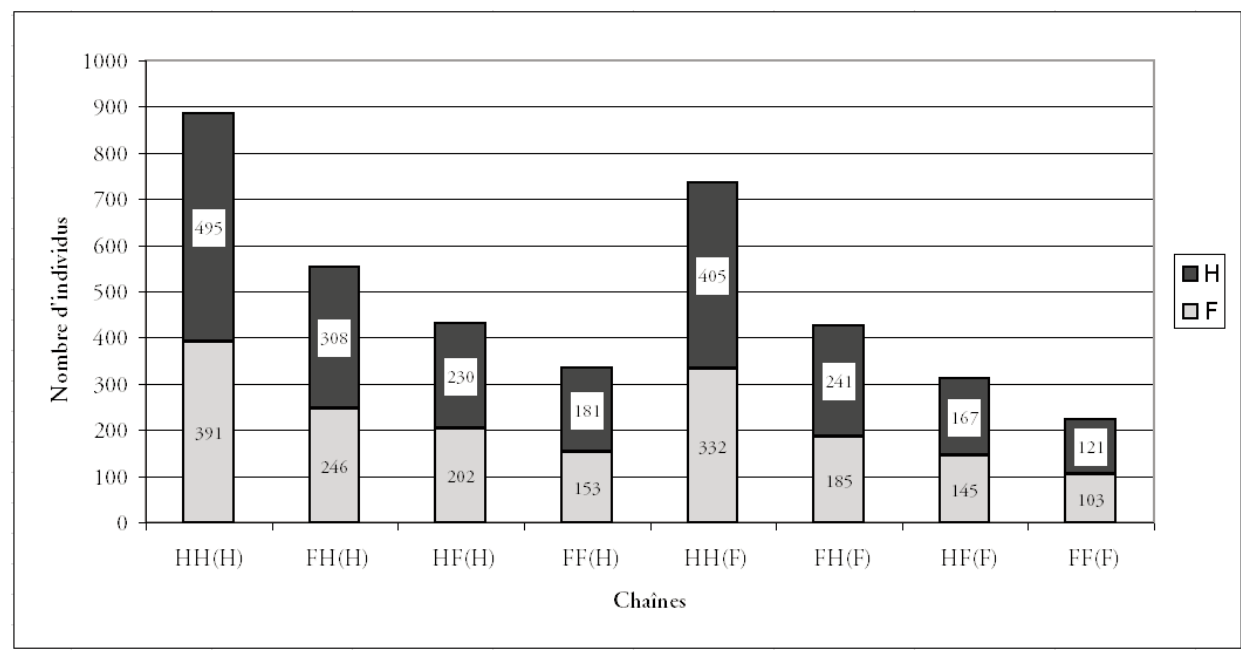

Tab.13 Individus mariés dont on ne connaît aucun des deux parents

\begin{tabular}{lcccc}
\hline & Banyo & Jafun & Mbororos & San Marino \\
\hline $\mathrm{H}$ & 130 & 98 & 109 & 2731 \\
\hline $\mathrm{F}$ & 190 & 139 & 172 & 4110 \\
\hline $\begin{array}{l}\text { Total des individus mariés } \\
\text { sans ascendance connue }\end{array}$ & 320 & 237 & 281 & 6841 \\
\hline Total des individus mariés & 794 & 800 & 953 & 18056 \\
\hline Total du corpus & 1475 & 1435 & 1678 & 24049 \\
\hline
\end{tabular}

Tab. 14 Individus mariés dont on connaît un seul des deux parents

\begin{tabular}{lcccc}
\hline & Banyo & Jafun & Mbororos & San Marino \\
\hline Total des individus mariés & 794 & 800 & 953 & 18056 \\
\hline Dont un seul parent connu & 119 & 144 & 137 & 3059 \\
\hline Père X(H) & $94,96 \%$ & $94,40 \%$ & $84,67 \%$ & $99,45 \%$ \\
\hline Mère X(F) & $5,04 \%$ & $5,60 \%$ & $15,33 \%$ & $0,55 \%$ \\
\hline
\end{tabular}

Si l'on observe maintenant, par exem- lesquelles sont très souvent connues ple pour San Marino, la connaissance uniquement comme épouses. Par généalogique des individus mariés, on ailleurs, lorsque pour les individus constate que près des deux tiers de ceux mariés, on ne connaît qu'un seul des dont on ne connaît pas l'ascendance, qui deux parents, il s'agit du père une fois représentent eux-mêmes plus d'un tiers encore dans l'écrasante majorité des cas des individus mariés, sont des femmes, (tableaux 13 et 14). 
Nous avions constaté, au fur et à mesure que nous progressions dans le dépouillement des sources, que nombre de femmes mariées pour lesquelles nous n'avions aucune connaissance généalogique figuraient en réalité en doublon dans le réseau, en tant que "filles de ", non mariées (figure 5). Dès lors que de nouveaux documents permettaient de faire le lien entre ces deux individus - qui formaient en réalité une seule et unique personne -, la connaissance généalogique de ses descendants s'en trouvait bien entendu accrue, comme, évidemment, les liens de parenté entre les différents groupes familiaux, les renchaînements d'alliances, le taux de mariages consanguins éloignés, en même temps que le nombre de femmes présentes dans le corpus diminuait, puisqu'une des deux était éliminée de la base de données. Ceci conduit à la question du lien que l'on pourrait intuitivement poser, en premier lieu, entre la plus faible proportion de la population féminine présente dans un corpus et le biais agnatique. Si des femmes figurent en doublon dans le réseau et que, au fur et à mesure de l'avancement de la collecte des données et de l'amélioration consécutive du corpus généalogique, les liens viennent, lorsqu'ils ont lieu d'être, à être reconstitués et reconnectés, nous sommes face à une double conséquence: la baisse du nombre de femmes dans le réseau, suite à l'élimination des doublons, et la chute concomitante du biais agnatique.

Fig. 5 Des doublons féminins

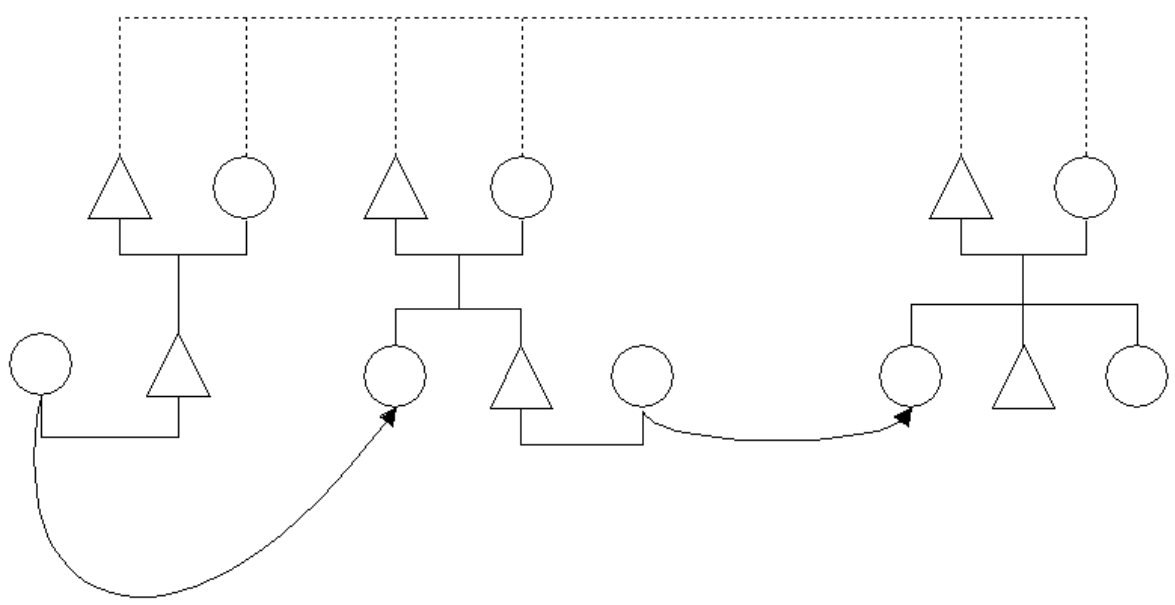

Notons qu'un tel phénomène s'observe également, pour les périodes les plus anciennes ( $\mathrm{XV}^{\mathrm{e}}$ et $\mathrm{XVI}^{\mathrm{e}}$ siècle), pour les hommes et les patrilignées, puisqu'un certain nombre d'ancêtres apicaux masculins ne sont connus que par leurs prénoms, dans la mesure où la stabilisation et l'attribution systématique des patronymes est très tardive (XVII siècle pour un grand nombre de familles), et que le phénomène de segmentation qui est par ailleurs intimement lié à l'instabilité onomastique - perdure jusqu'au milieu du XVIII siècle.

De fait, la méconnaissance généalogique implique non seulement les "vides " que comporte un réseau, mais également des relations généalogiques occupées plusieurs fois et non connectées alors qu'elles devraient l'être. Il y a ainsi un 
ensemble d'individus que l'on ne connait pas, ou bien que l'on connait, mais qui ne figurent pas à la place qui est la leur dans le réseau, ou plutôt aux différentes places qu'ils ont occupées, et qui n'assument pas les mêmes fonctions (alliance/filiation); tout cela a, bien entendu, des répercussions sur l'ensemble des relations qui composent le réseau, dans la mesure où la connaissance ou la reconnexion d'un seul individu pourrait engendrer à elle seule une quantité considérable de relations, verticales ou horizontales (pensons seulement aux renchaînements d'alliances ou aux mariages consanguins éloignés), ou placer au centre du réseau des groupes ou des relations qui figuraient pourtant, jusqu’à leur reconnexion, à sa périphérie.

\section{Deux mesures du poids agnatique* et utérin}

Le logiciel Puck inclut deux fonctions offrant un aperçu instantané du poids des relations agnatiques et utérines dans un corpus généalogique, et permettant de visualiser le cas échéant l'existence d'une inflexion.

\section{Poids agnatique et utérin}

Le premier graphique (figure 6) représente la proportion d'individus dont on connaît un ancêtre agnatique ou utérin de degré donné (abscisse) pour l'ensemble des individus du réseau San Marino pour lesquels on connaît un ancêtre soit agnatique, soit utérin, de même degré; une dernière courbe nous renseigne sur la proportion d'individus pour lesquels l'ensemble des ascendants unilinéaires est connu ${ }^{12}$. Le graphique reporté cidessous montre que pour les individus dont on connaît au moins un des deux parents, on connaît la mère dans un peu plus de $80 \%$ des cas, et le père dans près de la totalité des cas; l'écart croît sensiblement à mesure que l'on remonte les générations. Nombre de corpus présentent ce profil.

Fig. 6 Poids agnatiquelutérin, corpus San Marino

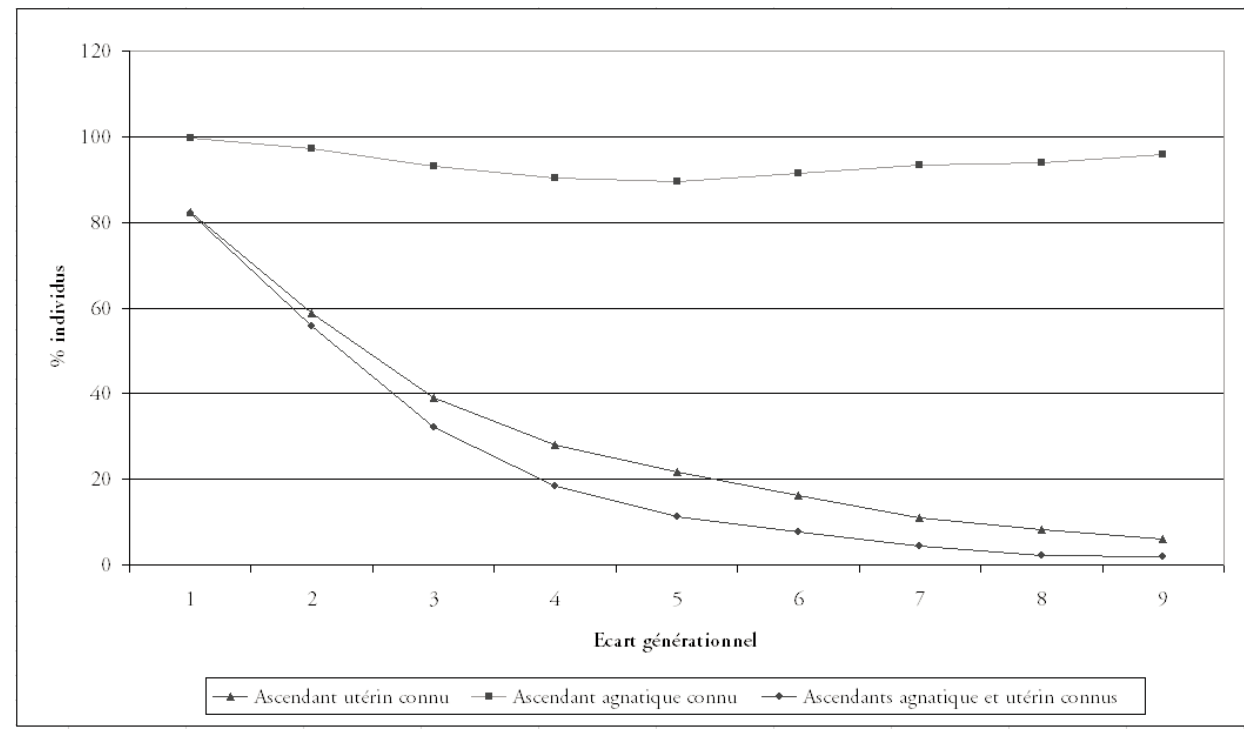


Fig. 7 Poids net agnatiquelutérin, corpus San Marino

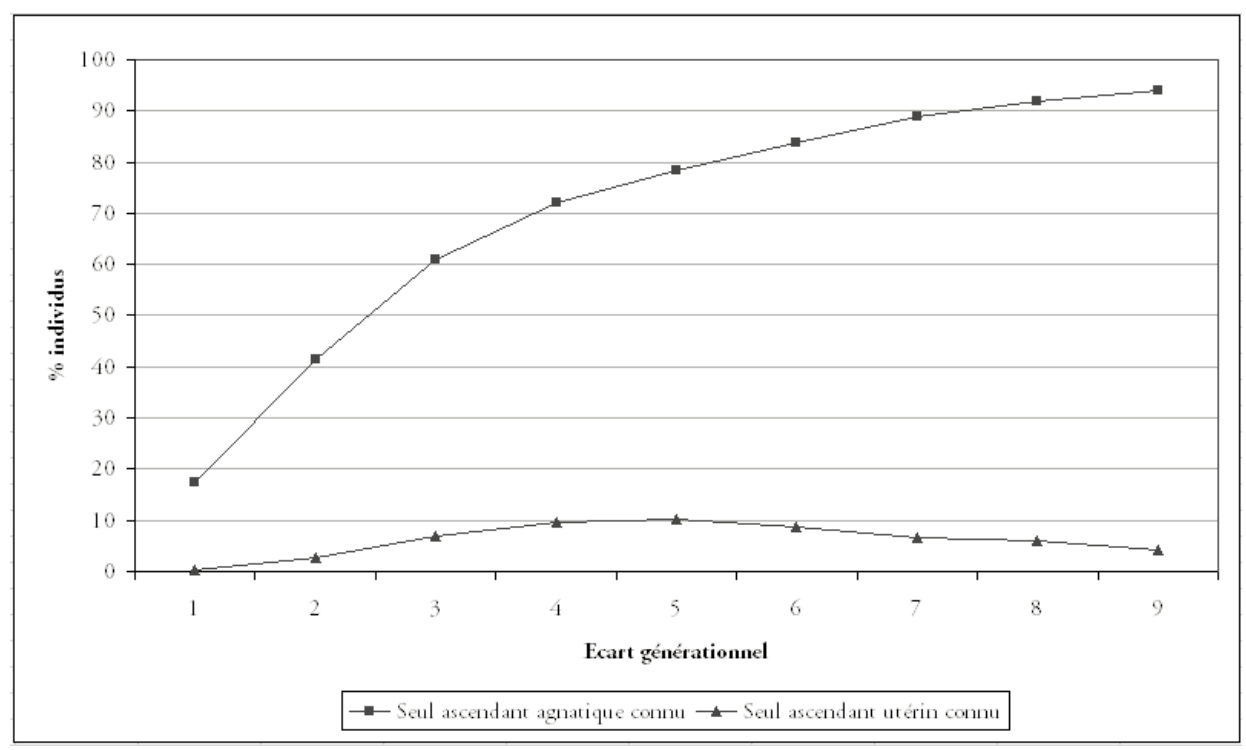

\section{Poids net agnatique et utérin}

Suivant le même principe, le second graphique (figure 7) renseigne quant à lui sur la proportion d'individus dont on connaît l'ancêtre agnatique ou utérin d'un degré donné sans connaître cette fois l'ancêtre utérin ou agnatique correspondant, pour l'ensemble des individus dont au moins un ancêtre de même degré, agnatique ou utérin, est connu ${ }^{13}$.

Ce deuxième graphique montre, par exemple, que sur l'ensemble des individus pour lesquels on connaît soit le père, soit la mère, ou les deux, il n'y en a quasiment aucun $(0,24 \%)$ dont on connaît la mère sans connaître le père. Cela permet de percevoir l'interdépendance et l'interconnexion de la mémoire généalogique; plus les courbes sont rapprochées, plus l'interdépendance est importante, plus elles s'éloi- gnent et montent, plus elles s'autonomisent, c'est-à-dire que l'on connaît soit les lignes agnatiques, soit utérines. Plus elles sont basses, et plus il y a interconnexion.

Rappelons à nouveau que ces chiffres "bruts", obtenus à partir des fonctions de Puck, reflètent seulement l'information qui nous est accessible au travers de l'analyse informatique sociocentrée d'un corpus, et non pas la manière dont les acteurs individuels eux-mêmes se remémorent, ou non, leurs parents agnatiques et utérins. Nous n'aborderons cette appréhension égocentrée qui est celle des acteurs réels euxmêmes - et la question de la connaissance généalogique réelle dont ils peuvent disposer, qu'un peu plus loin, lors de la discussion des réductions généalogiques. 
Fig. 8 Poids agnatique/utérin dans le corpus-type historique San Marino Individus nés au XVe siècle

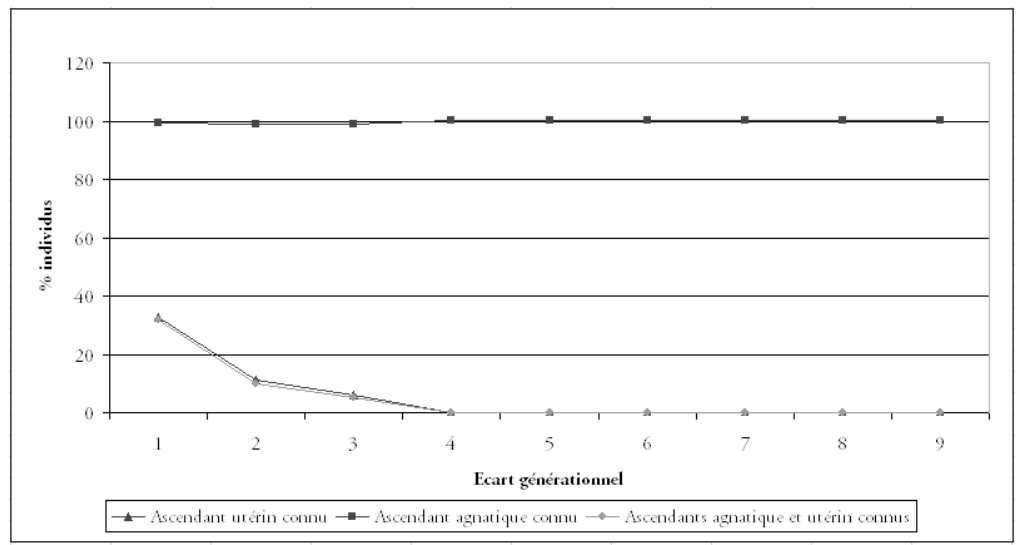

Individus nés au XVI siècle

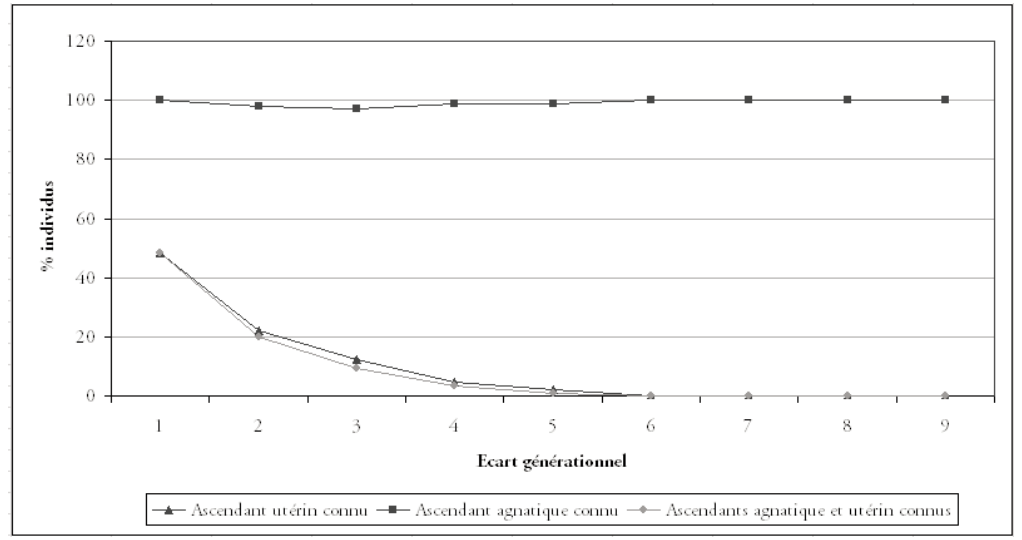

Individus nés au XVII siècle

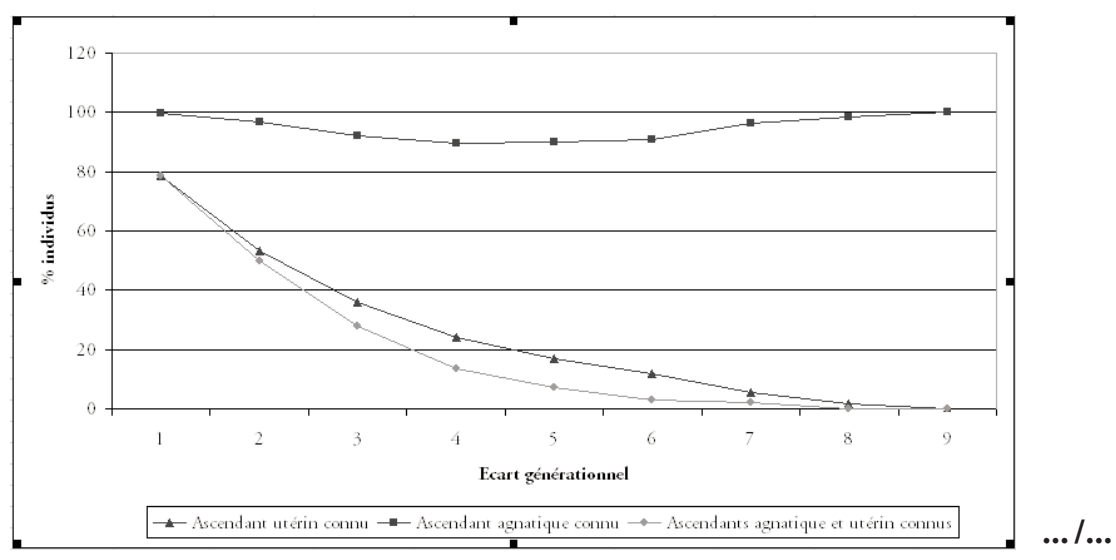


Fig. 8 Poids agnatiquelutérin dans le corpus-type historique San Marino (suite)

Individus nés au XVIII siècle

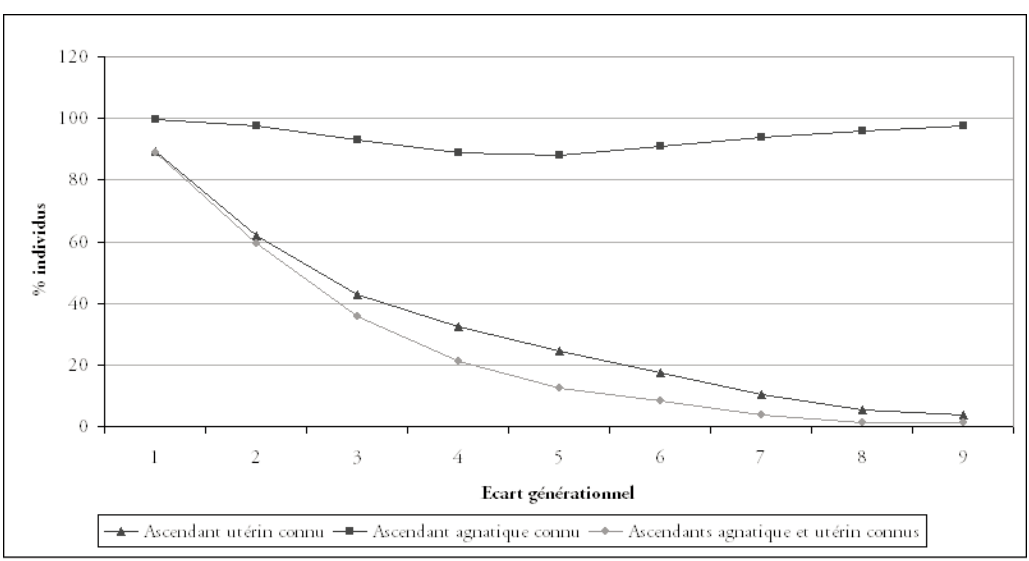

Individus nés au XIXe siècle

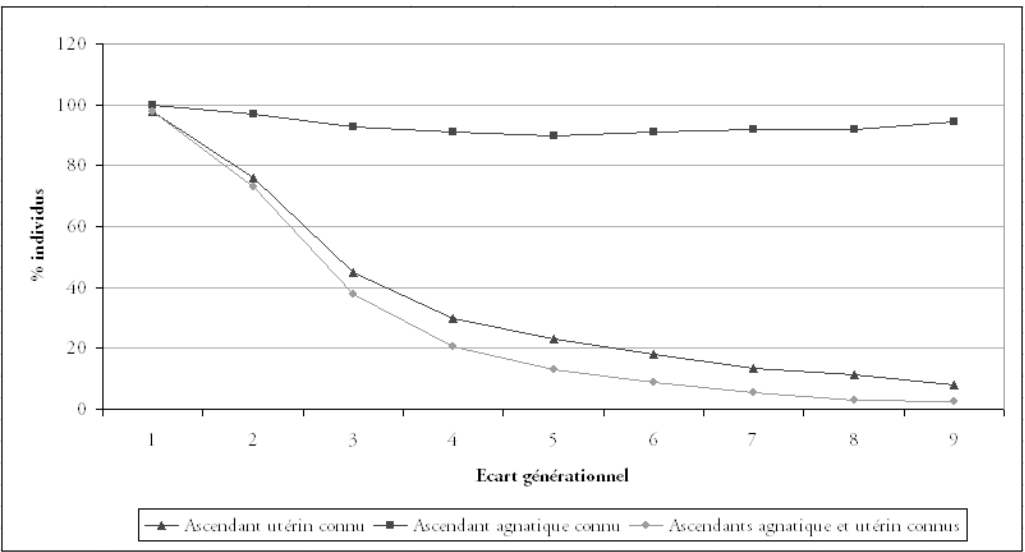


L'OUBLI DES ORIGINES. AMNÉSIE ET INFORMATION GÉNÉALOGIQUES

Tab. 15 Connaissance généalogique G+1-4, corpus San Marino, selon le siècle de naissance

\begin{tabular}{|c|c|c|c|c|c|c|}
\hline $\begin{array}{l}\text { Profondeur } \\
\text { généalogique }\end{array}$ & $\begin{array}{c}\text { Nombre } \\
\text { d'ascendants connus }\end{array}$ & $X V^{e}-X V I^{e}$ & $\mathrm{XVII}^{\mathrm{e}}$ & XVIII $^{\mathrm{e}}$ & $\mathrm{XIX}^{\mathrm{e}}$ & $\begin{array}{c}\text { Ensemble } \\
\left(\mathrm{XIII}^{\mathrm{e}}-\mathrm{XIX}^{\mathrm{e}} \text { s.) }\right.\end{array}$ \\
\hline \multirow[t]{4}{*}{$\mathrm{G}+1$} & 1 à 2 & 71,39 & 83,23 & 81,07 & 91,74 & 82,19 \\
\hline & 0 sur 2 & 28,61 & 16,77 & 18,93 & 8,26 & 17,81 \\
\hline & $1 \operatorname{sur} 2$ & 38,03 & 17,97 & 8,97 & 2,01 & 14,6 \\
\hline & $2 \operatorname{sur} 2$ & 33,36 & 65,25 & 72,1 & 89,74 & 67,59 \\
\hline \multirow[t]{6}{*}{$\mathrm{G}+2$} & 1 à 4 & 50,66 & 70,93 & 69,89 & 83,63 & 69,76 \\
\hline & 0 sur 4 & 49,34 & 29,07 & 30,11 & 16,37 & 30,24 \\
\hline & $1 \operatorname{sur} 4$ & 22,1 & 11,4 & 3,54 & 2,04 & 8,31 \\
\hline & $2 \operatorname{sur} 4$ & 14,56 & 15,44 & 18,09 & 15,24 & 16,07 \\
\hline & $3 \operatorname{sur} 4$ & 9,49 & 18,92 & 12,23 & 8,17 & 12,38 \\
\hline & $4 \operatorname{sur} 4$ & 4,52 & 25,17 & 36,04 & 58,18 & 33 \\
\hline \multirow[t]{10}{*}{$\mathrm{G}+3$} & 1 à 8 & 33,49 & 61,4 & 64,94 & 78,1 & 61,53 \\
\hline & 0 sur 8 & 66,17 & 38,6 & 35,06 & 21,9 & 38,47 \\
\hline & 1 sur 8 & 12,71 & 8,83 & 2,61 & 1,81 & 5,71 \\
\hline & $2 \operatorname{sur} 8$ & 8,69 & 8,58 & 7,4 & 11,91 & 8,95 \\
\hline & 3 sur 8 & 6,07 & 12,87 & 6,33 & 4,8 & 7,48 \\
\hline & $4 \operatorname{sur} 8$ & 2,95 & 10,07 & 16,33 & 19,91 & 13,2 \\
\hline & 5 sur 8 & 1,3 & 6,52 & 6,11 & 5,34 & 5,2 \\
\hline & $6 \operatorname{sur} 8$ & 1,57 & 5,74 & 8,1 & 13,57 & 7,65 \\
\hline & 7 sur 8 & 0,52 & 4,34 & 7,64 & 6,93 & 5,41 \\
\hline & 8 sur 8 & 0,02 & 4,44 & 10,41 & 13,83 & 7,93 \\
\hline \multirow[t]{18}{*}{$\mathrm{G}+4$} & 1 à 16 & 23,77 & 52,33 & 62,03 & 75,23 & 55,89 \\
\hline & 0 sur 16 & 76,23 & 47,67 & 37,97 & 24,77 & 44,11 \\
\hline & 1 sur 16 & 9,19 & 6,76 & 1,55 & 1,06 & 4,05 \\
\hline & 2 sur 16 & 5,74 & 7,89 & 3,58 & 8,15 & 6,08 \\
\hline & 3 sur 16 & 3,3 & 8,72 & 4,64 & 3,03 & 4,99 \\
\hline & $4 \operatorname{sur} 16$ & 1,7 & 5,52 & 7,52 & 12 & 7,01 \\
\hline & 5 sur 16 & 1,5 & 5 & 3,7 & 3,53 & 3,58 \\
\hline & 6 sur 16 & 1 & 5,07 & 5,16 & 8,24 & 5,12 \\
\hline & 7 sur 16 & 0,62 & 3,58 & 6,86 & 5,25 & 4,58 \\
\hline & 8 sur 16 & 0,35 & 2,91 & 8,1 & 10,94 & 6,1 \\
\hline & 9 sur 16 & 0,2 & 2,11 & 2,83 & 3,24 & 2,29 \\
\hline & 10 sur 16 & 0,05 & 1,59 & 3,69 & 6,14 & 3,1 \\
\hline & 11 sur 16 & 0,12 & 1 & 3,83 & 4,03 & 2,53 \\
\hline & 12 sur 16 & 0 & 0,96 & 3,66 & 4,8 & 2,63 \\
\hline & 13 sur 16 & 0 & 0,46 & 2,81 & 0,97 & 1,31 \\
\hline & 14 sur 16 & 0 & 0,54 & 1,54 & 2,38 & 1,22 \\
\hline & 15 sur 16 & 0 & 0,19 & 1,66 & 1,04 & 0,87 \\
\hline & 16 sur 16 & 0 & 0,05 & 0,92 & 0,45 & 0,44 \\
\hline
\end{tabular}




\section{Partitions chronologiques et générationnelles}

Point fort des historiens, la profondeur généalogique et la diachronie posent néanmoins plusieurs difficultés et interrogations, telles que la diminution ou l'absence des sources et des informations qu'elles contiennent, l'accumulation d'isolats, le renforcement du biais agnatique, ou encore les limites et la pertinence de la profondeur généalogique.

Le calcul du poids agnatique selon des périodes déterminées permet de rendre compte des déséquilibres présents à l'intérieur d'un réseau matrimonial historique étendu, pris dans sa globalité, et réfléchit parfaitement les modalités de sa composition au travers des différentes sources. Ici, comparés aux $\mathrm{XV}^{\mathrm{e}}$ et XVII ${ }^{\mathrm{e}}$ siècles nourris essentiellement par une documentation "qualitative», telles les archives notariales, par le biais desquelles les généalogies sont, de manière générale, difficiles à reconstituer (mobilité onomastique, présence majeure de certaines catégories sociales, etc.), où les chaînes unisexuées et les ancêtres apicaux agnatiques sont légions, les siècles qui suivent apparaissent nettement moins marqués par le poids agnatique, du moins en ce qui concerne les premières générations. En effet, la généralisation des états des âmes au XVII et surtout au XVIII ${ }^{e}$ siècle s'observe immédiatement en $\mathrm{G}+1$ : la proportion des mères connues augmente sensiblement, jusqu'à rejoindre le niveau du père au XIX⿸e siècle, période où les recensements de population, plus complets, améliorent également la connaissance généalogique à la génération suivante $(G+2)$. Cette dernière chute néanmoins presque au niveau des deux siècles précédents à partir de la troisième génération, mais parvient à se maintenir au-delà de $\mathrm{G}+4$ (voir figure 8 et tableau 15).

\section{RÉDUCTIONS GÉNÉALOGIQUES}

La notion de biais agnatique telle qu'elle est posée au départ dans le logiciel Puck via les fonctions de calcul qui y sont proposées, repose, comme nous l'avons signalé plus haut, sur un certain nombre de présupposés analytiques forts qui, nous semble-t-il, rendent son usage problématique. Nous reviendrons bientôt sur ce point.

$S$ 'il existe effectivement et, dira-t-on, fatalement une inégale représentation et distribution des relations de parenté dans un corpus, il apparaît peu évident d'en conclure que cette méconnaissance induit nécessairement un bouleversement profond des pratiques matrimoniales et donc du système de parenté. Mais il n'en demeure pas moins que la question de la qualité des corpus est essentielle et nécessite une importante réflexion, tant en amont, sur la constitution du corpus, la collecte et l'assemblage des données, qu'en aval, sur l'interprétation de ces vides, et sur la manière dont il nous faut nécessairement composer avec.

Nous pensons qu'il est possible d'envisager différemment ce phénomène de méconnaissance des origines ou, comme nous l'appellerons, «d'amnésie généalogique». Elle repose sur l'utilisation d'une méthode, que nous allons développer à présent, de «réduction généalogique». Cette dernière, fondée elle aussi sur un raisonnement simple, a pour intérêt immédiat de reposer sur une base bien plus empirique que celle organisant 
l'idée de biais agnatique. En effet, elle ne se propose ni de "compléter", ni de "corriger» un corpus réel à partir d'un calcul de simulation fondé sur le choix $a$ priori d'une hypothèse parmi d'autres, mais plutôt d'extraire et de tirer partie des zones les plus sûres de ce corpus pour estimer les caractéristiques globales du système matrimonial.

L'idée d' "impact agnatique " repose en effet sur une idée très tranchée : celle selon laquelle la sous-représentation de certaines relations, utérines par exemple, correspond à une sous-estimation équivalente des mariages ayant pu utiliser ces liens. Or cette hypothèse s'oppose radicalement à une autre, aussi plausible, selon laquelle l'oubli de ces liens est justement lié au fait qu'ils n'ont pas été activés dans le cadre d'une alliance.

La méthode des réductions généalogiques ne reposera, quant à elle, sur aucune de ces hypothèses a priori, même si, comme nous le verrons, elle pourra permettre in fine de trancher entre celles-ci et, dans ce cas, il apparaîtra à la lecture des exemples que nous avons utilisés ici que la seconde semble la plus fondée des deux. Elle ne postulera pas non plus l'existence de "mariages manquants» qu'il conviendrait de "rajouter " au corpus, mais se contentera d'ausculter les zones de celui-ci pour lesquelles l'information disponible est la plus complète et s'attachera à qualifier de préférence l'état matrimonial du système, à partir de celles-ci.

Pour illustrer ce procédé, retournons à présent à l'exemple peul et aux doutes que nous laissions planer sur le fait que l'expression d'un taux de consanguinité établie à partir du rapport " mariages consanguins/mariages non consanguins" puisse être été véritablement significative ou simplement utile à notre appréhension d'un système matrimonial global.

En prenant comme nous l'avons fait plus haut la totalité des mariages où les deux conjoints étaient peuls (2567 mariages dont 1231 mariages de femmes peules et 1336 d'hommes peuls pour un corpus de 3390 mariages au total), nous obtenions un pourcentage de $35,29 \%$ de mariages consanguins (906 des 2567 mariages entre hommes et femmes peuls). Or, dans ces unions il existait un nombre conséquent de cas pour lesquels nous ne connaissions que l'appartenance ethnique ou lignagère des conjoints sans disposer d'aucune information généalogique sur leurs ascendants ou encore d'une information si lacunaire qu'elle nous interdisait d'emblée de vérifier si ces mariages furent consanguins ou non.

C'était le cas, par exemple, lorsque nous ne disposions d'informations que sur les parents en $\mathrm{G}+1$ de l'un ou l'autre des conjoints ou même des deux, ou encore lorsque nous n'avions de renseignements pour les ascendants en $G+2$ que pour l'un des deux conjoints, etc. L'information disponible sera ainsi toujours insuffisante pour l'ensemble des mariages apicaux ou encore pour tous ceux des collatéraux situés en « bordure » du corpus, autrement dit pour toutes les unions d'individus situés sur les franges de la mémoire généalogique des informateurs ou des sources. Mais elle sera aussi trop réduite, par exemple, pour tous leurs descendants immédiats: quand bien même les enfants des ancêtres apicaux auraient tous fait des mariages consanguins, ces derniers nous resteront à jamais inconnaissables (sauf s'il s'agit de mariages frères/sœurs). De même, pour la génération des petits-enfants de ces ancêtres apicaux, nous ne pourrons au mieux que retracer les mariages entre cousins (ou entre parents plus proches) 
qu'ils auraient contractés, et toutes les unions consanguines entre apparentés plus éloignés resteront inaccessibles.

Ainsi, si nous analysons un "corpus brut» quelconque en partant de la génération des conjoints, nous savons que l'ensemble des couples pour lesquels nous ne disposons d'aucune information relative à leurs propres parents se verront ranger d'emblée dans le taxon «mariage non consanguin", non qu'ils le soient nécessairement, mais du simple fait de l'impossibilité qu'il y a à connaître l'éventuel lien de consanguinité qui les unit. Quant à ceux pour lesquels nous manquons d'informations pour les grands-parents de l'un ou des deux conjoints, nous ne repèrerons, dans le meilleur des cas, que les mariages entre oncles/nièces, tantes/neveux, frères/sœurs ou parents/enfants, alors que toutes les relations consanguines de degrés plus éloignés (par exemple celles entre cousins) nous échapperont. Or, il convient de rappeler que dans la majorité des corpus réels, ce sera justement au sein de cette dernière catégorie - celle des cousins germains et des parents plus éloignés - que se concentreront la majorité des unions consanguines. L'impossibilité où nous sommes de qualifier de façon appropriée ces mariages comme consanguins s'ils le sont, en l'absence d'une information minimale en $\mathrm{G}+2$, devient dès lors extrêmement préjudiciable. Et ce raisonnement peut bien entendu être étendu à l'identique à tous les niveaux généalogiques où l'absence d'informations sur certains des ascendants conduit automatiquement à une sous-estimation du nombre des unions consanguines.

Comme on le voit, ces biais liés à l'amnésie généalogique sont inhérents à l'ensemble des corpus généalogiques, qu'ils soient ethnographiques ou histo- riques, et indépendants de la plus ou moins bonne qualité de ceux-ci : un corpus de la meilleure facture possible ne pourra gommer aucun d'entre eux, là où un corpus de mauvaise qualité augmentera encore l'ampleur des pertes.

La notion de "réduction généalogique» que nous entendons développer vise alors à débarrasser le corpus d'une partie au moins de ces unions "orphelines " qui l'alourdissent et le gauchissent, et pour lesquelles l'absence d'informations minimales forclôt toute possibilité de les qualifier comme mariages consanguins versus non consanguins. Cette méthode ne permet certes pas l'obtention d'un " corpus utile " parfait - dans lequel chaque mariage pourrait être qualifié de façon univoque dans l'une ou l'autre des deux catégories précédentes - dans la simple mesure où il est impossible d'atteindre celui-ci et ce quelle que soit la technique utilisée (la simple existence dans tous les corpus d'ancêtres et de mariages apicaux suffit à démontrer le caractère illusoire d'un tel objectif). Mais elle vise en revanche à produire un corpus qui tende vers cette limite, en ce qu'il a éliminé les unions "parasites" les plus handicapantes et saillantes, celles pour lesquelles une information par trop défaillante renforçait outre mesure l'apparente entropie du système.

L'analyse ne portera pas pour autant, avec cette technique, sur un simple échantillon, mais bien toujours sur le corpus global, dans la mesure où certaines de ces " unions orphelines " que nous venons d'évoquer nous seront utiles pour en repérer d'autres (il faut conserver les mariages ancestraux pour retracer ceux de leurs descendants par exemple). En revanche, les réductions généalogiques permettront de n'établir les différents indices qualifiant un corpus 
(taux de consanguinité, d'endogamie, etc.) qu’à partir des unions pour lesquelles nous disposons d'une information généalogique minimale, suffisante pour repérer les éventuels liens de parenté qui les traversent.

\section{Méthodologie}

Le concept de réduction généalogique repose en pratique sur l'application de contraintes appliquées crescendo.

La contrainte minimale se contente ainsi d'éliminer tous les couples pour lesquels nous ne disposons d'aucune information généalogique pour une génération $G$ donnée $(G+1, G+2, G+3$, etc.). Autrement dit d'exiger qu'au moins un ascendant de l'un et l'autre des conjoints nous soit connu pour cette génération.

1) Nous parlerons dans ce cas de réduction de $1^{\text {er }}$ degré lorsque la contrainte impose qu'au moins un ascendant de la génération $G$ (ou des générations $\mathrm{G}, \mathrm{G}+1, \mathrm{G}+2$, etc.) soit connu.

Cette contrainte minimale, essentielle dans la mesure où elle supprime déjà du corpus l'ensemble des couples pour lesquels il est définitivement impossible de vérifier l'existence d'une relation consanguine et où elle réduit donc drastiquement la proportion des "fausses " unions non consanguines, ne nous donne toutefois qu'une faible probabilité de repérer un lien consanguin parmi celles restantes; ce du moins dans l'hypothèse où il n'existe pas de relation entre mémoire généalogique et pratique matrimoniale, restriction importante sur laquelle nous aurons l'occasion de revenir.

En effet, une réduction de degré 1 appliquée à la génération des grandsparents $(\mathrm{G}+2)$ comprend des unions (celles pour lesquelles un seul des ascen- dants en $\mathrm{G}+2$ des deux conjoints sera connu) pour lesquelles nous n'aurons toujours qu'une chance sur huit de repérer un mariage entre enfants de demigermain $s^{14}$ et une sur quatre entre cousins germains "complets" (dont les parents sont de même père et de même mère).

Pour diminuer encore la probabilité de ne pas repérer l'existence d'une relation consanguine là où elle existe du simple fait d'une information généalogique encore trop limitée, il semblerait évident d'imposer une contrainte plus forte. Par exemple, nous pouvons ne retenir dans le corpus utile que les couples pour lesquels nous connaissons au moins deux des ascendants à la génération $\mathrm{G}$.

2) Nous parlerons alors d'une réduction de second degré lorsque la contrainte porte sur connaissance d'au moins deux ascendants à la génération $\mathrm{G}$.

Nous pouvons ainsi continuer à augmenter les contraintes, en recourant à des réductions généalogiques de troisième degré (contrainte qui ne peut bien entendu être appliquée qu’à partir de la génération des grands-parents qui comporte quatre ascendants), de quatrième degré, de cinquième degré (contrainte applicable seulement à partir de $\mathrm{G}+3)$, etc.

Mais l'intérêt de l'imposition de ces contraintes a ses propres limites. Limites techniques et heuristiques, qui font que cette méthode, si elle permet un utile lissage des données, reste - et restera toujours - une approximation qui n'offre pas de solution définitive aux questions posées par la mémoire et par l'oubli généalogiques. Comme nous aurons l'occasion d'en discuter dans la conclusion de ce texte, où nous proposerons une première (auto)critique de ce concept de « réduction généalogique» (ainsi que de celui de «biais 
agnatique»), si l'application de contraintes raisonnables augmente fortement la fiabilité des données disponibles, l'application de contraintes trop fortes conduit en revanche à une déperdition d'informations susceptible d'engendrer à terme un biais analytique aussi important que celui que comporte les "corpus bruts».

Avant de soupeser plus précisément les avantages et limites de cette méthode, d'indiquer dans quelle mesure ils sont ou non dépendants de la nature du corpus et du type de source utilisé, et de les mettre en balance avec ceux inhérents à d'autres raisonnements, avec la notion de «biais agnatique» en particulier, commençons par examiner quelques exemples de son utilisation avec des corpus réels.

\section{Réductions peules}

Appliquons ainsi des contraintes de degré 1 et 2 aux corpus ethnographiques peuls.

Dans le cas peul, il conviendra de conserver à l'esprit que les taux de consanguinité sur lesquels nous allons nous fonder au départ (ceux obtenus en l'absence d'application de toute contrainte) sont d'emblée plus faibles que ceux mentionnés au tableau 6 . En effet, ces derniers, calculés à partir du logiciel Genos, l'étaient à partir des seuls mariages où les deux conjoints étaient Peuls. En revanche, pour des raisons techniques sur lesquelles nous ne nous étendrons pas ici, il nous a fallu utiliser pour le logiciel Puck les corpus matrimoniaux complets, lesquels ne distinguent pas entre unions intra et interethniques et comportent donc un certain nombre de mariages soit avec des HaaBe (des «non Peuls»), soit avec des conjoints d'origine inconnue (558 unions, dont 390 mariages masculins et
168 mariages féminins; $c f$. le tableau 3), unions pour lesquelles l'on ne peut, par définition, trouver de liens consanguins entre époux.

Cette déflation initiale (et artificielle) des taux de consanguinité n'aura toutefois pas d'incidence réelle sur notre propos puisque, comme nous allons le voir, ces derniers vont, avec l'application des contraintes de réductions généalogiques, bien vite dépasser à nouveau, et de beaucoup, ceux obtenus précédemment ${ }^{15}$.

Appliquons (tableaux 16, 17, 18) la contrainte minimale de degré 1 aux trois sous-corpus peuls (Jafun, Foulbés et Mbororos) afin de vérifier l'effet produit par celle-ci à différents niveaux générationnels (nous nous sommes limités à $\mathrm{G}+8$ afin que les sous-corpus restent comparables entre eux) sur: 1) Le taux de consanguinité: le rapport «mariages consanguins/tous mariages»; 2) les taux d'endogamie: les rapports «mariage agnatique/tous mariages» et «mariages agnatiques/tous mariages consanguins".

Ces tableaux appellent plusieurs commentaires: 1) Tout d'abord, nous constatons (cf. figure 9) que les taux de consanguinité (le rapport mariages consanguins/tous mariages) augmentent considérablement pour les corpus Jafun et Mbororos et très sensiblement pour le corpus Foulbés, et ce dès l'application de la contrainte minimale de $1^{\text {er }}$ degré à la génération des grands-parents $(\mathrm{G}+2)$. Cette croissance se voit d'ailleurs confortée par chaque nouvelle application de la contrainte à une génération plus élevée, même si les taux de consanguinité des corpus Foulbés et Jafun stagnent ou régressent à partir de $\mathrm{G}+5$. Ainsi, dans le cas Jafun nous passons de $36,78 \%$ en l'absence de contrainte à $100 \%$ de mariages consanguins lorsque 
nous appliquons la contrainte à la généconsanguinité, puisque de 32,22\% de ration le plus haute $(G+8)$. Pour le corpus Mbororos, c'est en $\mathrm{G}+4$ que la contrainte produit le plus fort taux de mariages consanguins en l'absence de contrainte, nous passons à 80,51\% des mariages.

Tab. 16 Mbororos Jafun. Réduction généalogique de $1^{\text {er }}$ degré

\begin{tabular}{|c|c|c|c|c|c|c|c|}
\hline & $\begin{array}{c}\text { Nb. } \\
\text { d'individus } \\
\text { (dont h/f) }\end{array}$ & $\begin{array}{c}\mathrm{Nb} \text {. } \\
\text { de mariages }\end{array}$ & $\begin{array}{l}\mathrm{Nb} \text {. de mar. } \\
\text { consanguins }\end{array}$ & $\begin{array}{l}\text { Nb. de mar. } \\
\text { endogames } \\
\text { (agnatiques) }\end{array}$ & $\begin{array}{l}\text { \% mar. } \\
\text { cons. }\end{array}$ & $\begin{array}{l}\text { Mar. endo. en } \\
\% \text { de tous les } \\
\text { mar. }\end{array}$ & $\begin{array}{l}\text { Mar. endo. en \% de } \\
\text { tous les mar. } \\
\text { consanguins }\end{array}$ \\
\hline $\begin{array}{c}\text { Pas de } \\
\text { contrainte }\end{array}$ & $\begin{array}{c}1435 \\
(789 / 646)\end{array}$ & 503 & 185 & 118 & 36,78 & 23,46 & 63,78 \\
\hline $\begin{array}{l}\text { Au moins } \\
1 \text { en } G+2\end{array}$ & $\begin{array}{c}1051 \\
(592 / 459)\end{array}$ & 372 & 185 & 118 & 49,73 & 31,72 & 63,78 \\
\hline $\begin{array}{l}\text { Au moins } \\
1 \text { en } G+3\end{array}$ & $\begin{array}{c}984 \\
(550 / 434)\end{array}$ & 343 & 180 & 117 & 52,48 & 34,11 & 65 \\
\hline $\begin{array}{l}\text { Au moins } \\
1 \text { en } G+4\end{array}$ & $\begin{array}{c}898 \\
(495 / 403)\end{array}$ & 292 & 175 & 113 & 59,93 & 38,7 & 64,57 \\
\hline $\begin{array}{l}\text { Au moins } \\
1 \text { en } G+5\end{array}$ & $\begin{array}{c}749 \\
(413 / 336)\end{array}$ & 227 & 143 & 90 & 63 & 39,65 & 62,94 \\
\hline $\begin{array}{l}\text { Au moins } \\
1 \text { en } G+6\end{array}$ & $\begin{array}{c}601 \\
(322 / 279)\end{array}$ & 147 & 108 & 74 & 73,47 & 50,34 & 68,52 \\
\hline $\begin{array}{l}\text { Au moins } \\
1 \text { en } G+7\end{array}$ & $\begin{array}{c}388 \\
(211 / 177)\end{array}$ & 61 & 45 & 32 & 73,77 & 52,46 & 71,11 \\
\hline $\begin{array}{c}\text { Au moins } \\
1 \text { en } \mathrm{G}+8\end{array}$ & $\begin{array}{c}109 \\
(64 / 45)\end{array}$ & 6 & 6 & 6 & 100 & 100 & 100 \\
\hline
\end{tabular}

Tab. 17 Foulbés. Réduction généalogique de $1^{\text {er }}$ degré

\begin{tabular}{|c|c|c|c|c|c|c|c|}
\hline & $\begin{array}{c}\text { Nb. } \\
\text { d'individus } \\
\text { (dont h/f) }\end{array}$ & $\begin{array}{c}\mathrm{Nb} \text {. } \\
\text { de mariages }\end{array}$ & $\begin{array}{l}\mathrm{Nb} \text {. de mar. } \\
\text { consanguins }\end{array}$ & $\begin{array}{l}\text { Nb. de mar. } \\
\text { endogames } \\
\text { (agnatiques) }\end{array}$ & $\begin{array}{l}\text { \% mar. } \\
\text { cons. }\end{array}$ & $\begin{array}{l}\text { Mar. endo. en } \\
\% \text { de tous les } \\
\text { mar. }\end{array}$ & $\begin{array}{l}\text { Mar. endo. en \% de } \\
\text { tous les mar. } \\
\text { consanguins }\end{array}$ \\
\hline $\begin{array}{l}\text { Pas de } \\
\text { contrainte }\end{array}$ & $\begin{array}{c}1475 \\
(772 / 703)\end{array}$ & 496 & 70 & 28 & 14,11 & 5,65 & 40 \\
\hline $\begin{array}{l}\text { Au moins } \\
1 \text { en } G+2\end{array}$ & $\begin{array}{c}938 \\
(505 / 433)\end{array}$ & 310 & 69 & 28 & 22,26 & 9,03 & 40,58 \\
\hline $\begin{array}{l}\text { Au moins } \\
1 \text { en } G+3\end{array}$ & $\begin{array}{c}904 \\
(487 / 417)\end{array}$ & 294 & 66 & 27 & 22,45 & 9,18 & 40,91 \\
\hline $\begin{array}{l}\text { Au moins } \\
1 \text { en } G+4\end{array}$ & $\begin{array}{c}886 \\
(479 / 407)\end{array}$ & 280 & 63 & 27 & 22,5 & 9,64 & 42,86 \\
\hline $\begin{array}{l}\text { Au moins } \\
1 \text { en } G+5\end{array}$ & $\begin{array}{c}825 \\
(451 / 374)\end{array}$ & 258 & 57 & 24 & 22,09 & 9,3 & 42,11 \\
\hline $\begin{array}{l}\text { Au moins } \\
1 \text { en } G+6\end{array}$ & $\begin{array}{c}719 \\
(387 / 332)\end{array}$ & 236 & 43 & 18 & 18,22 & 7,63 & 41,86 \\
\hline $\begin{array}{l}\text { Au moins } \\
1 \text { en } G+7\end{array}$ & $\begin{array}{c}711 \\
(381 / 330)\end{array}$ & 225 & 40 & 17 & 17,78 & 7,56 & 42,5 \\
\hline $\begin{array}{l}\text { Au moins } \\
1 \text { en } G+8\end{array}$ & $\begin{array}{c}694 \\
(373 / 321)\end{array}$ & 220 & 40 & 17 & 18,18 & 7,73 & 42,5 \\
\hline
\end{tabular}


Tab. 18 Autres Mbororos $^{16}$. Réduction généalogique de 1er degré

\begin{tabular}{|c|c|c|c|c|c|c|c|}
\hline & $\begin{array}{c}\text { Nb. } \\
\text { d'individus } \\
\text { (dont h/f) }\end{array}$ & $\begin{array}{l}\mathrm{Nb} . \mathrm{de} \\
\text { mariages }\end{array}$ & $\begin{array}{l}\text { Nb. de mar. } \\
\text { consanguins }\end{array}$ & $\begin{array}{l}\text { Nb. de mar. } \\
\text { endogames } \\
\text { (agnatiques) }\end{array}$ & $\begin{array}{l}\text { \% mar. } \\
\text { cons. }\end{array}$ & $\begin{array}{l}\text { Mar. endo. en } \\
\% \text { de tous les } \\
\text { mar. }\end{array}$ & $\begin{array}{l}\text { Mar. endo. en \% de } \\
\text { tous les mar. } \\
\text { consanguins }\end{array}$ \\
\hline $\begin{array}{l}\text { Pas de } \\
\text { contrainte }\end{array}$ & $\begin{array}{c}1678 \\
(873 / 783) \\
\end{array}$ & 537 & 173 & 114 & 32,22 & 21,23 & 65,9 \\
\hline $\begin{array}{l}\text { Au moins } \\
1 \text { en } G+2\end{array}$ & $\begin{array}{c}1139 \\
(607 / 523)\end{array}$ & 331 & 173 & 114 & 52,27 & 34,44 & 65,9 \\
\hline $\begin{array}{l}\text { Au moins } \\
1 \text { en } G+3\end{array}$ & $\begin{array}{c}912 \\
(485 / 419) \\
\end{array}$ & 226 & 138 & 99 & 61,06 & 43,81 & 71,74 \\
\hline $\begin{array}{l}\text { Au moins } \\
1 \text { en } G+4\end{array}$ & $\begin{array}{c}569 \\
(294 / 267)\end{array}$ & 118 & 95 & 72 & 80,51 & 61,02 & 75,79 \\
\hline $\begin{array}{l}\text { Au moins } \\
1 \text { en } G+5\end{array}$ & $\begin{array}{c}319 \\
(178 / 141)\end{array}$ & 66 & 51 & 40 & 77,27 & 60,61 & 78,43 \\
\hline $\begin{array}{l}\text { Au moins } \\
1 \text { en } G+6\end{array}$ & $\begin{array}{c}167 \\
(96 / 71)\end{array}$ & 9 & 5 & 5 & 55,56 & 55,56 & 55,55 \\
\hline
\end{tabular}

Fig. 9 Évolution du taux de consanguinité pour les corpus peuls, en fonction de la génération ascendante où s'opère une réduction de degré 1

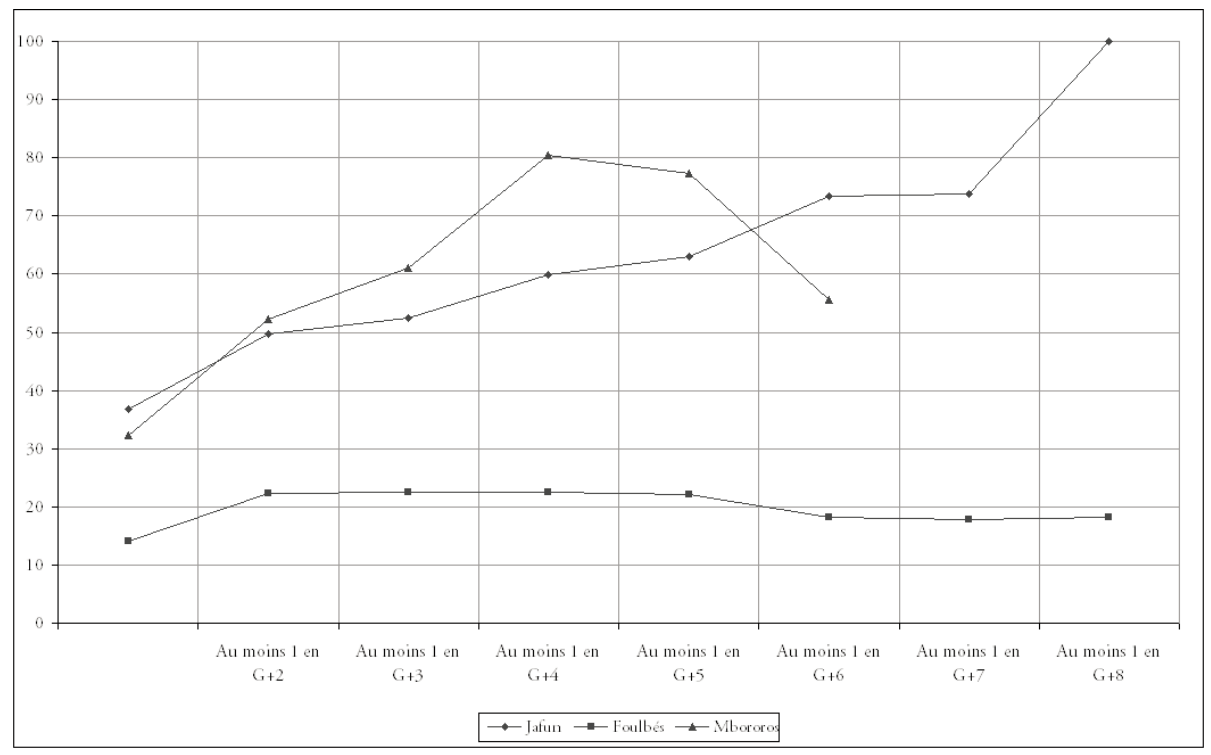

2) Nous voyons, en second lieu, qu'il en va de même des indices d'endogamie (de la proportion des mariages agnatiques). La croissance du rapport "mariages endogames/tous mariages" (figure 10) en particulier est tout à fait remarquable: il passe de $23,46 \%$ à $100 \%$ en G+8 chez les Jafun, de 5,65\% à 9,64\% en G+4 chez les Foulbés et de $21,23 \%$ à $61,02 \%$ en $\mathrm{G}+4 \mathrm{chez}$ les autres Mbororos.

Vérifions à présent si ces enseignements restent valables pour une réduction généalogique de degré 2 (tableaux 19, 20, 21). 
Fig. 10 Évolution du rapport " mariages endogames/tous mariages " pour les corpus peuls, en fonction de la génération ascendante où s'opère une réduction de degré 1

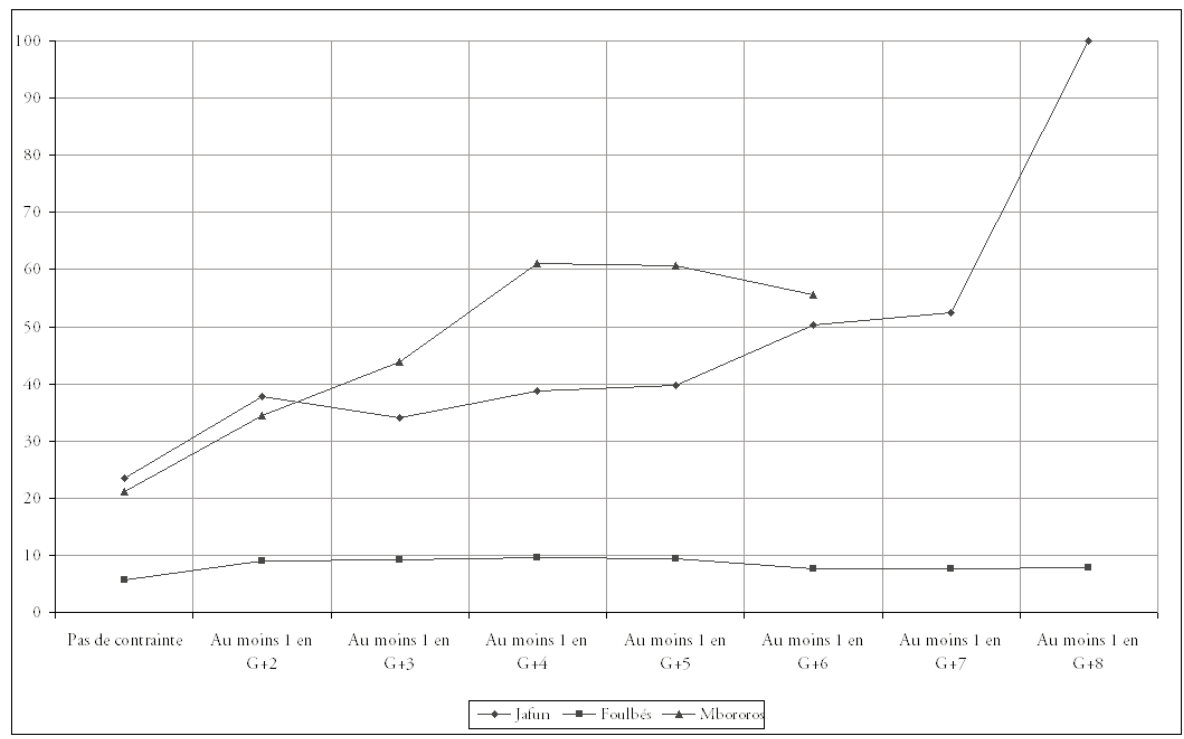

Tab. 19 Mbororos Jafun. Réduction généalogique de $2^{e}$ degré

\begin{tabular}{|c|c|c|c|c|c|c|c|}
\hline & $\begin{array}{c}\mathrm{Nb} . \\
\text { d'individus } \\
\text { (dont h/f) }\end{array}$ & $\begin{array}{l}\text { Nb. de } \\
\text { mariages }\end{array}$ & $\begin{array}{l}\text { Nb. de mar. } \\
\text { consanguins }\end{array}$ & $\begin{array}{l}\text { Nb. de mar. } \\
\text { endogames } \\
\text { (agnatiques) }\end{array}$ & $\begin{array}{c}\% \text { mar. } \\
\text { cons. }\end{array}$ & $\begin{array}{c}\text { \% mar endo./ } \\
\text { tous mar. }\end{array}$ & $\begin{array}{l}\text { \% mar. endo. / } \\
\text { mar. cons. }\end{array}$ \\
\hline $\begin{array}{l}\text { Pas de } \\
\text { contrainte }\end{array}$ & $\begin{array}{c}1435 \\
(789 / 646)\end{array}$ & 503 & 185 & 118 & 36,78 & 23,46 & 63,78 \\
\hline $\begin{array}{l}\text { Au moins } 2 \\
\text { en } G+2\end{array}$ & $\begin{array}{c}907 \\
(505 / 402)\end{array}$ & 332 & 143 & 97 & 43,07 & 29,22 & 67,83 \\
\hline $\begin{array}{l}\text { Au moins } 2 \\
\text { en } G+3\end{array}$ & $\begin{array}{c}889 \\
(487 / 402)\end{array}$ & 307 & 156 & 100 & 50,81 & 32,57 & 64,1 \\
\hline $\begin{array}{l}\text { Au moins } 2 \\
\text { en } G+4\end{array}$ & $\begin{array}{c}786 \\
(425 / 361)\end{array}$ & 236 & 137 & 83 & 58,05 & 35,17 & 60,58 \\
\hline $\begin{array}{l}\text { Au moins } 2 \\
\text { en } G+5\end{array}$ & $\begin{array}{c}749 \\
(322 / 260)\end{array}$ & 142 & 73 & 47 & 51,41 & 33,1 & 64,38 \\
\hline $\begin{array}{l}\text { Au moins } 2 \\
\text { en } G+6\end{array}$ & $\begin{array}{c}449 \\
(250 / 199)\end{array}$ & 91 & 43 & 32 & 47,25 & 35,16 & 74,42 \\
\hline $\begin{array}{l}\text { Au moins } 2 \\
\text { en } G+7\end{array}$ & $\begin{array}{c}288 \\
(161 / 127)\end{array}$ & 47 & 25 & 21 & 53,19 & 44,68 & 84 \\
\hline $\begin{array}{l}\text { Au moins } 2 \\
\text { en } G+8\end{array}$ & $\begin{array}{c}72 \\
(40 / 32)\end{array}$ & 1 & 1 & 1 & 100 & 100 & 100 \\
\hline
\end{tabular}


Tab. 20 Foulbés. Réduction généalogique de $2^{e}$ degré

\begin{tabular}{|c|c|c|c|c|c|c|c|}
\hline & $\begin{array}{c}\text { Nb. } \\
\text { d'individus } \\
\text { (dont } \mathrm{h} / \mathrm{f} \text { ) }\end{array}$ & $\begin{array}{l}\mathrm{Nb} . \mathrm{de} \\
\text { mariages }\end{array}$ & $\begin{array}{l}\text { Nb. de mar. } \\
\text { consanguins }\end{array}$ & $\begin{array}{l}\text { Nb. de mar. } \\
\text { endogames } \\
\text { (agnatiques) }\end{array}$ & $\begin{array}{c}\% \text { mar. } \\
\text { cons. }\end{array}$ & $\begin{array}{l}\% \text { mar endo./ } \\
\text { tous mar. }\end{array}$ & $\begin{array}{l}\text { \% mar. endo./ } \\
\text { mar. cons. }\end{array}$ \\
\hline $\begin{array}{l}\text { Pas de } \\
\text { contrainte }\end{array}$ & $\begin{array}{c}1475 \\
(772 / 703)\end{array}$ & 496 & 70 & 28 & 14,11 & 5,65 & 40 \\
\hline $\begin{array}{l}\text { Au moins } 2 \\
\text { en } G+2\end{array}$ & $\begin{array}{c}851 \\
(451 / 400)\end{array}$ & 270 & 59 & 27 & 21,85 & 10 & 45,76 \\
\hline $\begin{array}{l}\text { Au moins } 2 \\
\text { en } G+3\end{array}$ & $\begin{array}{c}792 \\
(414 / 378)\end{array}$ & 211 & 53 & 25 & 25,12 & 11,85 & 47,17 \\
\hline $\begin{array}{l}\text { Au moins } 2 \\
\text { en } G+4\end{array}$ & $\begin{array}{c}657 \\
(343 / 314)\end{array}$ & 103 & 38 & 15 & 36,89 & 14,56 & 39,47 \\
\hline $\begin{array}{l}\text { Au moins } 2 \\
\text { en } G+5\end{array}$ & $\begin{array}{c}329 \\
(176 / 153)\end{array}$ & 37 & 4 & 2 & 10,81 & 5,41 & 50 \\
\hline $\begin{array}{l}\text { Au moins } 2 \\
\text { en } G+6\end{array}$ & $\begin{array}{c}213 \\
(112 / 101)\end{array}$ & 18 & 2 & 1 & 11,11 & 5,56 & 50 \\
\hline $\begin{array}{l}\text { Au moins } 2 \\
\text { en } G+7\end{array}$ & $\begin{array}{c}139 \\
(74 / 65)\end{array}$ & 9 & 1 & 1 & 11,11 & 11,11 & 100 \\
\hline $\begin{array}{l}\text { Au moins } 2 \\
\text { en } G+8\end{array}$ & $\begin{array}{c}115 \\
(61 / 54)\end{array}$ & 9 & 1 & 1 & 11,11 & 11,11 & 100 \\
\hline
\end{tabular}

Tab. 21 Autres Mbororos. Réduction généalogique de $2^{e}$ degré

\begin{tabular}{|c|c|c|c|c|c|c|c|}
\hline & $\begin{array}{c}\mathrm{Nb} . \\
\text { d'individus } \\
\text { (dont } \mathrm{h} / \mathrm{f} \text { ) }\end{array}$ & $\begin{array}{l}\mathrm{Nb} . \mathrm{de} \\
\text { mariages }\end{array}$ & $\begin{array}{l}\text { Nb. de mar. } \\
\text { consanguins }\end{array}$ & $\begin{array}{l}\text { Nb. de mar. } \\
\text { endogames } \\
\text { (agnatiques) }\end{array}$ & $\%$ mar. cons. & $\begin{array}{l}\% \text { mar endo./ } \\
\text { tous mar. }\end{array}$ & $\begin{array}{c}\text { \% mar. endo./ } \\
\text { mar. cons. }\end{array}$ \\
\hline $\begin{array}{l}\text { Pas de } \\
\text { contrainte }\end{array}$ & $\begin{array}{c}1678 \\
(873 / 783)\end{array}$ & 537 & 173 & 114 & 32,22 & 21,23 & 65,9 \\
\hline $\begin{array}{l}\text { Au moins } \\
2 \text { en } G+2\end{array}$ & $\begin{array}{c}1032 \\
(544 / 479+ \\
9 \text { de sexe } \\
\text { inconnu) }\end{array}$ & 288 & 156 & 104 & 54,17 & 36,11 & 66,67 \\
\hline $\begin{array}{l}\text { Au moins } \\
2 \text { en } G+3\end{array}$ & $\begin{array}{c}825 \\
(436 / 381+ \\
8 \text { de sexe } \\
\text { inconnu) }\end{array}$ & 183 & 98 & 65 & 53,55 & 35,52 & 66,33 \\
\hline $\begin{array}{l}\text { Au moins } \\
2 \text { en } G+4\end{array}$ & $\begin{array}{c}508 \\
(262 / 238+ \\
8 \text { de sexe } \\
\text { inconnu) }\end{array}$ & 92 & 62 & 45 & 67,39 & 48,91 & 72,58 \\
\hline $\begin{array}{l}\text { Au moins } \\
2 \text { en } G+5\end{array}$ & $\begin{array}{c}295 \\
(164 / 131)\end{array}$ & 55 & 42 & 32 & 76,36 & 58,18 & 76,19 \\
\hline $\begin{array}{l}\text { Au moins } \\
2 \text { en } G+6\end{array}$ & $\begin{array}{c}153 \\
(89 / 64)\end{array}$ & 8 & 4 & 4 & 50 & 50 & 100 \\
\hline
\end{tabular}


Nous pouvons constater là aussi que la progression des taux de consanguinité et d'endogamie est très sensible si l'on en juge à l'aune de ceux obtenus sur un corpus brut, en l'absence de contrainte. On remarque que la progression est cette fois beaucoup plus nette que précédemment dans le corpus Foulbés, puisque le taux de consanguinité atteint $36,89 \%$ en $\mathrm{G}+4$ avec une contrainte de degré 2 , là où il n'était que de $22,5 \%$ à la même génération avec une réduction de degré 1.

\section{L'impact agnatique}

L'isomorphisme entre l'évolution des indices avec une contrainte de degré 2 et celle obtenue pour une réduction de degré 1 est encore plus apparent si nous le représentons graphiquement, comme nous le vérifions à la figure 11 pour le taux de consanguinité et à la figure 12 pour le rapport "mariages endogames/tous mariages ".

Un autre enseignement qu'il est possible d'inférer des réductions généalogiques va nous permettre de tester l'hypothèse centrale mise en avant par l'idée d' " impact agnatique ", telle qu'elle fut développée à l'origine par le logiciel Puck et les fonctions de calcul qu'il propose.

1) Rappelons-nous en effet que celle-ci adoptait le postulat selon lequel la disparition de la connaissance de certaines relations - notamment des relations par les femmes - aux générations élevées devait conduire à une sous-estimation des mariages empruntant à ces mêmes relations, autrement dit des unions entre parents utérins. L'idée étant alors qu'il conviendrait de "compenser» ce gauchissement de la connaissance du réseau matrimonial, qui mésestimerait les mariages tant utérins que cognatiques et surestimerait artificiel- lement les unions agnatiques, en s'appuyant pour ce faire sur l'intensité du biais agnatique calculé à partir de la connaissance généalogique.

2) Rappelons-nous aussi qu'une autre hypothèse, strictement inverse, supposait au contraire que si l'amnésie généalogique portait plus particulièrement sur certaines relations (en l'occurrence les relations utérines), c'était justement en raison de leur " innocuité " sociologique et matrimoniale. Autrement dit, si les acteurs avaient tendance à ne pas se rappeler des parents par les femmes, c'est justement parce qu'ils ne les épousaient pas, et donc qu'ils n'avaient que peu ou pas d'occasions de réactiver cette connaissance généalogique spécifique.

Entre ces deux hypothèses opposées qui nous parlent toutes deux de ce que nous qualifierons d' "impact agnatique", autrement dit l'effet du "biais agnatique » sur les mariages consanguins -, il ne semblait pas possible de trancher à partir des analyses portant sur des corpus «bruts». Or, la méthode des réductions va cette fois nous permettre de soupeser l'adéquation de ces deux hypothèses aux données, et il apparaîtra alors que - du moins pour les corpus étudiés ici - il semble bien que ce soit plutôt la seconde qui soit vérifiée. Comment est-il donc possible de faire le départ entre ces hypothèses contradictoires avec la technique des réductions? Tout simplement en analysant l'évolution d'un troisième indice, celui exprimant le rapport des mariages endogames, non pas à tous les mariages comme précédemment, mais à tous les mariages consanguins cette fois.

Nous reportons cette évolution à la figure 13 pour une réduction de $1^{\text {er }}$ degré et à la figure 14 pour une réduction de $2^{\mathrm{e}}$ degré. Les graphiques suivants ne portent cette fois que sur les cinq 
premières générations compte tenu de la diminution drastique des effectifs des mariages consanguins aux générations les plus hautes qui n’apparaissent plus statistiquement significatifs (lorsqu'il ne reste plus qu'un mariage consanguin pour les générations les plus hautes et qu'il se trouve que celui-ci est agnatique, dire que $« 100 \%$ des mariages sont endogames" n'a guère de sens).

Que nous apprennent ces graphiques si nous les comparons à ceux obtenus précédemment à partir du rapport «mariages endogames/tous mariages" (figures 10 et 11)? Comme nous le voyons, si l'indice d'endogamie est nécessairement toujours plus élevé pour ces dernières figures (puisqu'il n'est rapporté qu'aux seuls mariages consanguins), en revanche sa croissance est soit très faible, soit inexistante, voire négative à mesure que les réductions portent sur des générations de plus en plus éloignées.

Comparons ainsi l'évolution des deux indices d'endogamie entre l'absence de contrainte et une contrainte de $1^{\text {er }}$ degré en $\mathrm{G}+5$ (tableau 22).

Comme nous le voyons, dans le rapport "mariages endogames/tous mariages», l'application d'une contrainte en $\mathrm{G}+5$ triple le taux d'endogamie pour le corpus Mbororos et le double presque pour les corpus Jafun et Foulbé. En revanche, dans le rapport «mariages endogames/mariages consanguins", soit le taux d'endogamie reste stable pour les corpus Jafun et Foulbé, soit il n'augmente au plus que de $10 \%$ pour le corpus Mbororos. Que signifie alors la stabilité de ce dernier indice?

Tout simplement que l'augmentation du poids agnatique à mesure que l'on va vers les générations les plus hautes (pour lesquelles il y aura une sur-représentation des relations par les hommes) ne se traduit pas par une augmentation concomitante de la proportion des mariages agnatiques au détriment des autres unions consanguines. Autrement dit, ce n'est pas parce que l'on connaît plus d'ascendants agnatiques aux générations les plus élevés qu'on assiste à une déperdition des unions cognatiques ou utérines à ces mêmes générations. Or, l'absence de corrélation entre l'amnésie généalogique pour certaines relations (utérines ou cognatiques) et l'absence d'amnésie pour les unions fondées sur ces mêmes relations ne peut s'expliquer que d'une seule façon: par le fait que lorsqu'on se rappelle de relations généalogiques qui n'interviennent pas dans des mariages consanguins, on a bien un tropisme agnatique, par contre, à compter du moment où il $\mathrm{y}$ a eu un mariage consanguin, on a tendance à se rappeler des relations généalogiques entre les conjoints, peu importe alors qu'elles soient agnatiques, cognatiques ou utérines.

Dit d'une autre façon, l'absence de croissance de l'indice "mariages endogames/mariages consanguins" et la forte croissance de l'autre indice ("mariages endogames/tous mariages») signifient que les acteurs peuvent certes oublier systématiquement certains types de relations en l'absence de mariages empruntant à celles-ci, mais que dès lors que des unions consanguines utilisent ces mêmes relations, ils se rappellent alors assez systématiquement de celles-ci. Le mariage apparaît donc comme un support mémoriel fort, ce qui conforte ce faisant la seconde interprétation des phénomènes d'amnésies généalogiques - interprétation strictement opposée à celle sur laquelle se fondait l'idée de biais agnatique - selon laquelle si on oublie certains de nos consanguins, c'est justement qu'on ne les a pas épousés. 
Fig. 11 Évolution du taux de consanguinité pour les corpus peuls, en fonction de la génération ascendante où sopère une réduction de $2^{e}$ degré

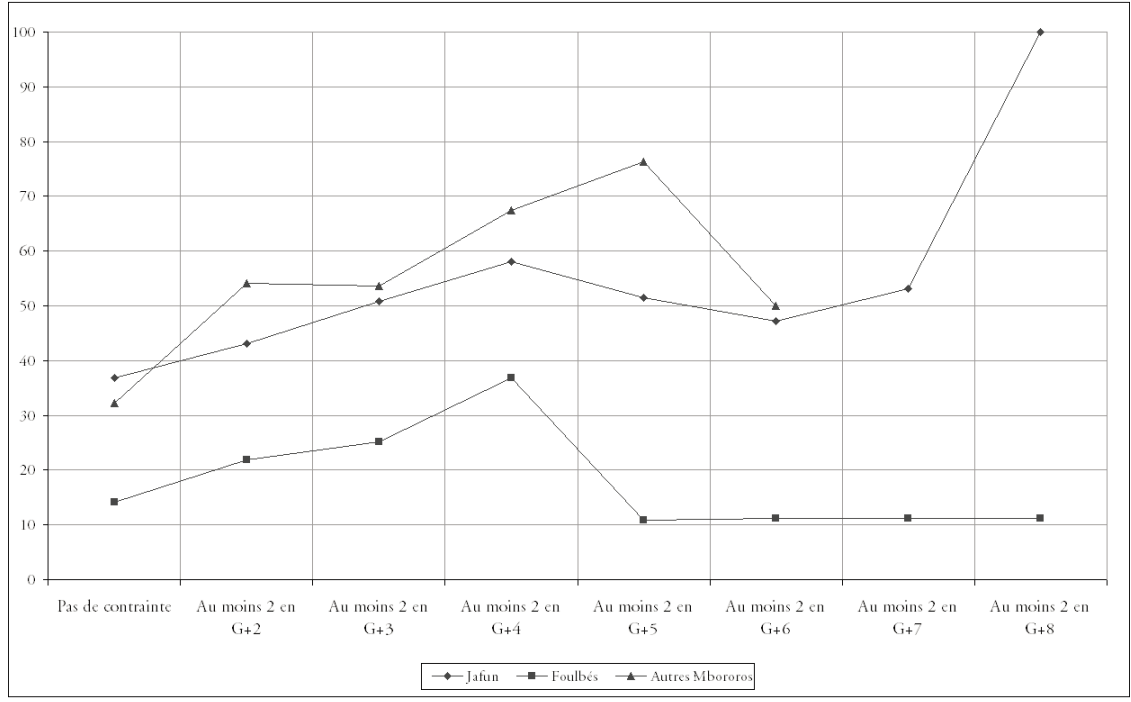

Fig. 12 Évolution du rapport "mariages endogames/tous mariages " pour les corpus peuls, en fonction de la génération ascendante où sopère une réduction de $2^{2}$ degré

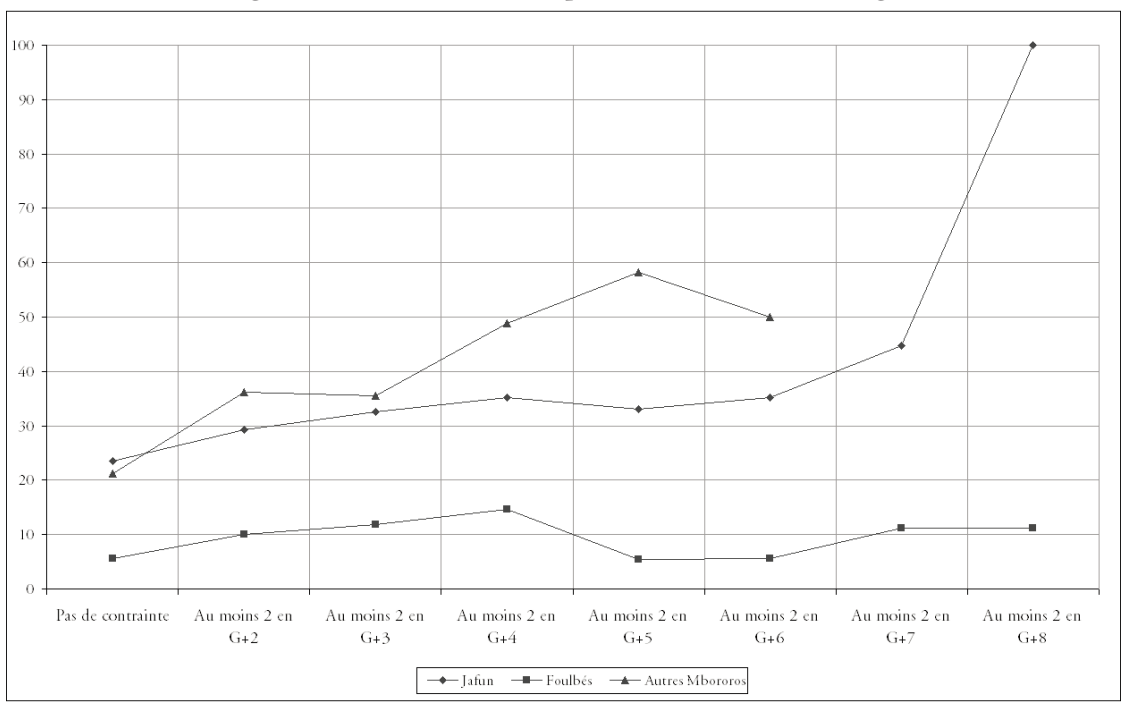


Fig. 13 Corpus peuls. Évolution du rapport "mariages endogames/mariages consanguins", en fonction de la génération ascendante où sopère une réduction de $1^{\text {er }}$ degré

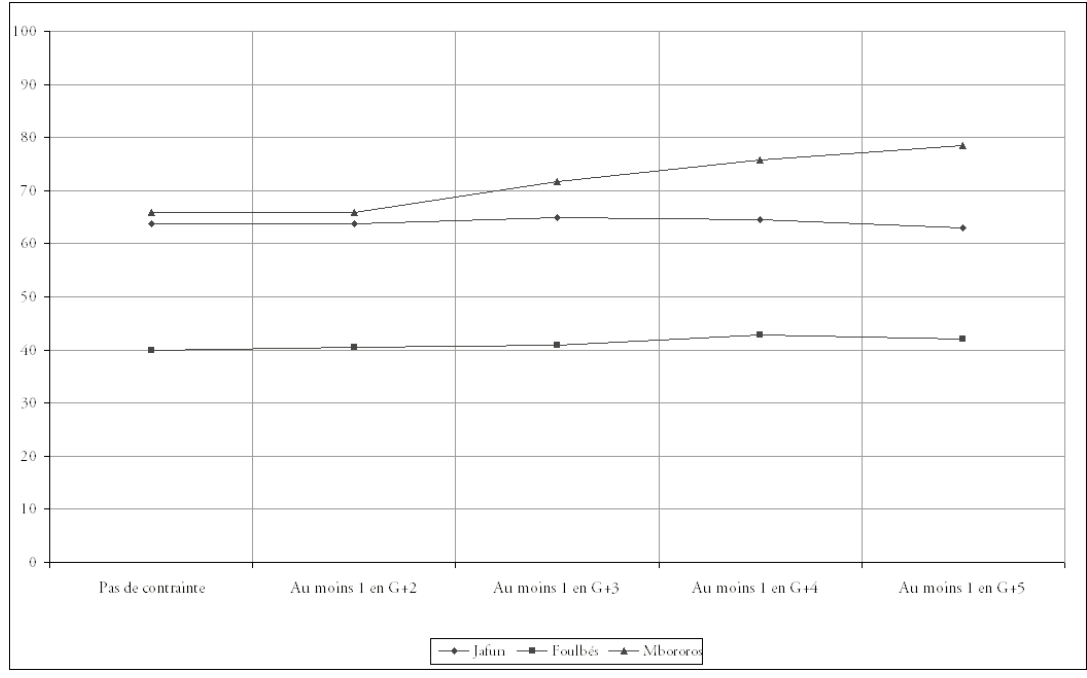

Fig. 14 Corpus peuls. Évolution du rapport "mariages endogames/mariages consanguins", en fonction de la génération ascendante où sopère une réduction de $2^{e}$ degré

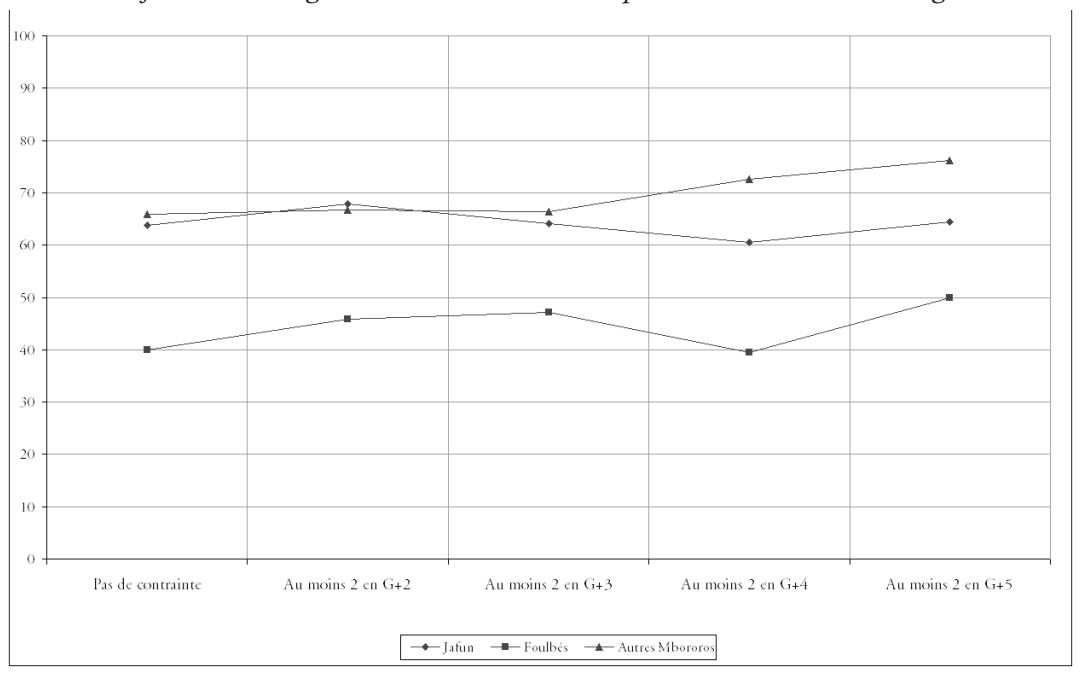

Tab. 22 Corpus peuls. Comparaison des deux indices d'endogamie (en \%) selon la présence ou l'absence d'une contrainte de ler degré

\begin{tabular}{|c|c|c|c|c|c|c|c|}
\hline $\begin{array}{l}\text { Rapport mariages endo- } \\
\text { games/tous mariages }\end{array}$ & Jafun & Foulbés & Mbororos & $\begin{array}{l}\text { Rapport mariages } \\
\text { endogames/mariages } \\
\text { consanguins }\end{array}$ & Jafun & Foulbés & Mbororos \\
\hline $\begin{array}{l}\text { En l'absence de } \\
\text { contrainte }\end{array}$ & 23,46 & 5,65 & 21,23 & $\begin{array}{l}\text { En l'absence de } \\
\text { contrainte }\end{array}$ & 63,78 & 40 & 65,9 \\
\hline $\begin{array}{l}\text { Avec une contrainte de } \\
\text { degré } 1 \text { en } G+5\end{array}$ & 39,65 & 9,3 & 60,61 & $\begin{array}{l}\text { Avec une contrainte de } \\
\text { degré } 1 \text { en } G+5\end{array}$ & 62,94 & 42,11 & 78,43 \\
\hline
\end{tabular}




\section{Des gaINS ET DES PERTES}

\section{La méthode des réductions}

La lecture des résultats obtenus après application des réductions généalogiques à différents niveaux générationnels n'est pourtant pas sans susciter à son tour un certain nombre de questions.

Si l'amélioration de la lecture des données induite par cette méthode nous semble en effet indiscutable, et si l'application d'une contrainte minimale au moins en $\mathrm{G}+2$ permet d'obtenir des indices (de consanguinité et d'endogamie) bien plus solides et réalistes que ceux relevés à partir d'un corpus brut, dans lequel une large part des unions mariages recensés se rangeront en définitive au nombre de ces "unions orphelines" que nous évoquions précédemment, cela ne signifie pas que l'application de cette technique des réductions ne comporte pas elle aussi des biais, et qu'elle n'engendre pas des marges d'indétermination, dont nous sommes conscients et que nous désirons évoquer dans une première (auto)critique de ce modèle.

Tout d'abord, ce procédé laisse en suspens une question importante: quel degré de contrainte et surtout quel niveau générationnel rendent le mieux compte d'un taux d'endogamie et de consanguinité se rapprochant au plus près de la «réalité» d'un système matrimonial?

Si les écarts considérables existant entre les résultats obtenus après l'application des contraintes et donnés dans le "corpus brut» confirment que ces derniers étaient largement sous-estimés, ce qui est déjà un enseignement important, il conviendrait dans l'absolu de pouvoir opter pour ceux des indices dont on peut supposer qu'ils s'approchent au plus près de la pratique empirique. Or, il ne semble pas y avoir de méthode objective - du moins n'en avons-nous pas à proposer pour l'heure permettant d'opérer un tel choix. Ceci tient au fait que la méthode des réductions comporte une part d'entropie qui augmente le bruit - la perte d'informations utiles - à mesure que l'on cherche à obtenir une mesure plus précise.

Ainsi, si les indices obtenus à partir de ce procédé tendent généralement à croître rapidement à mesure que la contrainte est appliquée à un niveau générationnel plus élevé, ils peuvent aussi décroître pour les niveaux les plus élevés, comme nous le vérifions à la figure 9, qui reporte l'évolution des taux de consanguinité pour la réduction de $1^{\text {er }}$ degré. A quoi tient alors cette décroissance terminale?

Comme nous le voyons à la lecture des colonnes concernant les effectifs de mariages consanguins, ceux-ci décroissent en valeur absolue à chaque nouvelle génération, comme le font les effectifs de la colonne « nombre de mariages » en général. Ceci signifie que l'application des contraintes a non seulement retiré des mariages pour lesquels il n'était pas possible de décider s'ils étaient consanguins, mais aussi des unions pour lesquelles nous avions toute la connaissance généalogique nécessaire nous permettant de les ranger dans un taxon donné: il s'agissait en l'occurrence de mariages consanguins.

Ainsi, par exemple, si nous ne retenons dans le corpus que les unions entre individus pour lesquels nous connaissons au moins un des ascendants (réduction de $1^{\text {er }}$ degré) disons à la $3^{\text {e }}$ génération ascendante, alors nous éliminons du même coup tous ceux pour lesquels nous avions une information généalogique suffisante en $G+2$ pour repérer des relations consanguines à ce niveau générationnel, mais insuffisante pour identifier celles présentes en $\mathrm{G}+3$. Dans cet 
exemple nous pourrions très bien avoir un corpus dans lequel la connaissance généalogique la plus courante se limitait à $\mathrm{G}+2$ et où (ou du fait que) la majorité des unions consanguines étaient des mariages de cousins germains que cette mémoire généalogique suffisait à identifier. En imposant alors une contrainte supplémentaire, celle de connaître un des arrière-grands-parents d'Ego et d'Alter, nous allons faire disparaître du corpus un certain nombre d'unions consanguines (l'ensemble des mariages de cousins germains pour lesquels nous n'avons pas d'informations généalogiques en $\mathrm{G}+3$ ).

Comme nous le précisions plus haut, l'intérêt de la notion de réduction généalogique a donc ses limites, qui font que cette méthode ne permet que d'améliorer la lisibilité d'un corpus sans pouvoir prétendre le rendre parfaitement transparent à l'analyse. Si, en effet, l'application de contraintes minimales augmente la fiabilité de la lecture des données, il appert que des contraintes trop fortes peuvent conduire a contrario à une perte d'informations qui se traduira par la réduction des effectifs de mariages "utiles» - et des indices qui les expriment - perte pouvant susciter un biais trop conséquent. Certes le problème ne se posera la plupart du temps que pour les niveaux de génération les plus élevés, et nous gagnerons toujours plus en qualité d'information en imposant une contrainte quelconque à un niveau générationnel bas ou intermédiaire qu'en n'en posant aucune. Mais, du fait de la perte inéluctable d'information qui résulte de l'application d'une contrainte à une génération plus élevée, il apparaît que le concept de réduction généalogique suit en pratique une trajectoire sinusoïdale, où il conviendra d'estimer - qualitativement cette fois - le bilan des gains et des pertes, le moment où l'augmentation de la solidité de l'information reste encore suffisamment appréciable pour contrebalancer sa déperdition quantitative progressive.

\section{Le "biais » agnatique}

Le concept de biais agnatique pouvait laisser supposer que les phénomènes d'amnésies généalogiques nous avaient fait "perdre» certains types d'unions qu'il convenait de reverser au pot commun, ce qui ne pouvait avoir que pour effet de «lisser» tous les corpus. Quand, par exemple, les liens utérins nous sont moins connus que les liens agnatiques, on postulera que les mariages potentiels passant par ces liens utérins ont été gommés dans la même proportion et l'on "corrigera " le corpus en considérant donc qưils ont été sous-estimés.

Or, nous avons vu qu'une grande partie de ces "amnésies généalogiques" découlent en fait d'une approche sociocentrée qui voit d'emblée les corpus matrimoniaux comme des réseaux où tous les éléments se valent. Cette approche, qui compte - du fait des biais méthodologiques sur lesquels elle repose et que nous avons détaillés plus haut - comme mémoire réelle (emic) la simple connaissance (etic) que nous avons de l'ascendance de chacun des ancêtres de nos informateurs réels, aboutit alors à des conclusions souvent surprenantes et toujours sociologiquement peu crédibles. À ce que seuls deux tiers des acteurs connaissent l'identité de leurs propres parents par exemple, ou encore à ce que la plupart d'entre eux ne soient tout simplement pas capables de se remémorer l'identité de leurs 
grands-parents ; exploit dont n'importe quel individu, même dans nos sociétés de traditions écrites, peut pourtant en principe se prévaloir.

Mais même dans les cas, nettement plus restreints, où la notion d'amnésie généalogique correspond bel et bien à une défaillance mémorielle réelle des acteurs (et non au biais automatiquement induit par une approche sociocentrée des corpus), alors il semble la plupart du temps plus crédible de supposer que l'amnésie généalogique, lorsqu’elle est focalisée sur certains types de liens (les relations par les femmes par exemple), témoigne surtout de l'innocuité sociale et matrimoniale de ces derniers ${ }^{17}$. Autrement dit, on oublie d'autant plus rapidement des relations généalogiques qu'elles n'ont justement pas été réactualisées par le biais d'une union. Si dans le "mariage arabe» par exemple, Ego se souvient plus souvent de ses parents agnatiques que de ses utérins, c'est justement du fait qu'il épouse régulièrement les premiers, rarement voire jamais les seconds.

Ceci ne signifie pas qu'il faille négliger la qualité des corpus, bien au contraire. Il est évident que certains d'entre eux auront davantage de lacunes qu'il nous faudra identifier, et dont il conviendra de comprendre tant la nature que l'origine. Mais nous pensons avoir montré que l'«amnésie généalogique» que l'on peut percevoir dans un corpus, relève de raisons fort différentes. Si le type de résidence est à lui seul un facteur important, le sont alors tout autant la disponibilité des sources ou, tout simplement, les présupposés analytiques liés aux outils informatiques que nous utilisons pour scruter un tel réseau. Et sur ce point, aucun outil n'est ni méthodologiquement, ni épistémologiquement "neutre». Il est ainsi évident qu'un parti pris qui privilégie une approche des corpus matrimoniaux en termes de réseaux, du fait qu'elle incorpore dans son analyse l'ensemble des générations y compris les plus anciennes - générations pour lesquelles la connaissance des ancêtres apicaux concerne, dans la grande majorité des cas, des hommes - plutôt que celle des seuls informateurs "réels", conduit à renforcer le déséquilibre, déjà existant mais artificiellement surdimensionné dans ce cas, entre la connaissance des liens utérins et des liens purement agnatiques ou même cognatiques. C'est ici en fait un problème récurrent propre à l'ensemble des approches purement sociocentrées des corpus généalogiques que privilégient les logiciels qui, comme Puck, envisagent d'abord et avant tout ceux-ci comme des réseaux composés d'éléments équivalents et interchangeables. Celui de mettre sur le même plan deux catégories d'individus. D'une part des individus réels, de l'autre des individus virtuels qui ne sont en définitive que des réminiscences appauvries de la mémoire généalogique des premiers.

Plusieurs solutions sont alors envisageables pour pallier ces manques. Celle de multiplier et croiser les analyses, de travailler à partir des réseaux matrimoniaux (voir Grange et Houseman dans ce numéro), de faire des partitions chronologiques (pour des corpus historiques) ou générationnelles (pour des corpus ethnologiques), ou encore d'opérer des réductions généalogiques, selon la méthode que nous venons d'exposer.

Laurent BARRY

EHESS barry@ehess.fr

Michael GASPERONI

Scuola Superiore di Studi Storici de San Marino/EHESS michael.gasperoni@wanadoo.fr 


\section{NOTES}

1. Sur la parenté occidentale, voir (Delille, 1994, 2000, 2001); (Legendre, 1988); se reporter aussi au chapitre III de (Héritier, 1981). Voir également (Barry, 2008), où les systèmes dits "complexes" sont étudiés à la lumière d'un modèle interprétatif général des systèmes de parenté.

2. A.S.R.S.M, Archivio Notarile, Not. Vincenzo Lorenzoni, b.112, X, p.64, 21.X.1650.

3. T. Jolas, Y. Verdier et F. Zonabend remarquent qu'à Minot, dans le Châtillonnais, "un propre cousin habitant un village éloigné et que l'on rencontre rarement se trouve être un conjoint en quelque sorte moins interdit qu'un cousin plus éloigné généalogiquement, mais habitant le même village» (cité dans Héritier, 1981, 159).

4. Le curé opérait le recensement maison par maison, indiquant l'ensemble des membres du feu (y compris les domestiques), leur âge, leur relation de parenté, etc. Il existe sur le propos une abondante littérature, dont (Belletini, 1975).

5. Fort du soutien de ses zélateurs Kadirawa, qui l'élisent "Amir al-mu'mini» (équivalent au Sarkin musulmi, i.e. "commandeur des croyants", voir Njeuma, 1978, 20), Oussoumanou Dan Fodio proclame le Jihad et, étant parvenu à rassembler une bonne partie des communautés peules jusqu'alors dispersées du lac Tchad à la vallée du Niger (Maliki Bonfiglioli, 1988, 23), il se tourne contre les monarques haussa du Gobir, accusés d'une trop grande tolérance vis-à-vis des pratiques "païennes» de certains de leurs sujets. Oussoumanou Dan Fodio parvient à s'emparer des principautés hausas avoisinantes: Katsina, Zaria, Nupe, Kebbi, et ayant établi Sokoto comme base militaire en 1809 laquelle devient par la suite capitale de l'empire (Last, 1967, LIX) -, il se proclame "cheikh" et commandeur des croyants. À sa mort en 1817 (Last, 1967, 60), son fils, Muhammad Bello, poursuit son œuvre (1817-1837), l'empire couvrant à son apogée une grande partie du Nigeria et du nord Cameroun actuels, et s'étendant en tout sur près de $650000 \mathrm{~km}^{2}$ (Adeleye, 1971, 3).
6. Que K. F. Hansen traduit par «sousÉmirs» (1999, 292).

7. Pour les Foulbés, les lignages recensés ici sont ceux des Baguarmi, Dargala Tara'en, Hueti'en, Huya'en, Kessou, Kilba, Kiri, Maïna, Mbewe, Ngara, Tara, VolarBe, Wawa et Yillaga. Pour les Mbororos il existe deux niveaux. D'abord le groupe migratoire qui rassemble divers lignages ayant partagé une histoire pastorale commune. Il en existe trois au Cameroun : les Jafun, les Aku et les WoDaaBe. Pour les Aku, les lignages concernés sont les Ba'en, Bodi'en, Bogoyanko'en, Butanko'en, Dagama'en, Danagu'en, Daneeji, Daneeji Mbebe'be, Daoranko'en, Gamanko'en, Jaoranko'en, Mbebe'en, NatirBe, Sadanko'en et Siromanko'en. Pour les Jafun, ce sont les Amaranko'en, Aoutanko'en, Bawanko'en, Bobdanko'en, Bodi'en, Dabanko'en, Faranko'en, Gabdanko'en, Gosi'en, JamUranko'en, Jaranko'en, Kounanko'en, Majanko'en, Uranko'en, Ringiimaji, Rujumanko'en, Saïganko'en et Toukanko'en. Enfin, pour les WoDaaBe, ce sont les Bawoy, Ronpo, Uba'en et Wandu.

8. À titre de comparaison, rappelons que les mariages d'hommes au sein du lignage des nomades Jijiru de Tahoua (Niger) étudié par M. Dupire, ne représentaient que 31,7\% des unions $(1970,523)$, même si la plupart des unions se faisaient entre lignages du même groupe migratoire (jusqu'à $77 \%$ des alliances). Si l'on se reporte à présent aux 29 sociétés pratiquant le mariage arabe recensées par P. Bonte $(1994,375)$ pour lesquelles nous disposons de données statistiques minimales, l'on constate que les lignages des fractions Aku et WoDaaBe connaissent des taux d'endogamie lignagère largement plus importants que tous ceux constatés à ce jour : la pratique matrimoniale la plus fortement endogame étant jusqu'alors celle des Arabes de l'Euphrate, laquelle ne porte que sur $62 \%$ des alliances.

9. C'est d'ailleurs bien la position adoptée, explicitement cette fois, par le concepteur du programme Puck dans son article, «L'analyse des réseaux de parenté: concepts 
et outils", publié dans ce même numéro : «Il y a, dans l'analyse des réseaux matrimoniaux empiriques, deux grands types d'erreurs dues à une illusion optique engendrée par des chiffres. Nous venons de voir le premier, qui se produit lorsqu'on prend pour une préférence ou un évitement ce qui n'est qu'un effet automatique. Le second consiste à prendre comme indicateur d'une préférence ou d'un évitement ce qui n'est en fait qu'une conséquence de la distribution inégale des relations de parenté, soit dans le réseau de parenté réel, soit dans la partie qui est connue du chercheur, donc dans le corpus. [...] Il suffit donc que le critère de genre intervienne d'une façon ou d'une autre dans l'organisation sociale (par une tendance virilocale, par des éléments de patrifiliation, par la polygynie...) pour que le corpus présente une distribution inégale des relations de parenté susceptible d'induire à son tour une distribution inégale des anneaux matrimoniaux, même en l'absence de toute préférence ou évitement. Dans un corpus avec un profond biais agnatique par exemple, le fait qu'on n'épouse pas de MFZDD ne révèlera pas obligatoirement un évitement de ce type de cousine, mais peutêtre simplement leur sous-représentation dans le réseau documenté: on compte peu de mariages avec ces cousines parce qu'il y a peu de cousines de cette sorte. Il faut alors compter les cousines existantes et pas seulement les cousines épousées pour repérer si un évitement ou une préférence se dégage.»

10. Quelque extension que l'on donne à l'enquête généalogique, la somme des informateurs interrogés restera toujours inférieure à la somme des individus dont ces mêmes informateurs se souviennent, et (sauf à ne retenir dans le corpus que les seuls informateurs et aucun des parents dont ils ont le souvenir) le nombre d'individus "virtuels» d'un corpus sera donc toujours bien plus conséquent que le nombre d'individus « réels».

11. Le système de notation ici utilisé $(\mathrm{XXX}(\mathrm{X}))$ est celui proposé par Laurent Barry (2004). Nous insistions alors sur la nécessité que le système de notation dût être à la fois le plus neutre possible et formuler au mieux la relation qu'il entend exprimer. Par rapport au système symbolique anglais (ex : MBD), il comporte peu de symboles et peu d'opérateurs, soit trois respectivement : $\mathrm{H}$ représente un homme, $\mathrm{F}$ une femme et $\mathrm{X}$ un individu dont on ne connaît pas le sexe ou pour lequel ce supplément d'information n'est pas nécessaire ; les opérateurs nous concernant directement sont au nombre de deux et sont représentés par des parenthèses "( )», qui indiquent le ou les ancêtres communs, ou par un point ".», qui désigne un mariage. Ego est toujours à gauche de la chaîne et Alter à droite. La position des symboles, à gauche ou à droite des parenthèses, indique ainsi le sens "ascendant" ou "descendant" de lecture de la chaîne. Le père d'un homme s'écrira ainsi $\mathrm{H}(\mathrm{H})$, sa mère $\mathrm{H}(\mathrm{F})$, le grand-père paternel $\mathrm{HH}(\mathrm{H})$ et le petit-fils agnatique de ce dernier (H) $\mathrm{HH}$.

12. Pour un écart générationnel donné, les mesures sont définies comme suit:

$\mathrm{pA}=|\mathrm{A}| /|\mathrm{A} \mathrm{v} \mathrm{U}| \quad \mathrm{pU}=|\mathrm{U}| /|\mathrm{A} \mathrm{v} \mathrm{U}|$ où $A$ et $U$ sont les ensembles des personnes dont on connaît l'ascendant agnatique/utérin du degré donné, v est l'union des ensembles et $|\mathrm{X}|$ est l'effectif de l'ensemble X.

13. Pour un écart générationnel donné, les mesures sont les suivantes :

$$
\begin{aligned}
& s A=|A \backslash U| /|A v U| \\
& s U=|U \backslash A| /|A v U|
\end{aligned}
$$

où "I" est la différence d'ensembles.

14. Autrement dit un mariage entre cousins dont l'un des parents de l'un n'est lié à l'un des parents de l'autre que par un seul ascendant: son père ou sa mère. En effet, si nous connaissons qu'un (ou une) ascendant(e) d'Ego sur ses quatre grands-parents, et un (ou une) ascendant(e) d'Alter, alors il y a une probabilité de $1 / 4 * 1 / 4=1 / 8$ pour que l'un et l'autre ascendant connu soit justement le même individu, celui qui faisait office d'ancêtre apical pour le couple. Dans le cas où les cousins étaient les enfants de germains complets, alors chacun des conjoints partage avec l'autre deux de ses quatre grandsparents. Dans ce cas, les chances de repérer à partir de la connaissance d'un seul ascendant 
de l'un et l'autre conjoint l'existence d'un lien consanguin sont augmentées à $1 / 2 * 1 / 2=1 / 4$.

15. Beaucoup de ces mariages seront ainsi éliminés dès l'application de la première contrainte (de degré 1 , exigeant de connaître au moins un ascendant en $\mathrm{G}+2$ ), dans la mesure où les Peuls ne conservent pas, le plus souvent du moins, la mémoire de la généalogie des HaaBe (des non-peuls). Ces unions interethniques sont au demeurant concentrées dans le corpus Foulbés, comme on le vérifie au tableau 5, et elles sont le fait soit d'alliances de notables peuls avec des filles de vassaux politiques (Wawa, Voutés, Kondja, etc.; pour un total $20,6 \%$ des mariages masculins), soit de mariages de femmes peules avec de riches commerçants de la ville de Banyo (Bamoun ou Haoussas; $7,82 \%$ des mariages féminins).

16. Ce tableau ne porte, pour cette réduction de degré 1 , que sur six générations car il n'y a pas de mariage où l'on connaît au moins un ascendant des deux conjoints en $\mathrm{G}+7$. Il en ira de même pour le tableau 21 qui portera sur le même sous-corpus pour une contrainte de degré 2 .

17. Du moins, dans le cas des corpus ethnographiques. Ce n'est pas toujours vrai des corpus historiques dans la mesure où, dans ce cas, la signification de l'information dépend de la nature de celle-ci.

\section{RÉFÉRENCES BIBLIOGRAPHIQUES}

Adeleye, R.A. (1971), Power and Diplomacy in Northern Nigeria, 1804-1906, New-York, Humanities Press.

BARRY, L. (1998), "Les modes de composition de l'alliance. Le "mariage arabe" ", L'Homme, 147, 17-50.

BARRY, L. (2000), "L'union endogame en Afrique et à Madagascar", 67-100, in Question de parenté, L'Homme, Laurent S. Barry (dir.), 154-155.

BARry, L. (2004), Historique et Spécificités techniques du programme Genos, École "Collecte et traitement des données de terrains",

http://llacan.vjf.cnrs.fr/SousSites/EcoleDonnees/ extras/Genos.pdf.

Barry, L. (2008), La parenté, Paris, Gallimard.

Bellettini, A. (1975), "Gli "Status animarum” : caratteristiche e problemi di utilizzazione nelle ricerche di demografia storica", 3-42, in Le Fonti della Demografia Storica in Italia, vol. 1, Rome, Comitato Italiano per lo studio della demografia storica.
Bonfiglioli, A. M. (1990), DuDal. Histoire de famille et histoire de troupeau chez un groupe de WoDaaBe du Niger, Identité et sociétés nomades.

Bourdieu, P. (1980), Le sens pratique, Paris, Éditions de Minuit.

Brown, C.H., SAmoyan, S. (1977), "Descent and Alliance in an Endogamous Society: A Structural Analysis of Arab Kinship", Social Science Information/ Information sur les Sciences Sociales, Vol. XVI, ${ }^{\circ}$ 5, 581-599.

Brunet, G., Lallich, S., Bideau, A. (2006), «Analyse quantitative des réseaux généalogiques ascendants, l'exemple des lignées familiales de la vallée de la Valserine", Bulletin et Mémoires de la Société d'Anthropologie de Paris, 89-104.

Caratini, S. (1989), «À propos du mariage "Arabe". Discours endogames et pratiques exogames: l'exemple des Rgaybàt du NordOuest Saharien ", L'Homme, 110, 30-49.

Cazes, M.-L., Cazes, P. (1996), «Comment mesurer la profondeur généalogique d'une ascendance?", Population, 51, n 1,117 140. 
Conte, E. (1979), "Politics and Marriage in South Kanem (Chad): a Statistical Presentation of Endogamy from 1895 to 1975 ”, Cahiers de L'Orstom, Série Sciences Humaines, 4, 262-275.

Conte, E. (1983), Marriage Patterns, Political Change and the Perpetuation of Social Inequality [In South Kanem (Chad)], Paris, ORSTOM.

Cuisenier, J. (1962), «Endogamie et exogamie dans le mariage arabe», L'Homme, II (2), 80-105.

Delille, G. (1994), "Consanguinité proche en Italie du XVI ${ }^{\mathrm{e}}$ au XIX ${ }^{\mathrm{e}}$ siècle», 323-340, in Épouser au plus proche. Inceste, prohibitions et stratégies matrimoniales autour de la Méditerranée, Pierre Bonte (dir.), Paris, EHESS.

Delille, G. (2000), «Échanges matrimoniaux entre lignées alternées et système européen d'alliance: une première approche», 219-252, in En substances. Textes pour Françoise Héritier, J.-L. Jamard, E. Terray et M. Xanthakou (dir.), Paris, Fayard.

Delille, G. (2001), "Réflexions sur le "système" européen de la parenté et de l'alliance», Annales. Histoire, Sciences Sociales, 2, 369-380.

Duby, G., Perrot, M. (2002), Histoire des femmes en Occident, tomes 1-5, Paris, Perrin, coll. «Tempus» (1 ${ }^{\text {re }}$ édition 1990-91).

FerChiou, S. (1992), «Structures de parenté et d'alliance d'une société arabe. Les 'aylāt de Tunisie", 137-167, in Hasab wa nasab. Parenté, alliances et patrimoine en Tunisie, S. Ferchiou (dir.), Paris, CNRS Éditions.

FioretTi, D. (1994), Dalla "Democrazia " alla " aristocrazia elettiva". Il ceto dirigente a San Marino nei secoli XVII e XVIII, Saint-Marin, Centro di Studi Storici Sammarinesi.

GaSperoni, M. (2009), La Repubblica di San Marino in epoca moderna. Popolazione, famiglie, parentela, Saint-Marin, Quaderni del Centro di Studi Storici, n²8.

Hansen, K. F. (1999), "Le califat de Sokoto, un État segmentaire: le segment de l'Adamaoua", 287-301, in Figures peules, édité par R. Botte, J. Boutrais, \& J. Schmitz, Paris, Karthala.

HérITIER, F. (1981), L'exercice de la parenté, Paris, Seuil.

Jolas, T., Verdier, Y., Zonabend, F. (1970), «Parler famille», L'Homme, X (3), 5-26.

LAMAISON, P. (1991), "Les structures complexes ont-elles une unité», 227-269, in Les complexités de l'alliance. Vol. II: Les systèmes complexes d'alliance matrimoniale, F. Héritier-Augé \& É. Copet-Rougier (dir.), Paris, Éditions des Archives contemporaines.

Last, M. (1967), The Sokoto Caliphate, London, Longman.

Lefebure, C. (1976), «Le mariage des cousins parallèles patrilatéraux et l'endogamie de lignée agnatique: l'anthropologie de la parenté face à la question de l'endogamie», 195-207, in Production, Pouvoir et Parenté dans le monde Méditerranéen de Sumer à nos jours, Actes du colloque organisé par l'ERA 357, CNRS/EHESS.

LEGENDRE, P. (1988), Le dossier occidental de la parenté. Textes juridiques indésirables sur la généalogie, Leçons IV, Paris, Fayard.

LÉVI-STrauss, C. (1949), Les structures élémentaires de la parenté, Paris, PUF.

Njeuma, M.Z. (1978), Fulani Hegemony in Yola (Old Adamawa) 1809-1902, Yaoundé, CEPER.

Rosental, P.-A. (1990), «Maintien/rupture: un nouveau couple pour l'analyse des migrations", Annales HSS, 6, 1403-1431.

Verducci, C. (1995), Popolazione ed emergenze economico-sanitarie a San Marino tra Medioevo e Ottocento, Saint-Marin, Quaderni del Centro di Studi Storici, $n^{\circ} 9$.

VisCEGLIA, M.-A. (1988), Il bisogno di eternità. I comportamenti aristocratici a Napoli in età moderna, Naples, Guida Editore.

ZonABEND, F. (1981), «Le très proche et le pas trop loin. Réflexions sur l'organisation du champ matrimonial des sociétés à structures complexes", Ethnologie française, 4, 311-318. 


\section{RÉSUMÉ}

Le recours à l'ordinateur pour traiter et analyser des données généalogiques est de plus en plus fréquent. S'il ouvre des voies nouvelles, il n'est pas sans poser quelques problèmes, dont certains se situent d'ailleurs en amont. En effet, les informations collectées dans les sources historiques, par exemple, privilégient souvent les hommes et de fait les lignées agnatiques sont davantage connues. En ethnologie aussi, les corpus généalogiques constitués à partir d'enquêtes de terrain comportent leur lot d'asymétries en ce qui concerne la «mémoire» généalogique. Que faire de ces "vides", de cette "amnésie» généalogique? Comment la mesurer ? A-t-elle un " impact " sur la structure matrimoniale d'un réseau de parenté? Est-il possible de la contourner? Larticle revient sur ces difficultés méthodologiques, et montre, avec l'aide du logiciel Puck, différentes façons de repérer et de qualifier la déperdition de l'information généalogique. Mais ces méthodes posent à leur tour un certain nombre de problèmes. L'article propose donc une méthode de «réductions généalogiques" qui, posant des contraintes allant crescendo, permet d'évacuer les "zones d'ombre» des corpus, ne prenant en compte, dans les recensements matrimoniaux, que les individus pour lesquels une connaissance généalogique minimale est disponible.

\section{SUMMARY}

Computers are more and more frequently used to analyse genealogical data. While this development has opened new perspectives, it also raises problems, many of which already existed to a certain degree. For example, the privileged place allotted to men in the data collected from historical sources has resulted in agnatic lines being better known than uterine ones. Similar, built-in asymmetries with regard to genealogical "memory" also exist in anthropological material gathered by means of primary investigations. What can be done about such "gaps", such genealogical "amnesia"? How can we measure it? Does it have an impact on the matrimonial structure of a kinship network? Can this impact be overcome? This article addresses these methodological difficulties and, using PUCK software, outlines different ways to identify and qualify the loss of genealogical information. These methods, however, also raise problems of their own. In answer to these, the authors suggests a method of increasingly constrained "genealogical reduction" whereby the "gray areas" in a body of data may be eliminated by retaining for matrimonial censuses only those individuals for whom minimum genealogical knowledge is available. 